\title{
The pathogenesis of endometriosis : Sampson was right
}

Citation for published version (APA):

Nap, A. W. (2004). The pathogenesis of endometriosis : Sampson was right. [Doctoral Thesis, Maastricht University]. Universiteit Maastricht. https://doi.org/10.26481/dis.20041210an

Document status and date:

Published: 01/01/2004

DOI:

10.26481/dis.20041210an

Document Version:

Publisher's PDF, also known as Version of record

\section{Please check the document version of this publication:}

- A submitted manuscript is the version of the article upon submission and before peer-review. There can be important differences between the submitted version and the official published version of record.

People interested in the research are advised to contact the author for the final version of the publication, or visit the DOI to the publisher's website.

- The final author version and the galley proof are versions of the publication after peer review.

- The final published version features the final layout of the paper including the volume, issue and page numbers.

Link to publication

\footnotetext{
General rights rights.

- You may freely distribute the URL identifying the publication in the public portal. please follow below link for the End User Agreement:

www.umlib.nl/taverne-license

Take down policy

If you believe that this document breaches copyright please contact us at:

repository@maastrichtuniversity.nl

providing details and we will investigate your claim.
}

Copyright and moral rights for the publications made accessible in the public portal are retained by the authors and/or other copyright owners and it is a condition of accessing publications that users recognise and abide by the legal requirements associated with these

- Users may download and print one copy of any publication from the public portal for the purpose of private study or research.

- You may not further distribute the material or use it for any profit-making activity or commercial gain

If the publication is distributed under the terms of Article $25 \mathrm{fa}$ of the Dutch Copyright Act, indicated by the "Taverne" license above, 


\section{The \\ Pathogenesis \\ Of \\ Endometriosis}

Sampson was right

Annemiek Nap 
(C) Annemiek Nap, Limbricht 2004

ISBN 90-90-18574-7

Design cover: Anne-Marie Krijns

Layout: Wil van Erk

Printing: Datawyse Universitaire Pers Maastricht

Financial support for the work presented in this thesis by Ferring B.V., The Netherlands, is gratefully acknowledged.

Publication of this thesis is financially supported by:

Abbott B.V., Ferring B.V., Organon Nederland N.V., Schering B.V.,

Serono Benelux B.V. and ABN AMRO Bank Sittard. 


\title{
THE PATHOGENESIS OF ENDOMETRIOSIS
}

\section{SAMPSON WAS RIGHT}

\author{
Proefschrift \\ ter verkrijging van de graad van doctor \\ aan de Universiteit Maastricht \\ op gezag van de Rector Magnificus, \\ Prof. mr. G.P.M.F. Mols,
}

volgens het besluit van het College van Decanen,

in het openbaar te verdedigen

op vrijdag 10 december 2004 om 14.00 uur

\author{
door \\ Anna Willemina Nap \\ geboren op 18 maart 1973 te Zetten
}




\section{Promotor}

Prof. dr. J.L.H. Evers

\section{Copromotores}

Dr. G.A.J. Dunselman

Dr. P.G. Groothuis

\section{Beoordelingscommissie}

Prof. dr. M.J.A.P. Daemen (voorzitter)

Prof. dr. T.M. D'Hooghe (Universiteit Leuven, België)

Prof. dr. E. Marbaix (Universiteit Brussel, België)

Prof dr. H.A.J. Struijker Boudier

Dr. J.W. Voncken 
It is not a disaster to be unable to capture your ideal, but it is a disaster to have no ideal to capture.

It is not a disgrace not to reach the stars, but it is a disgrace to have no stars to reach for. Not failure, but low aim is sin.

Origin unknown 



\section{Contents}

Chapter 1 General Introduction 9

Chapter 2 Tissue integrity is essential for ectopic implantation 27 of human endometrium in the chicken chorioallantoic membrane

Chapter 3 Inhibiting MMP activity prevents the development of endometriosis in the chicken chorioallantoic membrane. model

Chapter 4 Anti-angiogenic agents prevent the development of endometriosis-like lesions in the chicken chorioallantoic membrane

Chapter 5 Anti-angiogenesis therapy for endometriosis

Chapter 6 Use of oral contraceptives prevent ectopic implantation of endometrium in the chicken chorioallantoic membrane

Chapter 7 General Discussion

Summary / Samenvatting

Abbreviations

Appendices

Dankwoord

Curriculum Vitae

Publications 



\section{Chapter 1}

\section{General Introduction}

\section{Pathogenesis Of Endometriosis}

Annemiek W. Nap. Patrick G. Groothuis, Ayse Y. Demir, Johannes L.H. Evers and Gerard A.J. Dunselman

Adapted from: Pathogenesis Of Endometriosis. Best Practice and Research Clinical Obstetrics and Gynaecology 2004, 18, 233-244. 


\subsection{Introduction}

Endometriosis is defined as the presence of enclometrial glands and stroma outside the uterine cavity. Women with endometriosis present with characteristic signs and symptoms as dysmenorrhoea, dyspareunia, chronic pelvic pain or subfertility. Endometriosis is one of the most commonly encountered benign problems in gynaecology. It develops predominantly in women during the reproductive age and regresses after menopause or ovariectomy. A growing body of evidence indicates that a cornbination of genetic, hormonal, immunologic and anatomic factors contribute to the formation and development of the ectopic foci of endometrium. The natural history of peritoneal endometriosis is not exactly known, but most data support the contention that endometriosis in its superficial form is generally selflimiting. The notion of two distinct clinical entities, endometriosis as a phenomenon occurring intermittently in all menstruating women with patent tubes, and endometriosis as a disabling disease occurring in a subset of women, regained support in recent years (Koninckx, 1994). This concept, however, is not new: already in 1953 the iotea of intermittent occurrence of superficial endometriosis was thus worded by Scott: "If serial section of all pelvic tissue were feasible might not ali 40 year old women with patent tubes and normal menstrual cycles regardless of parity reveal some endometriosis?"' (Scott et al., 1953). In this chapter, the events that may contribute to the pathogenesis of the peritoneal endometriotic lesion will be described.

\subsection{Pathogenesis}

The first description of endometriosis was given by Cullen in 1896, who suggested that adenomyotic nodules in the rectovaginal septum resembled the mucous membrane of the uterus (Cullen, 1896). Later on, endometriosis was also described as implants of endometrium-like tissue on the peritoneum and the ovary. Because of the different locations, possible origins, appearances and hormone responsiveness, it was suggested recently that peritoneal endometriosis, ovarian endometriosis and adenomyotic nodules of the rectovaginal septum or deep invasive endometriosis are three different entities (Nisolle and Donnez, 1997'), each with a different pathogenesis. It was argued, however, that deep invasive endometriosis does not originate in the rectovaginal septum, but develops from superficial endometriotic impiants in the pouch of Douglas (Vercellini et al,, 2000). The most viable theses nowadays are the induction theory, the in-situ development theory and the retrograde transplantation theory. 


\subsubsection{Induction theory}

The proponents of this theory assume that degenerating menstrual endometrium releases endogenous factors, which subsequently induce a metaplastic process in the serosal epithelium of the ovaries and in the serosal cells of the mesothelium, resulting in endometrial tissue (Levander and Normann, 1955; Merill, 1966; Ohtake et al.,1999). To meet the criteria for the definition of endometriosis both endometrial glands and stroma should be present in the ectopic lesion. The reports supporting this theory have provided evidence that endometrium-like epithelium and glands are formed as a result of induction. However, no direct evidence showing the formation of endometrial stroma has been reported at the end of the metaplastic process

\subsubsection{In-situ development theory}

According to this theory, ectopic endometrium develops in situ from local tissues, including germinal epithelium of the ovary and remnants of the Mollerian and Wolffian ducts. In a broader context this theory also implies that peritoneal endometriosis is a result of in situ metaplasia of mesothelial serosal cells, which are totipotential (Haney, 1990; Fuji, 1991; Suginami, 1991). The fact that endometriosis mostly occurs when endometrium is present and that males are spared from this disease, weakens the power of the concept metaplasia to explain endometriosis

\subsubsection{Retrograde transplantation theory}

Sampson's retrograde transplantation theory implies that endometriosis is a consequence of the reflux of endometrial fragments through the Fallopian tubes during menstruation, with subsequent implantation and growth on and into the peritoneum and the ovary (Sampson, 1921; 1927; 1940). The reflux implantation theory is based on the assumption that retrograde menstruation takes place and that viable endometrial tissue reaches the abdominal cavity and implants. Sampson based his theory largely on clinical and anatomical observations, but over the years experimental evidence has been provided supporting his hypothesis. Retrograde menstruation is a common event in women with patent Fallopian tubes. Halme and co-workers obtained peritoneal fluid by laparoscopy in the perimenstrual period. Blood was found in $90 \%$ of the patients with patent tubes. If the Fallopian tubes were occluded only $15 \%$ had evidence of blood in the pelvis (Halme et al, 1984). Sampson's theory is also supported by the demonstration of the viability of shed menstrual endometrium in tissue culture (Halme et al.,1984; Koks et al.,1997), the distribution of endometriotic lesions in the abdominal cavity (Jenkins et al., 1968), the high prevalence of pelvic endometriosis in girls with congenital menstrual outflow obstruction (Sanfilippo et al., 1987) and animal experiments in which endometriosis was induced by the creation of uteropelvic fistulas ( Te Linde et al., 
1950 ) or by obstruction of antegrade menstruation, thus forcing retrograde. menstruation to take place (D'Hooghe et al., 1994). The latter observations suggest that increased retrograde shedding of menstrual endometrium increases the likelihood of developing endometriosis, which is supported by the finding that menstruations are often longer and heavier in women with endometriosis (Darrow et al., 1993; Vercellini et al.,1997).

\subsection{Early endometriotic lesion formation}

\subsubsection{Evading the defence mechanisms in the abdominal cavity}

Haney and co-workers were the first to report that menstrual effluent evokes an inflammatory response when arriving in the abdominal cavity (Haney et al., 1981). It attracts large numbers of polymorph nuclear neutrophils (PMNs), and subsequently phagocytic and chemotactic leukocytes from the circulation (Haney et al., 1981; Hill et al., 1988).

Prior to the onset of menstruation a marked influx of bone marrow-derived ceils is observed. Of these cells approximately $70 \%$ are CD56+ natural killer (NK) cells, $20 \%$ CD14+ macrophages and 10\% CD3+ T-cells (Jones et al., 1998). Conceivably, the regurgitated menstrual effluent also contributes to the increased numbers of endometrial cells in the peritoneal cavity.

The physiological role of the inflammatory response is to clear the ectopic cells and tissue from the abdomen. This is apparently not a very effective system since microscopic endometriosis is probably intermittently present in all women with patent Fallopian tubes and menstrual cycles (Koninckx, 1994). Longer menstrual periods and heavier menstrual blood flow will result in larger amounts of endometria! tissue in the abdominal cavity, which increases the risk of developing symptomatic endometriosis. Larger tissue fragments may have the capacity to develop into endametriotic lesions. They may have a higher chance of survival, since cells residing inside may be protected from the proteolytic enzymes and phagocytotic activity. These cells continue to produce angiogenic factors as a result of the continued hypoxic conditions. The eutopic endometrium of women with endometriosis was also shown to be more resistant to lysis by NK cells than the eutopic endometrium of controls (Oosterlynck et al., 1991), suggesting that endometrial tissue from endometriosis patients resides in the abdominal cavity for a longer period of time.

Evidence is available now to support the notion that protein factors present in the peritoneal fluid are able to affect processes in the peritoneum. Dunselman and coworkers demonstrated that small proteins with a molecular weight (MW) $<40 \mathrm{kD}$ 
could readily be exchanged between the vasculature and the peritoneal fluid (Dunselman et al., 1988). Therefore, if the concentration of a certain factor is elevated in the peritoneal fluid, it may reach the circulation. It was șhown that upon intraperitoneal injection, interleukin (IL)- 4 was able to inhibit basic Fibroblast Growth Factor (bFGF)-induced corneal neovascularisation (Volpert et al., 1998). Also, mice bearing tumours in the flank, and receiving repeated intraperitoneal injections of an antibody against macrophage inhibitory factor (MIF), showed significantly reduced tumour growth (Ogawa et al., 2000). This suggests that factors present in the peritoneal fluid, which is basically exsudate from the peripheral blood, can also enter or re-enter the circulation and exert their influence on endometriotic lesions in a systemic way.

\subsubsection{Adhesion to the peritoneal surface}

\subsubsection{Mesothelium}

Biopsied proliferative and secretory endometrial fragments, as well as antegradely shed menstrual endometrial fragments only adhere at locations where the mesothelial lining of the peritoneum is damaged, exposing the basement membrane and/or the extracellular matrix (ECM) (Groothuis et al., 1999; Koks et al., 1999). This suggests that an intact mesothelial lining serves as a barrier and prevents adhesion of menstrual endometrial fragments to the peritoneal lining, thus preventing the implantation of endometrial tissue (Dunselman et al., 2001). However " the mesothelium is fragile and can easily be damaged by surgery, inflammatory cells, or endometrium, thereby facilitating adhesion of endometrium. Analogous to tumour cells and tumour ascites, it was shown that cells isolated from menstrual effluent as well as conditioned medium prepared from menstrual effluent are able to induce morphological aiterations in mesothelial cells (Koks et al., 2000; Demir Weusten et al., 2000). Therefore, menstrual endometrium is harmful to the mesothelium and may create its own adhesion sites at the mesothelial lining, thereby facilitating the development of endometriosis (Dernir Weusten et al., 2000). The morphological alterations are in fact epithelial-mesenchymal transitions (Demir $e t$ al., 2003).

In other studies "in which single endometrial cells or glands were used, it was demonstrated that endometrial stromal and epithelial cells can adhere to intact mesothelium. This process would be mediated by the interaction between CD44 which is expressed on endometrial cells, and hyaluronic acid which is abundantly present on mesothelial cells. Individual endometrial (stromal) cells could migrate across a mesothelial cell monolayer within 18-24 hours (Witz et al., 2001; 2002; Dechaud et al., 2001). 


\subsubsection{Cell adhesion molecules}

Adhesive properties of endometrial cells determine the process of attachment of retrogradely shed endometrium to the peritoneal lining. Several cell adhesion molecules are expressed by endometrial cells and modulate cell-matrix and cell-cell attachment, including integrins, cadherins, laminin-binding proteins, the immunoglobulin superfamily and CD44 (Stetler-Stevenson et al., 1993). In endometrium and endometriosis, integrins and cadherins have been studied extensively. The integrins belong to a large family of transmembrane glycoproteins that provide an anchorage for cells to the ECM and are involved in direct invasion and motility of cells (Curran and Murray, 2000). The expression of integrins in the endometrium changes during the menstrual cycle (Tabibzadeh 1992; Van der Linden $\theta t$ al., 1995; Lessey et al., 1998). As conflicting results have been reported with regard to integrins in endometrium and endometriosis, their exact role remains controversial, but aberrant patterns of integrin expression have been associated with reproductive problems, including endometriosis (Lessey et al., 1994; StarzinskiPowitz et al., 1999).

Cadherins are transmembrane glycoproteins which mediate cell-cell adhesion. They can act as invasion suppressor molecules by inhibiting the ability of cells to escape from their primary site to initiate invasion. Immunohistochemical studies demonstrated that epithelial cadherin (E-cadherin) is expressed in epithelial glandular cells derived from menstrual effluent, in endometrium throughout the menstrual cycle, in peritoneal fluid, in peritoneum and in endometriosis, indicating a role in the maintenance of the epithelial architecture in endometrium (Van der Linden et al., 1994; 1995). In vitro, E-cadherin positive cells are retained in tumour tissue by cell-cell interaction, but when E-cadherin is absent or inactivated, these cells are no longer constrained and invasion can occur (Guilford et al., 1999). E-cadherin is therefore considered one of the central players in the establishment of metastasis in human carcinomas (Starzinski-Powitz et al., 1999). Gaetje and Starzinski-Powitz hypothesize that endometriotic cells and carcinoma cells share molecular mechanisms of invasion and metastasis that are related to the absence of E-cadherin (Gaetje et al., 1997; Starzinski-Powitz et al., 1999).

\subsubsection{Invasion}

Early lesion formation is an invasive event, which requires ECM breakdown. The ECM consists of collagens, proteoglycans and glycoproteins including fibronectin and laminin. In addition to its role in determining cell shape, the ECM is important in metabolic processes, influencing cellular proliferation, differentiation and apoptosis, and it serves as a repository for biologically active growth factors. Remodelling and breakdown of the ECM is mainly regulated by matrix metalloproteinases (MMPS). 
The involvement of MMPs in these processes was suspected after finding collagen breakdown products in the peritoneal fluid of endometriosis patients with mild endometriosis (Spuijbroek et al., 1992). Later, intervention studies demonstrated that lesion formation can be prevented in mice with experimentally induced endometriosis, by inhibiting MMP production and activation (Bruner et al., 1997).

MMPs are a family of structurally related, zinc-containing endoproteases that share structural domains but differ in substrate specificity, cellular sources and inducibility. All MMPs share the following functional features: they are capable of degrading ECM components, they are secreted in a latent proform and require activation for proteolytic activity. they contain zinc at their active site and need calcium for stability, they function at a neutral $\mathrm{pH}$, and they are inhibited by specific inhibitors of metalloproteinases (TIMPs) (Creemers et al., 2001). According to their substrate specificity and structure, members of the MMP family can be classified into subclasses: the collagenases, gelatinases, stromelysins, membrane-type (MT-) MMPs, and other MMPs.

The activity of MMPs is controlled by the induction of gene expression and by the activation of latent pro-enzymes. Induction at the level of gene expression is mediated by growth factors, hormones, and inflammatory cytokines including IL-1. IL-6, tumour necrosis factor-a (TNF-a), epidermal growth factor (EGF), plateletderived growth factor (PDGF) and basic fibroblast growth factor (bFGF) (Malik et al., 1996; Schonbeck et al., 1997). The activation of the latent pro-enzymes can be achieved (1) by stepwise activation in which plasmin is assumed to be the most potent physiological activator in vivo, (2) by activation at the cell-surface by MT= MMPs; and (3) by intracellular activation (Murphy et al., 1994; Nagase, 1997). In turn, the activity of MMPs in tissues is controlled by the antagonizing actions of their natural inhibitors, the TIMPs. TIMPs are present in the majority of tissues and body fluids, and are expressed by a variety of cells. TIMP-1, $-2,-3$ and -4 are structurally related and bind noncovalently to active MMPs. They have the ability to interact with the zinc-binding site within the catalytic domain of active MMPs.

In many reproductive processes including menstruation, ovulation, and embryo implantation MMPs are expressed in a highly regulated manner (Marbaix et al., 1995; Hulboy et al., 1997). In the endometrium, MMP expression is most pronounced during menstruation. A limited number of MMPs is expressed at low levels during the proliferative phase of the menstrual cycle, whereas expression generally declines during the early secretory phase, and reappears in the late secretory phase. Endometrial MMP expression is regulated by hormones, cytokines and growth factors. In particular, progesterone is a potent repressor both in vitro (Rodgers et al.. 1994; Bruner et al., 1999) and in vivo (Spuijbroek et al., 1992). The 
mechanism through which progesterone modulates MMP and TIMP activity is not yet clear. It has been proposed that progesterone regulates MMP expression indirectly through controlling the plasminogen activator pathway. Progesterone can increase the levels of plasminogen activator inhibitor (PAI)-1 and thus reduce plasmin-mediated activation of latent MMPs (Clark, 1992). Locally produced retinoic acid and transforming growth factor- $\beta$ (TGF- $\beta$ ) were shown to act as mediators of the progesterone suppression of MMPs, while enhancingl expression of TIMPs (Osteen et al., 2002). On the other hand, arguments against progesterone as the primary regulator of endometrial collagenase activity are that in vivo circulating progesterone levels decrease too early to explain the peri-menstrual increase in MMP expression, and tissue degradation at menstruation occurs at focal points rather than throughout the entire endometrium (Salamonsen and Woolley, 1996).

A number of MMPs has been described to be associated with endometriosis (reviewed by Osteen et al., 1996, 1999; Sillem et al., 1998; and Sharpe-Timms and Cox, 2002). The drawback of most studies available until now with regard to the role of MMPs in endometriosis is that they are only descriptive at the level of MMP expression, and that the functional involvement of MMPs in the development and progression of endometriosis has not been proven. Expression of a selection of MMPs has been reported, either because only a limited number of MMPs has been studied, or because expression of certain MMPs has not been found. In order to gain more insight in the functional role of MMPs in endometriosis, more intervention studies are required.

\subsubsection{Acquisition of a blood supply}

Ectopically implanted endometrium needs to trigger an angiogenic response, activating angiogenesis within and around the tissue, in order to survive in its new environment. Angiogenesis is the formation of new blood vessels from pre-existing capillaries. It involves the proteolytic degradation of the ECM, proliferation and migration of endothelial cells, and ultimately formation of a patent tubular network supplying the angiogenic stimulus.

Angiogenesis is essential in growth, wound healing, and in the female reproductive system including processes in the menstrual cycle and pregnancy. It occurs when the balance of local factors favoring vascular growth exceeds those factors inhibiting angiogenesis. Disruption of the balance between inhibitors and activators in favour of excessive angiogenesis may result in conditions such as cancer, atherosclerosis, chronic inflammation and endometriosis (McLaren, 2000). Several factors of peptide and non-peptide nature induce angiogenesis in vivo (reviewed by Smith, 1998). Vascular endothelial growth factor (VEGF) is suggested to be the most important. factor, based on its ability to induce endothelial cell proliferation and migration, to. 
induce vasodilatation, and on its endothelial cell permeability increasing effect (Griffioen and Molema, 2000).

Studies on the vascularisation of endometriotic lesions are rare, despite the fact that at laparoscopy, active superficial endometriotic lesions are easily recognized by the abundant vasculature. Two studies have compared the vascular density and luminal diameter in red, black, and white lesions as well as in endometriomas and lesions in the rectovaginal septum. Donnez and co-workers described that red lesions were better vascularised, and that this was the result of a larger vessel diameter rather than the number of vessels, which was significantly higher in black lesions (Donnez et al., 1998). The group of Matsuzaki found no differences in the numbers of vessels between the different types of lesions, but described that red lesions had more vessels with a small diameter $(<10 \mu \mathrm{m})$, whereas black lesions had significantly more vessels with a larger diameter $(>20 \mu \mathrm{m})$. (Matsuzaki et al., 2001). The fact that endothelial cell proliferation and smooth muscle cell-negative bloodvessels were observed in these lesions, suggests that an angiogenic process is ongoing in these lesions.

Studies in the chicken chorioallantoic membrane (CAM) model indicate that human endometrium is highly angiogenic, and therefore capable of attracting blood vessels from the surrounding tissue (Maas et al., 1999). In the endometrium, angiogenesis is regulated by many angiogenic factors, of which VEGF-A appears to be the most important one. In the proliferative phase of the menstrual cycle, oestradiol triggers VEGF-A expression in endometrial epithelial cells and stromal fibroblasts, which is increased in the secretory phase (Charnock-Jones of al., 1993). Prior to menstruation, the endometrium becomes hypoxic as a result of vasoconstriction. which enhances the production of VEGF-A in the endometrial tissue even more (Smith, 2001).

In eutopic endometrium of endometriosis patients endothelial cel! proliferation and VEGF-A content were significantly higher than in the endometrium of disease-free women (Donnez et al., 1998; Wingfield et al., 1995). The significance of VEGF-A and of angiogenesis in early endometriotic lesion formation was illustrated by Hull and co-workers (Hull et al., 2003). Antagonizing the actions of VEGF-A by administering the soluble VEGF receptor sflt-1 reduced the number of lesions formed in nude mice after intraperitoneal injection of minced endometrial tissue. This suggests that anti-angiogenic therapy may be effective in preventing the development of endometriosis. 


\subsubsection{Survival post-implantation}

Endometriosis is an estrogen dependent disease. Hormonal treatment of endometriosis, with for instance Gonadotrophin Releasing Hormone (GnRH) analogues or progestins, is aimed at creating a hypoestrogenic environment, which keeps the endometrium dormant. An increase in proliferative activity of endometrial cells has been demonstrated in the eutopic endometrium of women with endometriosis as compared to the eutopic endometrium of women without the disease (Wingfield et al., 1995; Jurgensen et al., 1996). However, the relevance of this observation is disputed by the finding that hardly any difference in proliferation was present between eutopic and ectopic endometrium (Nisolle et al, 1997), or even a reduced proliferation in the epithelium of endometriotic lesions compared to eutopic endometrium (Scotti et al., 2000). This supports the contention that the implantation of endometrium is a process which requires extensive changes in tissue organization, rather than increased proliferation.

It has become evident that local production of estrogens is an important factor in the pathogenesis of diseases of the female reproductive tract. This is also the case in endometriosis. The conversion of estrogens from androgens is catalysed by aromatase P450. Aromatase is normally expressed in a number of human tissues including the ovary and the adipose tissue, but usually not in normal endometrium (Noble et al., 1996; Kitawaki et al., 1997). However, this enzyme has been found in endometriotic tissue and in the endometrium of women with endometriosis (Noble et al., 1995; 1997). Moreover, endometriotic tissue is often deficient in $17 \beta$ hydroxysteroid dehydrogenase (17 $\beta-H S D)$ type 2 , which normally converts the strong estrogenic $17 \beta$-oestradiol into the weak estrogenic estrone. Consequently. this protective mechanism that lowers oestradiol levels is lost in endometriotic tissue (Zeitoun et al., 1998). The higher oestradiol level of menstrual effluent in women with endometriosis as compared to controls supports this hypothesis (Takahashi et al. 1989).

As a result of increased estrogen production in eutopic and ectopic endometrium, a positive feedback loop is initiated, which results in the continuous. local production of estrogen (Noble et al., 1997; Buiun et al., 2001). Estrogen stimulates the production of cyclooxygenase type 2 (COX-2) enzyme. This results in elevated levels of prostaglandin $E_{2}\left(P G E_{2}\right)$, which is a potent stimulator of aromatase activity in endometriosis:

The clinical relevance of these findings has been exemplified by the successfull treatment of an aggressive case of post-menopausal endometriosis using an aromatase inhibitor (Takayama et al., 1998), and the beneficial effects of non- 
steroidal anti-inflammatory drugs (NSAIDs) for the treatment of endometriosisrelated pain symptoms (Corson et al., 1978).

\subsection{Problem}

In order for endometrial tissue to implant in an ectopic location, it must be viable. adhere to the peritoneum, degrade the extracellular matrix, invade, acquire a blood supply, and survive. This sequence of events cannot be studied in man, but has been studied extensively in various model systems, in vitro, ex vivo and in vivo. From these studies it has become apparent that the endometrial tissue itself is a key element in the development of endometriosis. However, the exact role of endometrial tissue integrity, matrix metalloproteinases, angiogenesis and steroid hormones in the pathogenesis of the disease is unknown.

\subsection{Hypothesis}

Innate properties of human endometrium determine the success of implantation and endometriotic lesion formation

\subsection{Objectives}

To test the hypothesis the following objectives were formulated.

1. To investigate the impact of tissue integrity on the success of implantation and of endometriosis-like lesion formation. To this end, enclometrial tissue colfected from ali phases of the menstrual cycle was transplanted orito the CAM.

2. To study the involvement of MMPs in the early development of endometriotic lesions. The function of MMPS in endometriotic lesion formation was investigated by applying an MMP inhibitor to the CAM after transplantation, of human endometrial fragments.

3. To determine whether angiogenesis is required for early endometriotic lesion formation. To this end, angiostatic agents were applied to the CAM after transplantation of human endometrial fragments.

4. To determine whether angiogenesis is required for the maintenance of already developed endometriotic lesions. To this end, angiostatic agents were administered intraperitoneally and subcutaneously to nude mice three weeks after lesion induction by transplantation of human endometrial fragments. 
5. To study the influence of the use of oral contraceptives $(\mathrm{OC})$ on the ability of endometrium to implant ectopically. To this end, menstrual endometrium and endometrium of OC users were compared with regard to the potential to form endometriosis-like lesions in the CAM. Microarray studies were performed to identify gene transcripts in menstrual endometrium and in endometrium of $\mathrm{OC}$ users that may be involved in the ectopic implantation of endometrium. 


\section{References}

Bouckaert PXJM Evers JLH, Doesburg WH, Schellekens LA and Rolland R (1986) Patterns of changes in glycoproteins. polypeptides, and steroids in the peritoneal fluid of women during the periovulatory phase of the cycle J Clin Endocrinol Metab 62, 293-299

Bruner KL. Matrisian LM. Rodgers WH. Gorstein F and Osteen KG (1997) Suppression of matrix metalloproteinases inhibits establishment of ectopic lesions by human endometrium in nude mice. J Clin Invest $99.2851-2857$

Bruner KL. Eisenberg E, Gorstein F and Osteen KG (1999) Progesterone and transforming growth factor- $\beta$ co-ordinately regulate suppression of endometrial matrix metalloproteinases in a model of experimental endometriosis Steroids 64 , $648-653$

Bulun SE Yang S. Fang Z. Gurates B. Tamura M. Zhou J and Sebastian S (2001) Role of aromatase in endometrial disease. J Ster Biochem Molec Biol 79. 19-25

Charnock-Jones DS, Sharkey AM, Rajput-Williams J, Burch D, Schofield JP. Fountain SA, Boocock CA and Smith SK (1993) Identification and Iocalization of alternately spliced mRNAs for vascular endothelial growth factor in human uterus and estrogen regulation in endometrial carcinoma cell lines Biol Reprod 48, 1120-1128

Chung HW Wen $Y$. Chun SH, Nezhat C, Woo BH and Lake Polan M (2001) Matrix metalloproteinase-9 and tissue inhibitor of metalloproteinase-3 mRNA expression in ectopic and eutopic endometrium in women with endometriosis a rationale for endometriotic invasiveness Fertil Steril 75, 152-159

Chung HW. Lee JY. Moon H-S. Hur SE. Park MH. Wen Y and Polan ML (2002) Matrix metalloproteinase2. membranous type 1 matrix metalloproteinase, and tissue inhibitor of metalloproteinase-2 expression in ectopic and eutopic endometrium Fertil Steril 78, 787-795

Clark DA (1992) Cytokines in uterine bleeding in Alexander NJ and d'Arcangues C (eds) Steroid hormones and uterine bleeding. American Association for the Advancement of Science, Washington, USA, pp 263-275

Corson SL and Bolognese RJ (1978) Ibuprofen therapy for dysmenorrhea. J Reprod Med 20, 246-252

Cox KE, Piva M and Sharpe-Timms KL (2001) Differential regulation of matrix metalloproteınase-3 gene expressioni in endometriotic lesions compared with endometrium Biol Reprod 65, 1297-1303.

Creemers EEJM, Cleutjens JPM, Smits JFM and Daemen MJAP (2001) Matrix metalloproteinase inhibition after myoçardial infarction. A new approach to prevent heart fạilure? Circ Research 89. 201-210

Cụllẹn TS (1896) Adeno-myoma uteṇ diffusum benınum John Hopkıns Hospital Bulletin 6. 133-137

Curran S and Murray GI (2000) Matrix metalloproteinases molecular aspects of their roles in tumour invasion and metastasis. Eur J Cancer 36, 1621-1630

Darrow SL, Vena JE. Batt RE, Zielezny MA, Michalek AM and Selman S (1993) Menstrual cycle characteristics and the risk of endometriosis. Epidemiology 4, 135-142

Dechaud H, Witz CA, Montoya-Rodriguez IA, Degraffenheid, LA and Schenken RS (2001) Mesothelial cel!associatedi hyaluronic acid promotes adhesion of endometrial cells to mesothelium Fertil Steril 76. $1012-1018$

Demir-Weusten AY, Groothuis PG. Dunseiman GAJ. De Goeij AFPM. Arends JW and Evers JLH (2000) Morphological changes in mesothelial cells induced by shed menstrual endometrium in vitro are not primarily due to apoptosis or necrosis. Hum Reprod 15, 1462-1468

Demir AY. Groothuis PG. Nap AW, Punyadeera C. De Goeij AFPM, Evers JLH and Dunselman GAJ (2004) Menstrual effluent induces epithelial to mesenchymal transitions in mesothelial cells Hum Reprod. 19. 21-29 
D'Hooghe TM. Bambra CS, Suleman MA, Dunselman GAJ, Evers JLH and Koninckx PR (1994) Development of a model of retrograde menstruation in baboons (Papio anụbis). Fertil Steril 62, 63638

Donnez J, Smoes. P. Gillerot S, Casanas-Roux F and Nisolle M (1998) Vascular endothelial growth factir (VEGF) in endometriosis. Hum Reprod 13, 1686-1690.

Dunselman GA.J, Hendrix MGR, Bouckaert PXJM and Evers, JLH (1988) Functional aspects of peritoneal macrophages in endometriosis of women. J Reprod Fertil 82, 707-710.

Dunselman GAJ, Groothuis PG. De Goeij AFPM and Evers JHL (2001) The mesothelium, Teflon uf Velcro? Hum Reprod 16, 605-607.

Fuji S (1991) Secondary mullerian system and endometriosis. Am J Obste! Gynecol 165, 219-225.

Gaetje R, Kotzian S, Hermann G. Baumann R and Starzinski-Powitz A (1997) Nonmalignant epithelial cells, potentially invasive in human endometriosis, lack the tumour suppressor molecule $\mathrm{E}$-cadherit Am J Pathol 150, 461-467

Gazvani R and Templeton A (2002) Peritoneal environment, cytokines and angiogenesis in thi pathophysiology of endometriosis. Reproduction 123, 217-226.

Gilaberi-Estelles J. Estelles A, Gilabert J. Castello R, Espana F, Falco C, Romeu A. Chirivella M, Zorio I And Aznar J (2003) Expression of several components of the plasminogen activator and matri: metalloprofeinase systems in endometriosis. Hum Reprod 18, 1516-1522.

Gottschalk C. Malberg K. Arndt M, Schmitt J, Roessner A, Schultze D, Kleinstein J and Ansorge S (2000 Matrix metalloproteinases and TACE play a role in the pathogenesis of endometriosis. Adv Exp Mec Biol 477, 483-485

Griffioen AW and Molema G (2000) Angiogenesis Potentials for pharmacologic infervention in the treatment of cancer, cardiovascular diseases and chronis inflammation. Pharm, flovitews 52,255 - 268 .

Groothuis PG. Koks CAM, De Goeil AFPM, Dunselman GAJ, Arends JW and Eversi JLH (1999) Adhesion of human endometrial fragments to peritoneum in vitro. Fertil Steril 71, 1119-1124

Guilford P (1999) E-cadherin downregulation in cancer fuel on the fire? Molec Med Today 5, 172-177

Halme J. Hammond MG. Hulka JF. Raj SG and Talbert LM (1984) Retrograde menstruation in healthy women and in patients with endometriosis. Obstet Gynecol 64, 151-154

Halme J. Becker S and Haskili S. (1987) Altered maturațion and function of peritoneal macrophages: Possible role in pathogenesis of endometriosis. Am J Obstet Gynecol 156.783-789

Halme J (1991) Role of peritoneal inflammation in endometriosis-associated infertility. Ann N Y Acad Sci 622. 266-274

Haney AF. Muscato JJ and Weinberg JB (1981) Peritoneal fluid cell populations in infertility patients Fertil Steril 35, 696-698

Haney AF (1990) Etiology and histogenesis of endometriosis. Progr Clin Biol Res 323, 1-14

Haney AF (1993) Endometriosis, macrophages, and adhesions. Prog Clin Biol Res, 381, 19-44

Harada T, Iwabe T and Terakawa N (2001) Role of cytokines in endometriosis Fertil Steril 76, 1-10

Hill JA. Faris HM, Schiff I and Anderson DJ (1988) Characterization of leukocyte subpopulations in the peritoneal fluid of women with endometriosis. Fertil Steril 50, 216-222

Hulboy DL. Rudolph LA and Matrisian LM (1997) Matrix metalloproteinases as mediators of reproductive function. Molec Hum Reprod 3, 27-45

Hufl ML. Charnock-Jones DS, Chan CLK, Bruner-Tran KL, Osteen KG. Tom BDT. Fan T-PD and Smith SK (2003) Antiangiogenic agents are effective against endometriosis J Clin Endocrinol Metab 88. 28892899 
Jenkins S. Olive DL and Haney AF (1968) Endometriosis pathogenetic implications of the anatomic distribution Obstet Gynecol 67, 355-358

Jones RK. Bulmer JN and Searle RF (1998) Phenotypic and functional studies of leukocytes in human endometrim and endometriosis. Hum Reprod Update 4. 702-709

Jurgensen A. Mettier L. Volkov NI and Parwaresch R (1996) Proliferative activity of the endometrium throughout the menstrual cycle in infertile women with and without endometriosis Fertil Steril 66. 369375

Kitawaki J. Noguchi T, Amatsu T. Maeda K. Tsukamoto T. Fushiki S. Osawa $Y$ and Honjo. H (1997) Expression of aromatase cytochrome $\mathrm{P} 450$ protein and messenger ribonucleic acid in human endometrotic and adenomyotic tissues but not in normal endometrium Biol Reprod 57. 514-519

Kokorine I. Nisolle M. Donnez J. Eeckhout Y. Courtou PJ and Marbaix E (1997) Expression of interstitial collagenase (matrix metalloproteinase-1) is related to the activity of human endometriotic lesions Fertil Steril $68,246-251$

Koks CAM Dunselman GAJ De Goeij AFPM, Arends JW and Evers JLH (1997) Evaluation of a menstrual cup to collect shed endometrium for in vitro studies Fertil Steril 68, 560-564

Koks CAM, Groothuis PG, Dunseiman GAJ, De Goeij AFPM and Evers JL.H (1999) Adhesion of shed menstrual tissue in an in-vitro model using amnion and peritoneum a light and electron microscopic study Hum Reprod 14, 816-822

Koks CAM. Demir-Weusten AY, Groothuis PG, Dunselman GAJ, De Goeij AFPM and Evers JLH (2000) Menstruum induces changes in mesothelial cell morphology Gynaecol Obstet Invest 50, 13-18.

Koninckx PR (1994) Is mild endometriosis a condition occurring intermittently in all women? Hum Reprod 9. 2202-2205

Koninckx PR. Kennedy SH and Barlow DH (1998) Endometriotic disease the role of peritoneal fluid. Hum Reprod Update 4. 741-751

Lessey BA, Castelbaum AJ, Sawin SW, Buck CA, Schinnar R, Bilker W and Strom BL (1994) Aberrant integrin expression in the endometrium of womeri with endometriosis. J Clin Endocrinol Metab 79, 643649

Lessey BA (1998) Endometrial integrins and the establishment of uterine receptivity Hum Reprod 13 suppl 3. $247-258$

Levander $\mathrm{G}$ and Normann $\mathrm{P}^{\prime}$ (1955) The pathogenessis of endometriosis An experimental study Acta Obstet Gynecol Scand 34. 366-398

Maas JWM. Le Noble FAC. Dunselman GAJ, De Goeij AFPMI Struijker Boudier HAJ and Evers JLH (1999) The chick embryo chorioallantoic membrane as a model to investigate the angiogenic properties of human endometrium Gynecol Obstet Invest 48, 108-112

Malik N. Greenfield BW. Wahl AF and Kiener PA (1996) Activation of human monocytes through CD4C induces matrix metalloproteinases. J Immun 156, 3952-3960.

Marbaix E, Kokonine I, Hennet P. Donnez J, Courtoy PJ and Eeckhout Y (1995) The expression of interstitial collagenase in human endometrium is controlled by progesterone and by oestradiol and is related to menstruation. Biochem J 305, 1027-1030

Matsuzakı S, Canis M, Murakami T. Dechelotte P. Bruhat MA and Okamura K (2001) Immunohistochemical analysis of the role of angiogenic status in the vasculature of peritoneal endometriosis Fertil Sterl 76, 712-716

McLaren J (2000) Vascular endothelia! growth factor and endometriotic angiogenesis Hum Reprod. Update 6, 45-55

Merrill JA (1966) Endometrial induction of endometriosis across millipore filters Am J Obstet Gynecol 94 $780-789$ 
Murphy G, Willenbrock F. Crabbe T, O'Shea M. Ward R, Atkinson S. O'Connell J and. Docherty A (1944) Regulation of matrix metalloproteinase activity. Ann N Y Acad Sci 732, 31-41.

Nagase $H$ (1997) Activation mechanisms of matrix metalloproteinases. Biol Chem 378, 151-160

Nisolle M, Casanas-Roux F and Donnez J (1997) Immunohistochemical analysis of proliferative activty and steroid receptor expression in peritoneal and, ovarian endometriosis. Fertil Steril 68, 912-919.

Nisolle Mt and Donnez Ji (1997) Peritoneal endometriosis, ovarian endometriosis, and adenomyaic nodules of the rectovaginal septum are three different entities. Fertil Steril 68, 585-596.

Noble LS, Simpson ER, Johns A and Bulun SE (1996) Aromatase expression in endometriosis. J. Cin Endocrinol Metab 81, 174-179.

Noble LS. Takayama K, Zeitoun KM, Putman JM, Johns DA, Hinshelwood MM, Agarwal VR. Zhao Y, Carr $B R$ and Bulun SE (1997) Prostaglandin $E_{2}$ stimulates aromatase expression in endometriosis-derived stromal cells J Clin Endocrinol Metab 82, 600-606.

Ogawa H. Nishihira J, Sato $Y$, Kondo M. Takahashi N, Oshima T and Todo S (2000) An antibody br macrophage migration inhibitory factor suppresses fumour growth and inhibits tumour-associatted angiogenesis Cytokine 12, 309-314.

Ohtake H. Katabuchi $\mathrm{H}_{4}$ Matsuura $\mathrm{K}$ and Okamura $\mathrm{H}$ (1999) A novel in vitro experimental model for ovarien endometriosis: the three-dimensional culture of human ovarian surface epithelial cells in collagen gek Fertil Steril 71, 50-55

Oosteriynck DJ, Cornillie FJ, Waer M. Vandeputte MI and Koninckx PR (1991) Womerl with endometrioss show a defect in natural killer activity resulting in a decreased cytotoxicity to autologous endometriun Fertil Steril 56, 45-51

Osteen KG. Bruner KL. and Sharpe-Timms KL (1996) Steroid and growth factor regulation of matrx

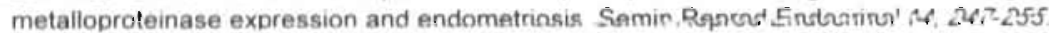

Osteen KG, Keller NR. Feltus FA and Melner MH (1999) Paracrine regulation of matrix metalloproteinase expresșion in the normai human endometrium Gynecol Obstet Irivest 48 suppl 1, 2-13.

Osteen KG. Bruner-Tran KL. Keller NR and Eisenberg E (2002) Progesterone-mediated endometrial maturation timits matrix metalloproteinase (MMP) expression in an inflammatory-like environment a. regulatory system altered in endometriosis. Ann NY Acad Sci 955, 37-47

Rodgers WH. Osteen KG, Matrisian LM. Navre M and Gorstein F (1993) Expression and localization of matrilysin, a matrix metalloproteinase, in the human endometrium during the reproductive cycle. Am $J$ Obstet Gynec 16ิ8, 253-260

Rodgers WH, Matrisian LM. Giudice LC, Dsupin B. Cannon P. Svitek C. Gorstein F and Osteen KG (1994) Patterns of matrix metalloproteinase expression in cycling endometrium imply differential functions and regulation by steroid hormones. J Clin Invest 94, 946-953

Salamonsen LA and Woolley DE (1996) Matrix metalloproteinases in norma! menstruation. Hum Reprod 11 (Suppl 2). 124-133

Sampson JA (1921) Perforating hemorrhagic (chocolate) cysts of the ovary, their importance and especially their relation to pelvic adenomas of endometrial type (adenomyoma of the uterus, rectovaginal septum. sigmoid. etc), Arch Surg 3, 245-323

Sampson JA (1927) Pentoneal endometriosis due to menstrual dissemination of endometrial tissue into the peritoneal cavity Am J Obstet Gynecol 14, 422-469

Sampson JA (1940) The development of the implantation theory for the origin of peritoneal endometriosis Am J Obstet Gynecol 40, 549-557

Sanfilippo JS. Wakim NG. Schikler KN and Yussman MA (1986) Endometriosis in association with uterine anomaly Am J Obstet Gynecol 154, 39-43 
Schonbeck U, Mach F. Sukhova GK. Murphy C. Bonnefoy JY. Fabunmi RP and Libby P (1997) Regulation of matrox metalloproteinase expression in human vascular smooth muscle cells by $T$ lymphocytes: a role for CD40 signaling in plaque rupture? Circ Res 81, 448-454

Scott RB. Te Linde RW and Wharton LR. jr (1953) Further studies on expenmental endometnosis Am J Obstet Gynecol 66, 1082-1099

Scott S, Regidor PA. Schindler AE and Winterhager E (2000) Reduced proliferation and cell adhesion in endometriosis Molec Hum Reprod 6, 610-617

Sharpe-Timms KL and Cox KE (2002) Paracrine regulation of matrix metalloproteinase expression in endometriosis. Ann NY Acad Sci 955, 147-156

Sillem M, Prfti S, Neher M and Runnebaum B (1998) Extracellular matrix remodelling in the endometrim and its possible relevance to the pathogenesis of endometriosis. Steroids $64,648-653$

Smith SK (1998) Angiogenesis, vascular endothelial growth factor and the endometrium Hum Reprod Update 4. 509-519

Smith SK (2001) Regulation of angiogenesis in the endometrium TRENDS Endocrin Metab 12, 147-151

Spujbroek MDEH. Dunseiman GAJ. Menheere PPCA and Evers JLH (1992) Early endometriosis invades the extracellular matrix Fertil Stent $58,929-933$

Starzinski-Powitz A, Handrow-Metzmacher $H$ and Kotzian S. (1999) The putative role of cell-adhesion molecules in endometriosis can we learn from tumour metastasis? Molec Med Today 5, 304-309

Stetler-Stevenson WG, Liotta LA and Kleiner DE (1993) Extracellular matrix 6 role of matrix metalloproteinases in tumour invasion and metastasis FASEB J 7, 1434-1444

Suginami $\mathrm{H}$ (1991) A reappraisal of the coelomic metaplasia theory by reviewing endometriosis occurring in unusual sites and instances. Am J Obstet Gynecol 165, 214-218

Szamatowicz J, Laudanskı P and Tomaszewska I (2002) Matrix metalloproteinase-9 and tissue inhibifor of matrix metalloproteinase-1 a possible role in the pathogenesis of endometriosis Hum Reprod 17, 284288

Tabibzadeh S (1992) Patterns of expression of integrin molecules in human endomefrium throughout the menstrual cycle Hum Reprod 7, 876-882

Takahashi K. Nagata $\mathrm{H}$ and Kitao M (1989) Clinical usefulness of determination of estradiol level in the menștrual blood for patients with endometriosis Nippon Sanka Fujinka Gakkai Zasshi 41, 1849-1850

Takayama K, Zeitoun K, Gunby RT. Sasano H. Carr BR and Burun SE (1998) Treatment of severe postmenopausal endometriosis with an aromatase inhibitor Fertil Steril 69, 709-713

Te Linde RW and Scott RB (1950) Experimental endometriosis Am J Obstet Gynecol 60, 1147.1173

Tseng JF, Ryan IP., Milam TD. Murai JT. Schriock ED, Landers DV' and Taylor RNi (1996) Interleukin-6 secretion in vitro is up-regulated in ectopic and eutopic endometrial cells from women with endometriosis J Clin Endocrinol Metab 81, 1118-1122

Ueda M. Yamashita Y. Takehara M. Teraı Y. Kumagaı K, Uekı K, Kanda K, Yamaguchı H, Akıse D. Hung $Y$ and Ueki Mi (2002) Survivin gene expression in endometriosis. J Clin Endocrinol Metab 87. 3452 3459

Van der Linden PJQ. De Goeij AFPM. Dunșelman GAJ. Van der L.inden EPM Ramaekers FCS and Evers JLH (1994) Expression of integrins and E-cadherin in cells from menstrual effluent, endometrium, peritoneal fluid'. peritoneum and endometriosıs Fertil Șteril 61 , 85-90

Van der Linden PJQ. De Goej AFPM. Dunselman GAJ. Erkens HWH and Evers JLH (1995) Expression of cadherins and integrins in human endometrium throughout the menstrual cycle. Fertil Steril 63. 1210. 1216

Vercellini P. Aimi G. Panazza S. Vicentinı S. Pisacreta A and Crosıgnanı PG (2000) Deep endomefriosis conundrum evidence in favor of a peritoneal origin Fertil Steril 73, 1043-1046 
Vercellini P. De Giorgi O, Aimi G, Panazza S, Uglietti A and Crosignani PG (1997) Menstrual characteristics in women with and without endometriosis. Obstet Gynecol 90, 264-268.

Volpert OV, Fong T. Koch AE, Peterson JD, Waltenbaugh C, Tepper RI and Bouck NP (1998) Inhibition of angiogenesis by interleukini 4. J Exp Med 188, 1039-1046.

Wingfield M, Macpherson A, Healy DL and Rodgers PA. (1995), Cell proliferation is increased in the endometrium of women with endometriosis. Fertil Steril 64, 340-346.

Witz CA, Thomas MR, Montaya-Rodriguez IA, Nair AS, Centonze VE and Schenken RS (2001) Short-term culture of peritoneum explants confirms attachment of endometrium to intact peritoneal mesotheliurn. Fertil Steril 74. 385-390

Witz CA, Allsup KT, Montoya-Rodriguez IA , Vaughn SL, Centonze VE and Schenken RS (2002) Culture yt menstrual endometrium with peritoneal explants and mesothelial monolayers confirms attachment $b$ intact mesothelial cells. Hum Reprod 17, 2832-2838.

Zeitoun K. Takayama K, Sasano H, Suzuki T, Moghrabi N, Andersson S, Johns A, Meng L, Putman N, Carr B and Bulun SE (1998) Deficient 17ß-hydroxysteroid dehydrogenase type 2 expression ih endometriosis: fallure to metabolize $17 \beta$-estradiol J Clin Endocrinol Metab 83, 4474-4480 


\section{Chapter 2}

Tissue integrity is essential for ectopic implantation of human endometrium in the chicken chorioallantoic membrane

Annemiek W. Nap, Patrick G. Groothuis,

Ayse Y. Demir, Jacques W.M. Maas,

Gerard A.J. Dunselman, Anton F.P.M. de Goeij, and Johannes L.H. Evers

Human Reproduction 2003, 18, 30-34. 


\section{Abstract}

\section{Background}

Not all women with patent tubes develop clinically manifest endometriosis. Quality and quantity of endometrium in retrograde menstruation may be the determining factor in the development of the disease. We hypothesize that retrograde shedding of endometrial fragments with preserved integrity facilitates implantation of endometrium in ectopic: locations, resulting in endometriotic lesion development. We evaluate the impact of tissue integrity on the success of endometriosis-like lesion development in the chicken embryo chorioallantoic membrane (CAM) model.

\section{Methods}

Menstrual and non-menstrual (cyclic) endometrium were collected by biopsy, and either minced or enzymatically dispersed. Spontaneously shed menstrual effluent was collected by a menstrual cup. and cells and tissue were isolated. We evaluated whether infiltration or lesion formation in the CAM occurred after transplantation of endometrium onto the CAM.

\section{Results}

Transplantation of biopsied menstrual and cyclic endometrial fragments, and of endometrial fragments larger than $1 \mathrm{~mm}^{3}$ isolated from menstrual effluent resulted in lesion formation. Transplantation of endometrial cells isolated from menstrual effluent dic not leadi to lesion formation. After transplantation of digested biopsied cyclic endometrium, infiltration in the CAM but no lesions were observed.

\section{Conclusion}

In the CAM assay, integrity of tissue architecture deterrnines the success of implantation of human endometrium in ectopic locations. 


\section{Introduction}

According to Sampson's hypothesis on the pathogenesis of endometriosis, viable. spontaneously shed endometrial tissue arrives in the abdominal cavity and implants in the peritoneum (Sampson, 1927). It is not clear how endometriotic lesions come into existence after the adhesion of endometrium to the peritoneum. Transplantation of endometrium, biopsied during the non-menstrual phase of the cycle (cyclic endometrium) results in the development of endometriosis-like lesions in the chicken embryo chorioallantoic membrane (CAM) that has been used to study tumour transplantation and invasion (Murphy, 1912; Leighton, 1964; Scher et al., 1976). These endometriosis-like lesions consist of human stromal and glandular cells, as confirmed by in situ hybridisation for human chromosome 1 (Maas et al., 2001)

Since menstrual endometrium enters the abdominal cavity and is supposedly "the seed" that develops into endometriotic lesions, menstrual endometrium is the most appropriate tissue to study the early pathogenesis of endometriosis (Groothuis. 1999). Until now, menstrual or endometrial characteristics responsible for the ectopic implantation of endometrium are not yet clear. Shedding of a sufficient amount of endometrium with preserved integrity may facilitate implantation of endometrium in an eclopic location. This hypothesis is supported by the association of increased amounts of retrograde menstruation with a higher risk of developing endometriosis (Sanfilippo et al., 1986; Darrow et al.,1993; D'Hooghe et al., 1994). Moreover, Sillem and co-workers demonstrated in the cynomolgus monkey model that collagenase digestion of endometrial tissue fragments prior to transplantation reduces the ability to implant (Sillem et al., 1996).

In the present study, the CAM model will be used to evaluate the impact of endometrial tissue integrity on endometriosis-like lesion formation.

\section{Materials and methods}

\section{Study design}

We transplanted onto the CAM (1) biopsied cyclic endometrium, (2) biopsied menstrual endometrium, (3) cells and tissue fragments isolated from spontaneously shed menstrual effluent, and (4) enzymatically dispersed endometrium. To account for the effects of tissue handling and manipulation of endometrium, the impact of storage of endometrium in the Keeper (a vaginal cup used for the collection of spontaneously shed menstrual effluent) and of tissue handling on the potential to 
form lesions was evaluated. To this end we transplanted onto the CAM (5) biopsied menstrual endometrium stored in the Keeper, and (6) biopsied menstrual endometrium stored in the Keeper and processed as under (3). Infiltration and endometriosis-like lesion formation were evaluated. In addition, proliferation in endometrium prior to and after transplantation onto the CAM was studied.

\section{Tissue handling}

\section{Biopsied endometrium}

Endometrium was collected by biopsy from 12 women with normal ovulatory cycles undergoing laparoscopy for benign conditions. An Endobiops endometrium sampling device (Gynotec, Malden, The Netherlands) was used. Endometrium was collected during the non-menstrual phase of the cycle $\left(n=6\right.$, cyclic endometrium) $0^{*}$ during menstruation ( $n=6$, menstrual endometrium). After collection, endometrium was placed in serum-free medium composed of DMEM/HAM's F12 supplemented with $2 \mathrm{mmol} / \mathrm{l}$ L-glutamine (Gibco Life Technologies, Breda, The Netherlands), 100 $\mathrm{IU} / \mathrm{ml}$ penicillin, $100 \mu \mathrm{g} / \mathrm{ml}$ streptomycin, and $2.5 \mu \mathrm{g} / \mathrm{ml}$ amphotericin $\mathrm{B}$, and stripped of blood. The endometrial tissue was carefully dissected into uniform pieces of 1-2 $\mathrm{mm}^{3}$ and transplanted onto the CAM (Maas ot al., 2001). To monitor infiltration and lesion development after transplantation of biopsied menstrual endometrium, CAMs were embedded in paraffin after 24,48 and 72 hours.

\section{Isolation of endometrium from menstrual effluent}

Menstrual effluent was collected by 10 volunteers with regular menstrual cycles. These women had no history of endometriosis and did not use oral contraceptives. Collection took place in a menstrual cup for 2 to 3 hours during day 1 or day 2 of menstruation. The soft natural rubber cup, shaped like a cone ("Keeper", Den Haag, The Netherlands), was inserted into the upper vagina with the opening enclosing the cervix. Immediately after collection, the menstrual effluent was brought to the laboratory in a sterile plastic container (Koks et al., 1997). Menstrual effluent was resuspended in serum-free medium, layered on a Ficoll-Paque gradient (SigmaAldrich Chemie BV, Zwijndrecht, The Netherlands) and centrifuged at $1200 \mathrm{~g}$ for 30 minutes at $4^{\circ} \mathrm{C}$. The interphase containing endometrial and inflammatory cells was collected and washed twice in routine medium. The pellet was resuspended in 20-30 $\mu \mathrm{l}$ of serum-free medium and transferred onto the CAM.

In case endometrial fragments larger than $1 \mathrm{~mm}^{3}$ could be identified in the menstrual effluent just below the interphase after the Ficoll-Paque gradient centrifugation, these fragments were picked up from the suspension with a forceps and transplanted onto the CAM. 


\section{Collagenase digestion of cyclic endometrium}

In order to evaluate the effect. of destruction of tissue integrity on the ability to form endometriosis-like lesions, collagenase digestion of endometrium was performed. After collection of biopsied cyclic endometrium $(n=8)$, endometrium was rinsed in serum-free medium and minced into small pieces. The suspension was centrifuged, and the medium was replaced by medium containing $0.25 \%$ collagenase type I (ICN Biomedicals BV, Zoetermeer, The Netherlands) and 0.1\% trypsin (Gibco BRL). The tissue was digested for 15 to 20 minutes at $37^{\circ} \mathrm{C}$ and filtered through a $400-\mu \mathrm{m}$ stainless steel sieve (Sigma-Aldrich Chemie BV. Zwijndrecht, The Netherlands). The cells were pelleted and washed once in serum-free medium. The pellet consisting of collagenase-digested glandular and stromal cells was resuspended in 20-30 $\mu$ l of serum-free medium and transplanted onto the CAM.

\section{Biopsied menstrual endometrium stored in the Keeper}

To evaluate whether tissue collection in the Keeper affects the ability to form lesions, biopsied menstrual endometrium $(n=4)$ was stored in a small amount of serum-free medium in a Keeper for 2 to 3 hours at $37^{\circ} \mathrm{C}$. Subsequently, the endometrial tissue was stripped of blood and carefully sectioned into uniform pieces of $1-2 \mathrm{~mm}^{3}$ and transplanted onto the CAM.

Biopsied menstrual endometrium stored in the Keeper and processed as menstrual fluent

To evaluate whether laboratory procedures necessary to isolate endometrial celts and tissue from spontaneously shed menstrual effluent affect lesion formation, biopsied menstrual endometrium ( $n=4$ ) was kept in a Keeper at $37^{\circ} \mathrm{C}$ for 2 to 3 hours in a small amount of serum-free medium, and subsequently processed in the same way as menstrual effluent. After processing, endometrial tissue fragments were transplanted onto the CAM. Of each endometrial sample collected for this study, 1 tissue fragment was fixed in formalin immediately after collection and embedded in paraffin. Paraffin sections $(4 \mu \mathrm{m})$ were cut and either stained with Haematoxylin and Eosin (H\&E) for histological evaluation or stored for later imrnunohistochemical analysis. The use of human tissue for this study was approved by the Institutional Review Board of the University Hospital Maastricht, and all women participating in the study gave their written informed consent.

\section{CAM model}

Fertilised eggs of Lohman-selected White Leghorns were incubated for 3 days at $37^{\circ} \mathrm{C}, 55 \%$ relative air humidity, while being rotated hourly. At day 3 of incubation, a rectangular window $(1 \times 1.5 \mathrm{~cm})$, was made in the eggshell. Two $\mathrm{ml}$ of albumen was 
withdrawn using a 21 Gauge $(\mathrm{G})$ needle, through the large blunt edge of the egg. The window was covered with Scotch tape to prevent dehydration. The eggs were replaced in the incubator without rotation until day 8 to 11 of incubation.

The CAM is an impenetrable barrier to invasive cells unless it has been traumatized by removing the upper peridermal part of the double epithelial layer, leaving the basal layer intact. Therefore, just before the transplantation of endometrium a small part of the CAM was gently traumatised by laying a $1 \mathrm{~cm}^{2}$ wide strip of sterile etherextracted lens paper onto the surface of the epithelium and then removing it immediately (Armstrong et al., 1982; Maas et al., 2001).

Endometrial tissue was transplanted onto the CAM. Following transplantation, the window was covered again and the egg was placed back in the incubator. After incubating for 24, 48, and 72 hours, the transplanted tissue including the surrounding CAM was excised, fixed in formalin and embedded in paraffin. Paraffin sections were cut and either stained with H\&E for histological evaluation or stored for later immunohistochemical analysis.

\section{Immunohistochemistry}

Proliferation was evaluated by immunohistochemistry using a mouse monoclonal antibody against the proliferation marker Ki67 (MIB-1, 1:25, Boehringer, Mannheim, Germany). Epithelium was stained using a mouse monoclonal antibody against pancytokeratin (Clone MNF 116, 1:100, DAKO, Glostrup, Denmark). In short, paraffin sections were deparaffinised by incubation with xylene for 2 times 3 minutes and rehydrated in alcohol series. Endogenous peroxidase activity was blocked by incubation with $0.25 \%$ hydrogen peroxide in methanol for 20 minutes. Sections were rinsed 3 times in phosphate-buffered saline (PBS) and were heated to $95^{\circ} \mathrm{C}$ in citrate buffer $(\mathrm{pH} 6.0)$ for 20 minutes in preparation for incubation with the MIB-1 antibody, or digested in $0.1 \%$ pepsin in $0.1 \mathrm{~N} \mathrm{HCL}$ for 30 minutes in preparation for incubation with the pan-cytokeratin antibody. After rinsing again in PBS, sections were incubated overnight at $4^{\circ} \mathrm{C}$ with the primary antibody. After 3 PBS rinses, sections were exposed to Envision anti-mouse for 30 minutes. After rinsing in PBS, antibody binding was visualized with 3'-3-diaminobenzidin (DAB). Sections were washed and counterstained with haematoxylin, washed again, dehydrated and mounted for light microscopy.

\section{Statistical analysis}

Differences in infiltration and endometriosis-like lesion formation between biopsied. cyclic endometrium and the other endometrial cell and tissue preparations used in this study were calculated using $\chi^{2}$ tests. P-values $<0.05$ were considered statistically significant. 


\section{Results}

\section{Lesion development in biopsied menstrual endometrium}

Twenty four hours after transplantation of biopsied menstrual endometrium. endometrial cells were observed in direct contact with the CAM mesenchyme (Figure 1a, 1b). Forty eight hours after transplantation, lesions were observed consisting of endometrial glands and heterogeneous stroma, with blood vessels containing nucleated erythrocytes in close proximity of the edge of the lesions (Figure 1c). Seventy two hours after transplantation, organized lesions were observed in the CAM mesenchyme, with intact glands and surrounding endometrial stroma, mimicking normal endometrium and endometriotic lesions. Nucleatederythrocytes containing vessels were present within the lesions (Figure 1d).
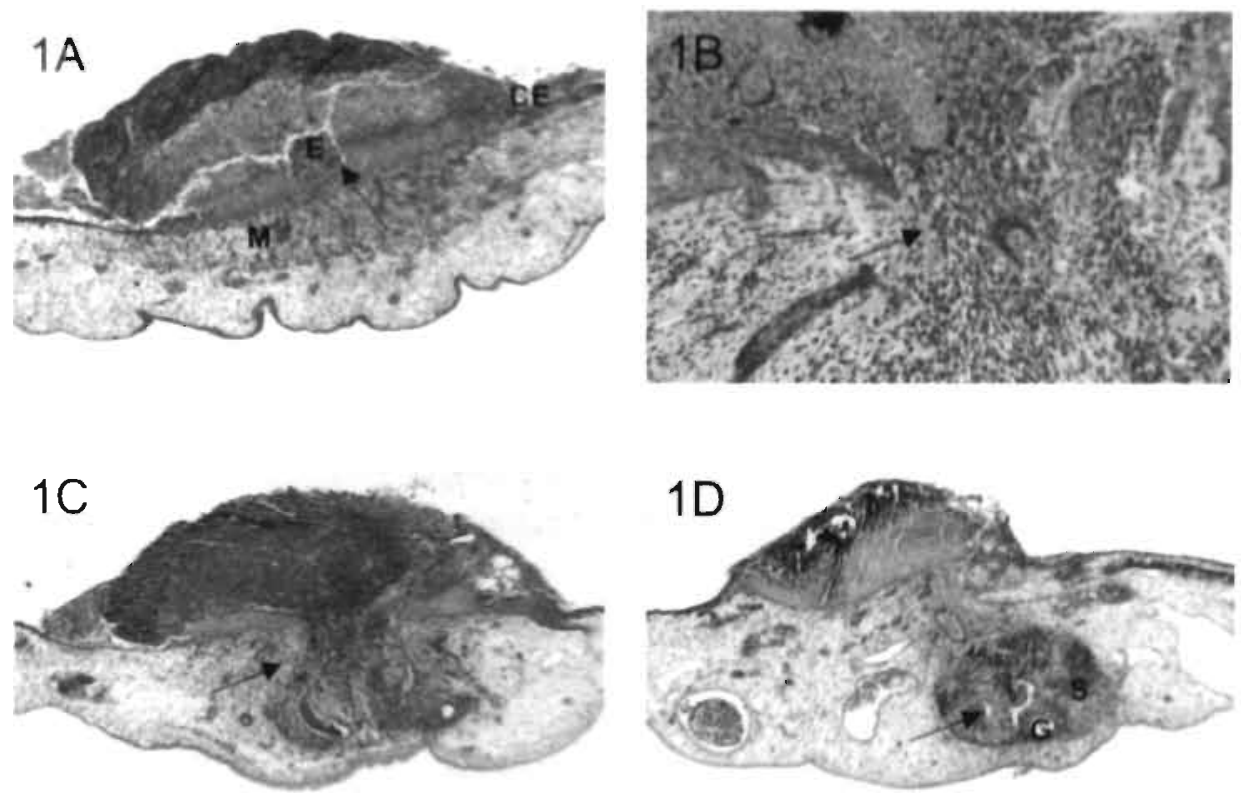

Figure 1. Development of endometriosis-like lesion after transplantation of biopsied menstrual endometrium onto the CAM.

(1.A) Direct contact (arrow) of endometrium (E) and CAM mesenchyme (M), 24 hours after Iransplantation. CE: chononic epithelium.

(1B) Detail of cytokeratin positive epithelial cells 24 hours after transplantation Direct contact (arrow) of endometrium and CAM mesenchyme

(1C) Infiltration (arrow) of endometnal tissue 48 hours after transplantation

(1D) Organized lesion with intact glands (G) and surrounding endometrial stroma (S). with enlarged vessels in the CAM (arrow) 72 hours affer transplantation (A, C. D haematoxylin and eosin staining. B. cytokeratin staining) 


\section{Proliferation}

Prior to transplantation, Ki67 positive cells were present. both in menstrual and in cyclic endometrium (Figure 2a). Seventy two hours after transplantation, Ki67 staining was almost absent (Figure 2b).
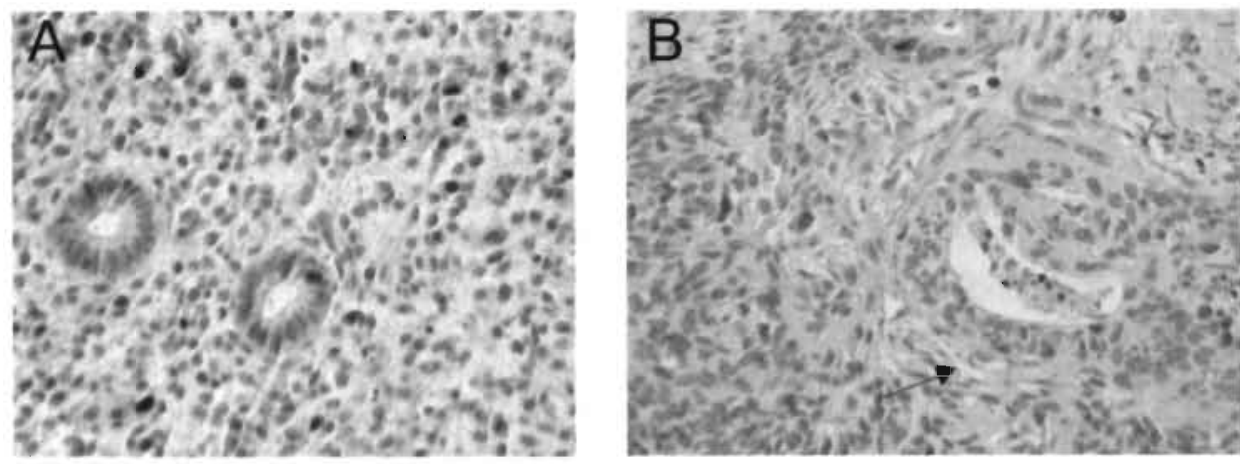

Figure 2. Immunostaining of proliferation marker Ki67 in biopsied cyclic endometrium.

(2A) Ki67 staining prior fo transplantation, and (2B) 72 hours after transplantation. Note the vessels in the lesion (arrow).

\section{Impact of tissue integrity on lesion formation}

The abilities of the various cell and tissue preparations to infiltrate the CAM and to form endometriosis-like lesions 72 hours after transplantation are summarized in Table 1. Transplantation of biopsied cyclic and biopsied menstrual endometrium resulted in infiltration in $74 \%$ and $78 \%$ and in formation of endometriosis-like lesions in $68 \%$ and $67 \%$ of CAMs, respectively. Transplantation of endometrial cell suspensions isclated from spontaneously shed menstrual effluent collected by the Keeper resulted neither in infiltration nor in lesion formation in the CAM. In 4 out of 10 menstrual effiuent samples, intact tissue fragments with a size iarger than $1 \mathrm{~mm}^{3}$ were present in menstrual effluent and could be picked up from the suspension with a forceps. These fragments were composed of intact glands and stromal tissue as confirmed by immunohistochemical staining for cytokeratin and vimentin respectively (data not shown). After transplantation onto the CAM they were able to infiltrate in $63 \%$ and to form lesions in $44 \%$ of CAMs. Transplantation of endometrium after collagenase digestion resulted in infiltration in 53\%, but did not result in lesion formation in the CAM. After transplantation of biopsied menstrual endometrium that had been stored in the Keeper, or had been processed in the same way as menstrual effluent, infiltration as well as lesion formation in the CAM were still observed. 
Tabie 1. Impact of tissue integnty on infiltration and endometnosis tike lesion formation in the CAM

\begin{tabular}{|c|c|c|c|}
\hline Endometrium & * of CAMs & Infiltration & Lesion \\
\hline biopsied cyclic endometrium & 19 & $14(74 \%)$ & $13(68 \%)$ \\
\hline biopsied menstrual endometrum & 18 & $14(78 \%)$ & $12(67 \%)$ \\
\hline endometrial cells isolated from menstrual effuent collected in Keeper & 50 & $0(0 \%)^{*}$ & $0(0 \%)^{*}$ \\
\hline tissue fragments in menstrual effuent collected in Keeper & 16 & $10(63 \%)$ & $7(44 \%) *$ \\
\hline collagenase digested biopsied cyclic endometrum & 45 & $24(53 \%) *$ & $1(2 \%)^{*}$ \\
\hline biopsied menstrual endometrium, stored in Keeper & 13 & $10(77 \%)$ & $9(69 \%)$ \\
\hline $\begin{array}{l}\text { biopsied menstrual endometrium, stored in Keeper, processed as } \\
\text { menstrual effluent }\end{array}$ & 11 & $6(55 \%)$ & $4(36 \%) *$ \\
\hline
\end{tabular}

"statistically significant compared to biopsied cyclic endometrium, $* 0<0 ., * p<0.1$

\section{Discussion}

\section{Lesion development}

In this study we have shown that biopsied menstrual endometrium and endometrial tissue fragments isolated from spontaneously shed menstrual effluent are able to form endometriosis-like lesions in the CAM model, in a similar fashion as biopsied cyclic endometrium. Twenty four hours after transplantation, direct contact between the endometrium and the CAM mesenchyme is observed, and after 72 hours complete lesions are present in the CAM.

These abservations imply that lesions originate from endometrial cells that have migrated into the CAM mesenchyme. Alternatively, lesions may develop from rapidy proliferating endometrial cells. Contrary to what we expected, proliferation marker $\mathrm{Ki67}$ is hardly expressed in the lesions while it is expressed in the endometrium prior to transplantation. This suggests a minor role for cell proliferation in the organization of lesions. These findings are in accordance with results of other authors, who reported a significantly reduced proliferation activity in the epithelium of ectopic: lesions as compared to the eutopic endometrium (Jones et al.,1995; Scotti et al., 2000). Therefore, it is likely that the ability of infiltrated endometrial cells to rebuild the original tissue structure is responsible for lesion formation. However, we cannot exclude the possibility that hormonal or other environmental factors in the body which are absent in the CAM may play a role in lesion formation as well. 


\section{Impact of tissue integrity on lesion formation}

Transplantation of biopsied cyclic and menstrual endometrium results in infiltration and endometriosis-like lesions, whereas transplantation of single endometrial cells isolated from spontaneously shed menstrual effluent does not. This suggests that the tissue architecture of biopsied endometrium, which consists of organized glandular epithelium and stroma, is pivotal for the ability of endometrium to infiltrate and to form lesions. During menstruation, endometrial tissue is exposed to high levels of matrix degrading enzymes (Koks et al., 2000; Marbaix et al., 1995). In most cases " menstrual effluent consists of single endometrial glandular and stromal cells instead of intact tissue fragments. These endometrial cells adhere easily to the basement membrane of amnion and peritoneum (Koks et al., 1999), but they are not able to infiltrate and develop endometriosis-like lesions in the CAM. Apparently, single endometrial cells lack the essential mutual contact in which glandular structures are intact and surrounding stromal cells are present, and consequently lack the ability to form lesions. In 4 out of 10 menstrual effluent samples in this study, intact endometrial fragments larger than $1 \mathrm{~mm}^{3}$ could be retrieved from the menstrual effluent. These fragments, composed of intact glandular structures and surrounding stromal cells, were able to induce endonetriosis-like lesions in the CAM, whereas single cells from the same menstrual effluent samples were not.

Compared to biopsied endometrium, the number of lesions formed was slightly reduced, suggesting a diminished capacity of shed fragments of endometrium to form lesions, most likely as a result of the tissue degradation process which has been initiated at menstruation. Therefore, it is tempting to suggest that women who shed intact endometrial fragments in their menstrual effluent are more prone to clevelop endometriosis.

The capacity to form lesions disappeared once biopsied cyclic endometrium was digested by collagenase prior to transplantation. This is in accordance with the findings of Sillem and co-workers in the cynomolgus monkey model. These authors found that enzymatic treatment of endometrial tissue reduced the development of endometriotic lesions (Sillem ef al., 1996).

The observation that transplantation of endometrial cells isolated from menstrual effluent does not result in lesion formation may alternatively be a consequence of the contact of menstrual effluent with the Keeper, or of laboratory procedures necessary to isolate endometrial cells and fragments from menstrual effluent. For this reason we have exposed biopsied menstrual endometrium to storage in the Keeper, and to the same laboratory procedures that were used for isolation of endometrial cells and tissue from menstrual effluent. Lesion formation was not affected after storage of biopsied menstrual endometrium in the Keeper. When 
biopsied menstrual endometrium was processed in the same way as shed menstrual effluent, lesion formation was slightly reduced. For this reason, we consider it safe to argue that laboratory procedures used to isolate endometrial cells and tissue from menstrual effluent prior to transplantation are not responsible for the complete lack of lesion formation after transplantation of cells isolated from menstrual effluent.

In conclusion, we have shown that biopsied menstrual endometrium is able to develop into endometriosis-like lesions in the CAM model. Spontaneously shed menstrual endometrium will also form lesions if tissue fragments are of sufficient size, assuring preservation of tissue architecture and interaction between epithelial glands and the stromal compartment. These findings indicate that tissue integrity is crucial for the development of endometriotic lesions.

\section{Acknowledgements}

The authors wish to acknowledge Mrs. Jacqueline Schouten, Ms. Michelle Versleijen, Mrs. Lilian Kessels, Ms. Christa de Veen and Ms. Natasja Kisters for excellent laboratory assistance. 


\section{References}

Armstrong PB, Quigley JP and Sidebottom E (1982) Transepithelial invasion and intramesenchymal infiltration of the chick embryo chorioallantois by tumour cell lines. Cancer Res 42, 1826-1837.

Bartosik D, Jacobs SL and Kelly LJ (1986) Endometrial tissue in peritoneal fluid. Fertil Steril 46, 796-800.

Darrow SL, Vena JE, Batt RE, Zielezny MA, Michalek, AM and Selman S (1993) Menstrual cycle characteristics and the risk of endometriosis. Epidemiology 4, 135-142.

D'Hooghe TM, Bambra CS, Suleman MA, Dunselman GAJ, Evers JLH and Koninckx PR (1994) Development of a model of retrograde menstruation in baboons (Papio anubis). Fertil Steril 62, 635638.

Groothuis P (1999) What is the most! appropriate phase of endometrium to use for peritoneal attachment studies? Fertil Steril $72,381-382$

Jones RK. Bulmer JN and Searle RF (1995) Immunohistochemical characterization of proliferation, oestrogen receptor and progesterone receptor expression in endometriosis: comparison of eutopic and ectopic endometriumwith normal cycling endometrium. Hum Reprod 10، 3272-3279.

Koks CAM, Dunselman GAJ, De Goeij AFPM, Arends JW and Evers JLH (1997) Evaluation of a mensțtrual cup to collect shed endometrium for in vitro studies. Fertil Steril 68, 560-564.

Koks CAM, Groothuis PG. Dunseiman GAJ. De Goeil AFPM and Evers JLH (1999) Adhesion of shed menstrual tissue in an in vitro model using amnion and peritoneum: a light and electron micrsocopic study Hum Reprod 14, 816-822

Koks CAM, Groothuis, PG. Slaats P. Dunseiman GAJ, De Goeil AFPM and Evers JLH (2000) Matrix metalloproteinases and their tissue inhibitors in antegradely shed menstruum and peritoneal fluid. Fertil Stenil 73, 604-612

Leighton J (1964) Invasion and metastasis of heterologous tumours in the chick embryo. Progr Exp Tumour Res 4.98-125

Maas JWM, Groothuis PG. Dunseiman GAJ, De Goeij AFPM, Struijker Boudier HAJ and Evers JLH (2001) Development of endometriosis-like lesions after transplantation of human endometrial fragments onto the chick embryo chorioallantoic membrane Hum Reprod 16, 627-631

Marbaix E. Kokonine I. Henriet P. Donnez J. Courtoy PJ and Eeckhout Y (1995) The expression of interstitial collagenase in human endometrium is controlled by progesterone and by oestradiol and is felated to menstruation. Biochem J 305, 1027-30.

Murphy JB (1912) Transplantability of malignant tumours to the embryos of foreign species. J Am Med Assoc 59, 874-875

Sampson JA (1927) Peritoneal endometriosis due to the menstrual dissemination of endometrial tissue into the peritoneal cavity Am J Obstet Gynecol 14.422-469

Sanfilippo JS, Wakim NG, Schikler KN and Yussman MA (1986) Endometrosis in association with uterine anomaly . Am J Obstet Gynecol 154, 39-43

Scher CD. Haudenschild C and Klagsbrun M (1976) The chick chorioallantoic membrane as a model system for the study of tissue invasion by viral transformed cells. Cell $8.373-382$

Scotti S. Regidor PA, Schindler AE and Winterhager E (2000) Reduced proliferation and cell adhesion in endometriosis Mol Hum Reprod 6, 610-617

Sillem M. Hahn U. Coddington CC $3^{\text {rd }}$, Gordon K, Runnebaum B and Hodgen GD (1996) Ectopic growth of endometrium depends on its structural integrity and proteolytic activity in the cynomolgus monkey (Macaca Fascicularis) model of endometriosis. Fertil Steril 66, 351-353 


\section{Chapter 3}

Inhibiting MMP activity prevents the development of endometriosis in the chicken chorioallantoic membrane model 


\section{Abstract}

\section{Background}

Matrix metalloproteinases (MMPs) are essential for extracellular matrix remodeling and may contribute to the development of endometriosis. Transplantation of endometrium onto the chicken chorioallantoic membrane (CAM) results in endometriosis-like lesion formation, a process that requires extensive tissue remoclelling. We investigated the expression of a wide range of MMPs in menstrual endometrium, endometriosis-like lesions in CAMs, in peritoneal endometriosis and in endometriosis in the rectovaginal space, as well as the function of MMPs in early lesion formation in the CAM model.

\section{Methods}

Expression of MMPs was evaluated by immunohistochemistry and MMP function was studied in the CAM by inhibiting MMP activity during lesion formation.

\section{Results}

Nearly all MMPs were present in all tissues studied. No significant differences in the expression of a majority of MMPs were found in endometriosis-like lesions in CAMs when compared to human endometriosis. Inhibition of the MMP-1, -2, $-3,-7$ and -13 activities significantly impaired endometriosis-like lesion formation in CAMs

\section{Conclusion}

The MMP expression profiles of experimentally induced endometriosis in CAMs and human endometriosis are similar. The prevention of endometriosis-like lesion formation in the CAM by inhibiting MMP activity strongly suggests that MMPs have a function in the early development of endometriotic lesions. 


\section{Introduction}

Endometriosis presents as lesions of endometrium with glands and stroma that grow at locations outside the uterus, predominantly within the peritoneal cavity. It presumably develops after the ectopic implantation of endometrium, which has entered the peritoneal cavity via the Fallopian tubes during menstruation (Sampson, 1927). The initial phase of the disease is an invasive event, which requires. extracellular matrix (ECM) breakdown (Spuijbroek et al., 1992; Bruner et al. , 1997). Matrix metalloproteinases (MMPs) are essential in the remodelling of the ECM in normal development, growth and repair of tissues, and are implicated in cancer and in inflammatory and degenerative diseases.

MMPs, a large family of zinc-dependent, structurally related endoproteases can be. distinguished in 5 subclasses according to structure and function, i.e. collagenases, gelatinases, stromelysins, membrane-type (MT-)MMPs and other MMPs. A survey of the known MMPs, their substrates and their tissue inhibitors (TIMPs) is presented in Table I. The possible role of MMPs and TIMPs in endometriosis has been discussed in various reports (Osteen et al., 1996, 1999, 2002; Sillem et al., 1998; Sharpe-Timms and Cox, 2002). Table 2 presents an overview of recent studies with regard to the relationship between MMP expression and endometriosis. The results of these studies are difficult to compare since different techniques are used, and only a selection of MMPs is studied in different case and control groups. Moreover, the results of some of these studies are conflicting. Although the expression of a number of MMPs is described, information on the function of these enzymes in the initial steps of the development of endometriosis is lacking.

The early phases in endometrictic lesion formation, when MMP activity is supposed to be particularly essential, are difficult to study in man in vivo. Recently, the functions of some MMPs in endometriosis have been evaluated in a murine model of experimentally induced endometriosis (Bruner et al., 1997, 2002). These studies demonstrated that endometriosis-like lesion formation in this model can be prevented by inhibition of MMPs. However, no specific information with regardi to MMP types was obtained, since the inhibitory actions affected a wide range of MMPs, and the relevance of these studies for the human situation is limited. 
Table 1 MMPs and their substrates.

\begin{tabular}{lll} 
MMP & MMP \# MMP name $\quad$ Substrafe. \\
Subclass & \\
\hline
\end{tabular}

Collagenases

$\begin{array}{ll}\text { MMP-1 Interstitial } & \text { Collagens I, II, III, VIII, VIII, X; gelatin; aggrecan; L-selectin; IL-1 } 1 \text {; } \\ \text { collagenase } & \text { proteoglycans; entactin; ovostatin; tenascin; TNF-a; MMP-2; MMP. } \\ & 9\end{array}$

MMP-8 Neutrophil Collagens I, II, III, V, VII, VIII, X; gelatin; aggrecan; fibronectin; collagenase entactin; tenascin.

MMP-13 Collagenase-3 Collagens I, II, III, IV, VII, IX, X, XIV; gelatin; plasminogen; aggrecan; perlecan; fibronectin; osteonectin; MMP-9

MMP-18 Collagenase-4

Gelatinases

MMP-2 Gelatinase A

MMP-9 Gelatinase B

stramelysips

MMP-3 Stromelysin 1

MMP-10 Stromelysin 2

MMP-11 Stromelysin 3

Membrane-type MMPs
Gelatin; elastin; fibronectin; collagen I, IV, V, VII, X, XI, XIV; fibronectin; TINF- $\alpha$; aggrecan; osteonectin; MBP; laminin-1; MMP. 1; MMP-9: MMP-13

Collagens I, IV, V; VII, X, XI, XIV; gelatin; entactin; aggregan; elastin; fibronectin; osteonectin; plasminogen; MBP; IL-1 B; TNF- a

Collagens III, IV, V, IX, X, XI; fibrin/fibrinogen; tenascin; gelatin; aggrecan; perlecan; decorin; laminin; elastin; casein; osteonectin; ovostatin; entackin; plasminogen; MBP; IL-1.. ; proteoglycans; fibronectin; proteoglycans; MMP-1, MMP-2/TIMP-2; MMP-7; MMP8: MMP.9; MMP-13

Collagens III, IV, V. IX, X, XI; gelatin; casein; aggrecan; elastin; proteoglycans; fibronectin; laminin; fibrin/fibrinogen; entactin; tenascin; vitronectin; MMP-1; MMP-8

Laminin; fibronectin; aggrecan

Collagens I, II, III; gelatin; casein; fibronectin; laminin; vitronectin; entactin; proteoglycans; aggrecan; MMP-2; MMP-13

Fibronectir; entactin; laminin; perlecan; gelatin; vitronectin; collagen; aggrecan; MMP-2

Collagen III: gelatin; casein; fibronectin; vitronectin; aggrecan; MMP-2

Gelatin

Gelatin; fibronectin; vitronectin, collagen; aggrecan

Gelatin, collagen IV, fibrin; fibronectin; laminin-1; pro-gelatinase-A 


\begin{tabular}{|c|c|c|c|}
\hline $\begin{array}{l}\text { MMP } \\
\text { Subclass }\end{array}$ & MMP $=$ & MMP name & Substrate \\
\hline \multicolumn{4}{|l|}{ Others } \\
\hline & MMP.7 & Matrilysin & $\begin{array}{l}\text { Collagens III, IV. V, IX, X, XI; gelatin; aggrecan; decorin; } \\
\text { fibronectin; laminin; entactin; elastin; casein; transterrin; } \\
\text { plasminogen; MBP, } \beta 4 \text {-integrin; proteoglycans; fibrin/ibrinogen; } \\
\text { lenascin; vitronectin; UPA, TNF. } \alpha \text {, MMP.1; MMP.2; MMP.9; MMP. } \\
\text { 9/TIMP.1 }\end{array}$ \\
\hline & MMP.12 & Metalloelastase & $\begin{array}{l}\text { Collagen IV, gelatin, elastin; casein; fibronectin; vitronectin; } \\
\text { laminin, entactin; MBP, fibrin/fibrinogen; ptasminogen; } \\
\text { proteoglycan }\end{array}$ \\
\hline & MMP-19 & Unnamed & $\begin{array}{l}\text { Gelatin; tenascin; fibronectin; collagen IV; Iaminin; entactin; } \\
\text { fibrin/fibrinogen; aggrecan }\end{array}$ \\
\hline & MMP-20 & Enamelysin & Amelogrenein; aggrecan; \\
\hline & MMP.23 & Unnamed & Gelatin \\
\hline & MMP-26 & Endometase & Gelatin I a, PI \\
\hline
\end{tabular}

Abbreviations IL interleukin, MBP myelin basic protein. MMP matrix metalloproteinase, PI protein inhibitor. TIMP tissue inhibitor of MMP. TNF- $\alpha$ tumour necrosis factor- $\alpha$, uPA urokinase-fype plasminogen activator References McCawley and Matrisian, 2001. Whittaker and Ayscough, 2001

The chicken chorioallantoic membrane (CAM) model has been used to study the invasive, metastatic and angiogenic potential of neoplastic cells (Scher et al., 1976; Armstrong et al., 1982), and can be used to differentiate between non-invasive and invasive epithelial cells (Schroyens et al., 1989). Collagen type $\mathbf{I}$ and IV, laminin, and fibronectin are present in the ECM of the CAM (Giannopoulou et al., 2001). which is similar to the ECM of the human peritoneum (Witz et al., 2001). We have reported earlier that transplantation of human endometrium onto the CAM results in the formation of endometriosis-like lesions with endometrial glands and stroma of human origin (Maas et al., 2001). The early phase of endometriosis-like lesion formation in this model is a rapid, proliferation-independent process, in which extensive tissue remodelling has been observed (Nap et al., 2003). Consequently. we hypothesize that the expression of MMPs and TIMPs in human endometriosis is reflected in experimental endometriosis-like lesions in the CAM and that the CAM model is a helpful tool to evaluate functional involvement of MMPs in the development of endometriosis.

To test this hypothesis, the expression of MMPs $-1,-2,-3,-7,-8,-9,-10,-11,-13$, $-14,-15,-16,-23$, and of TIMP-1, -2 and -3 was evaluated in menstrual endometrium, in endometriosis-like lesions in the CAM and in human peritoneal and deep invasive endometriosis using semiquantitative immunohistochemistry. Subsequently, the MMP' expression profile of experimentally induced endometriosis 
in the CAM was compared to that of human endometriosis in order to see whether these profiles were similar. Finally, as expression of MMPs does not provide information about the activity of these enzymes, a functional study in the CAM was performed in which an MMP inhibitor was applied after transplantation of menstrual endometrium onto the CAMs. We selected a broad spectrum inhibitor which antagonizes the MMPs that were prominently present in the menstrual endometrium, the tissue that is thought to adhere and implant ectopically and to develop into endometriosis. The inhibiting effect on endometriosis-like lesion formation in the CAM was evaluated.

Table 2. MMPs and endometriosis in literature

\begin{tabular}{|c|c|c|c|c|c|}
\hline Author & $\begin{array}{l}\text { MMPs } \\
\text { TIMPs }\end{array}$ & technique & Material & Results & $\begin{array}{l}\text { Phase of } \\
\text { cycle }\end{array}$ \\
\hline $\begin{array}{l}\text { Kokorine ef al. } \\
1997\end{array}$ & MMP-1 & ISH & $\begin{array}{l}\text { Red and black } \\
\text { lesions, OE, and } \\
\text { RVE }\end{array}$ & $\begin{array}{l}\text { MMP-1 present in red PE and OE, } \\
\text { not in black PE and } R V \text { lesions }\end{array}$ & Various days \\
\hline $\begin{array}{l}\text { Wenzl et al. } \\
1998\end{array}$ & MMP-2 & $\mathrm{IHC}$ & $\begin{array}{l}\text { Eut and ect from } \\
\text { pat, eut from co }\end{array}$ & $\begin{array}{l}\text { MMP- } 2 \text { higher in ect than in eut in } \\
\text { pat; no difference in eut between pat } \\
\text { and co }\end{array}$ & Unknown \\
\hline $\begin{array}{l}\text { Gottschalk et al. } \\
2000\end{array}$ & $\begin{array}{l}\text { MMP. } \\
1,2,3,9 \\
\text { TIMP. } \\
1,2\end{array}$ & IHC. ISH & $\begin{array}{l}\text { Eut and ect from } \\
\text { pat }\end{array}$ & $\begin{array}{l}\text { MMP-1 higher, TIMP-1, }-2 \text { lower in: } \\
\text { ect than in eut }\end{array}$ & Various days \\
\hline $\begin{array}{l}\text { Chung et al, } \\
2001\end{array}$ & $\begin{array}{l}\text { MMP.9 } \\
\text { TIMP.3 }\end{array}$ & PCR & $\begin{array}{l}\text { Eut and ect from } \\
\text { pat, eut from co }\end{array}$ & $\begin{array}{l}\text { Lower TIMP-3 in eut and ect from pat } \\
\text { than in eut from co; higher MMP-9 } \\
\text { and higher MMP.9/TIMP- } 3 \text { ratio in ect } \\
\text { than in eut from pat and co }\end{array}$ & Various days \\
\hline $\begin{array}{l}\text { Sillem et al. } \\
2001\end{array}$ & $\begin{array}{l}\text { MMP. } \\
1,2,3,9 \\
\text { TIMP. } \\
1,2\end{array}$ & ELISA & $\begin{array}{l}\text { Eut from pat and } \\
\text { co; treatment with } \\
\text { diethyl stilbestrol, } \\
\text { TNF-a, IL-1, } \\
\text { promegestone }\end{array}$ & $\begin{array}{l}\text { MMP-1. - } 3 \text { reduced by promegestone } \\
\text { in pat and co: MMP. } 2 \text { not influenced. } \\
\text { MMP- } 3 \text { upregulated by TNF- } \mathrm{a} \text { in all } \\
\text { samples; but by IL-1 in pat only. }\end{array}$ & Various days \\
\hline $\begin{array}{l}\text { Bruner-Tran ef } \\
\text { al. } 2002\end{array}$ & $\begin{array}{l}\text { MMP. } \\
3,7\end{array}$ & ISH, WB & $\begin{array}{l}\text { Eut and ect from } \\
\text { pat and eut from co }\end{array}$ & $\begin{array}{l}\text { MMP-3, MMP-7 similar in ect and eut } \\
\text { (proliferative); MMP-3, MMP-7 absent } \\
\text { in normal secretory eut but present in } \\
\text { eut and ect from pat. }\end{array}$ & Various days \\
\hline $\begin{array}{l}\text { Chung et al. } \\
2002\end{array}$ & $\begin{array}{l}\text { MMP. } \\
2,14 \\
\text { TIMP-2 }\end{array}$ & $\begin{array}{l}\text { RT-PCR, } \\
Z, W B\end{array}$ & $\begin{array}{l}\text { Eut and ect from } \\
\text { pat, eut from co }\end{array}$ & $\begin{array}{l}\text { MMP- } 2 \text { and }-14 \text { higher, and TIMP-2 } \\
\text { lower in eut from pat than from } c 0\end{array}$ & Unknown \\
\hline Liu ef at., 2002 & MMP-9 & $z$ & $\begin{array}{l}\text { Eut and ect from } \\
\text { pat }\end{array}$ & $\begin{array}{l}\text { MMP-9 higher in ect than in eut from } \\
\text { patients, and higher in severe ect }\end{array}$ & Unknown \\
\hline $\begin{array}{l}\text { Mizumoto et al., } \\
2002\end{array}$ & $\begin{array}{l}\text { MMP. } \\
1,2,3,7,9 \\
\text { TIMP-1 }\end{array}$ & $\begin{array}{l}\text { IHC, WB, } \\
\text { ELISA }\end{array}$ & $\begin{array}{l}\text { OE fluid from pat } \\
\text { and eut from co }\end{array}$ & $\begin{array}{l}\text { In OE: MMP. } 1,-2,-7,-9 . \text { TIMP.-1 } \\
\text { present in menstrual phase; MMP.3 } \\
\text { in macrophages in all phases of cycle }\end{array}$ & Various days \\
\hline
\end{tabular}




\begin{tabular}{|c|c|c|c|c|c|}
\hline Author & $\begin{array}{l}\text { MMPs } \\
\text { TIMPs }\end{array}$ & lechnique & Material & Results & $\begin{array}{l}\text { Phase of } \\
\text { cycle }\end{array}$ \\
\hline $\begin{array}{l}\text { Nezhat et al. } \\
2002\end{array}$ & MMP-9 & $\mathrm{HHC}$ & Ect and $O E$ & $\begin{array}{l}\text { MMP.9 more expressed in ect than in } \\
\text { OE }\end{array}$ & Uniknown \\
\hline Ria et al., 2002 & $\begin{array}{l}\text { MMP. } \\
2,9\end{array}$ & ISH & $\begin{array}{l}\text { Stage III and IV OE } \\
\text { from pat and eut } \\
\text { from } \infty 0\end{array}$ & $\begin{array}{l}\text { MMP-2, }-9 \text { higher in OE stage IV than } \\
\text { stage IIt; higher in OE than in eut } \\
\text { from co }\end{array}$ & $\begin{array}{l}\text { Pat: } \\
\text { unknown: } \\
\text { Co: } \\
\text { midsecretory }\end{array}$ \\
\hline $\begin{array}{l}\text { Szamatowicz ef } \\
\text { at. } 2002\end{array}$ & $\begin{array}{l}\text { MMP-9 } \\
\text { MP-1 }\end{array}$ & ELISA & $\begin{array}{l}\text { PF from pat vs. PF } \\
\text { from co }\end{array}$ & $\begin{array}{l}\text { Active MMP. } 9 \text { the same in PF of pat } \\
\text { and } c 0 ; \text { TIMP. } 1 \text { lower in PF of pat } \\
\text { than of } c 0\end{array}$ & Days 8-12 \\
\hline Ueda et al., 2002 & $\begin{array}{l}\text { MMP. } \\
2,9,14\end{array}$ & $\begin{array}{l}\text { IHC, } \\
\text { RT-PCR }\end{array}$ & $\begin{array}{l}\text { Ect from pat and } \\
\text { eut from co }\end{array}$ & $\begin{array}{l}\text { MMP. } 2,-9,-14 \text { higher in ect from pat } \\
\text { than in eut from } c 0\end{array}$ & Unknown \\
\hline $\begin{array}{l}\text { Gilabent-Estelles. } \\
\text { ef al., } 2003\end{array}$ & $\begin{array}{l}\text { MMP-3 } \\
\text { TIMP-1 }\end{array}$ & ELISA & $\begin{array}{l}\text { Eut, and } P F \text { from } \\
\text { pat and } c 0, O E \\
\text { trom pat }\end{array}$ & $\begin{array}{l}\text { MMP. } 3 \text { higher, TIMP. } 1 \text { equal in eut } \\
\text { from pat compared to co; MMP. } 3 \\
\text { higher, TIMP. } 1 \text { lower in eut than in } \\
\text { OE from pat; no differences in PF }\end{array}$ & Various days \\
\hline $\begin{array}{l}\text { Wolber et al. } \\
2003\end{array}$ & $\begin{array}{l}\text { MMP. } \\
1,2\end{array}$ & PCR & $\begin{array}{l}\text { Eut from co } \\
\text { cultured on CAM }\end{array}$ & $\begin{array}{l}\text { MMP.1 upregulated, MMP-2: } \\
\text { unaltered after culturing eut on CAM }\end{array}$ & Various days \\
\hline
\end{tabular}

\section{Abbreviations}

IHC Immunohistochemistry, ISH In Situ Hybridisation, (RT-)PCR (Reverse Transcriptase-) Polymerase Chain Reaction, WB Western Blot. Z Zymography Co Control women without endometriosis Pat Patients, Ect Ectopic endometrium or endometriosis. Eut Eutopic endometrium, OE Ovarian Endometriosis. PE: Peritoneal Endometriosis. RV Rectovaginal Endometriosis, PF Peritoneal Fluid

\section{Materials and methods.}

\section{Tissue}

\section{Human endometrial tissue}

Endometrium was collected by biopsy from 10 women with normal ovulatory cycles, undergoing laparoscopy for benign conditions. No visible endometriosis was present. An Endobiops endometrium sampling device (Gynotec, Malden. The Netherlands) was used. Endometrium was collected during the menstrual phase of the cycle ( 1 to 3 days after the onset of bleeding). The use of human endometrium was approved by the Institutional Ethical Review Committee of the University Hospital Maastricht. All women participating in the study gave their written informed consent. Immediately after collection, blood clots were removed and the endometrium was carefully minced in fragments of $1-2 \mathrm{~mm}^{3}$ and kept in serum-free DMEM/HAM's F12 culture medium supplemented with 2 mmol// L-glutamine, 100 $\mathrm{IU} / \mathrm{ml}$ penicillin, $100 \mu \mathrm{g} / \mathrm{m}$ ! streptomycin, and $2.5 \mu \mathrm{g} / \mathrm{ml}$ amphotericin B (all from Gibco Life Technologies, Breda, The Netherlands). Part of the biopsied menstrual 
endometrium was used for transplantation onto the CAM. Of each endometrium biopsy, tissue was embedded in paraffin, sectioned, Haematoxylin \& Eosin (H\&E) staining was performed for histological evaluation and to assess tissue integrity, and immunohistochemical analysis for MMP expression was performed.

\section{Archival human endometriotic tissue}

Paraffin blocks of red peritoneal lesions $(n=5)$ and of endometriosis located in the rectovaginal space $(n=5)$ collected from patients undergoing surgery in order to remove their endometriosis, were obtained from the archives of the Department of Pathology of the University Hospital Maastricht. Sections were prepared and stained with H\&E to confirm the presence of endometriotic lesions.

\section{Chorioallantoic membrane model}

Fertilised eggs of Leghorn chickens were incubated and prepared as described previously (Nap et al., 2003). Fragments of biopsied menstrual endometrial tssue were transplanted onto the CAM. After 72 hours of incubation the area of the CAM containing the endometrial fragment was excised, fixed in $3.7 \%$ buffered formaldehyde and embedded in paraffin. The entire specimen was sectioned ( $4 \mu \mathrm{m}$, 150-200 sections). Every fifth section was stained with H\&E for histological evaluation to identify the lesion.

\section{Immunohistochemistry}

Immunohistochemistry was performed on paraffin sections from biopsied menstrual endometrium, from endometriosis-like lesions in CAMs and from archival peritoneal and deep invasive endometriotic tissue.

Expression of MMPs was evaluated by immunohistochemistry using the commercially available antibodies against human MMPs which were suitable to. stain paraffin-embedded tissue (Oncogene, La Jolla, CA, USA) (Appendix 1). These included MMPs $-1,-2,-3,-7,-8,-9,-10,-11,-13,-14,-15,-16,-23$, and TIMPS $-1,-2$ and -3 . All antibodies were monoclonal mouse antibodies, except anti-MMP-23, which was a polyclonal rabbit antibody. The antibody dilutions were optimized for application on routinely-fixed, paraffin-embedded tissue sections using breast cancer, colon cancer and placental tissue as positive controls. For each MMP, all tissues were included in 1 staining procedure in order to keep variability to a minimum. In short, paraffin sections were deparaffinised in xylene for $2 \times 3$ minutes and rehydrated in alcohol series. Endogenous peroxidase activity was blocked by incubation with $0.25 \%$ hydrogen peroxide in methanol for 20 minutes. Sections were rinsed 3 times in phosphate-buffered saline (PBS). For incubation with primary antibodies against MMPs $-1,-3,-7$, and -23 antigen retrieval in Tris EDTA buffer (20 
minutes at $95^{\circ} \mathrm{C}$ ) was required. After rinsing again in PBS, sections were incubated overnight at $4^{\circ} \mathrm{C}$ (except for the antibodies against MMPs-10 and -16 which were incubated for 2 hours at room temperature) with the appropriately diluted primary antibodies. After 3 rinses in PBS, sections were exposed to Envision Chemmate (DAKO, Glostrup, Denmark) for 30 minutes. After rinsing again in PBS, antibody binding was visualised with 3'-3-diaminobenzidin (DAB). Sections were washed and counterstained with haematoxylin, washed again, dehydrated and mounted for light microscopic evaluation. Sections in which the primary antibody was left out of the immunostaining procedure served as negative controls.

\section{Evaluation of immunostaining}

Immunostaining was assessed semi-quantitatively using a staining index. The staining was evaluated by 3 independent observers at a magnification of $400 \mathrm{x}$. Menstrual endornetrial specimens and the CAM lesions were evaluated entirely. In the bissue containing endometriosis, a representative lesion was selected and evaluated by all observers.

The semiquantitative staining index was caiculated according to the following equation: Proportion of stained cells $\times$ Staining intensity. The proportion of stained cells was expressed as $0,1,2$, or $3,10 \%,<10 \%, 10-50 \%$ or $>50 \%$ of cells, respectively), and intensity of staining as 1, 2, or 3 (weak, moderate, or strong, respectively). The minimum score was 0 and the maximum score was 9 . The threshold for positive staining was set at a staining index of 1 . The average of the scores of the 3 observers was calculated and taken as the staining index for that particular section. Intra- and interobserver variability was $9 \%$. Since all MMPs except MMP-7 are predominantly present in the stroma (Hulboy et al., 1997). staining indices were calculated in the stromal compartment for all MMPs except for MMP-7. MMP-7 is known to be expressed in the epithelium (Hulboy ef al., 1997), in which tissue the staining index for MMP-7 was calculated.

\section{Inhibition of MMP activity}

The effect of the inhibition of MMP activity on endometriosis-like lesion formation was studied by the administration of an MMP inhibitor that inhibits MMP $-1,-2,-3$; -7. and -13. (MMP inhibitor III, Catalog number 444264; Calbiochem, La Jolla, CA, USA), to the menstrual endometrial fragments after transplantation onto the CAM. MMP inhibitor III was dissolved in DMSO and diluted 1:1000 in normal saline ( $\mathrm{NaCl}$ ) to reach a final concentration of $1 \mu \mathrm{M}$ (stock). Prior to the first application of the MMP inhibitor, endometrial fragments were allowed to attach to the CAMs for 1 to 2 hours in order to avoid mechanical removal of the fragments by flushing during the administration of the MMP inhibitor. Vehicle (diluted DMSO) was applied to 10 
CAMs and did not change or damage the CAMs. The MMP inhibitor was administered 2 times on days 0,1 and $2(65 \mu$ of the $1 \mu \mathrm{M}$ stock). After incubation for 72 hours, CAMs were fixed, embedded in paraffin, sectioned and stained as described above. Endometriosis-like lesion formation was assessed in 28 CAMs treated with the MMP inhibitor and 86 control CAMs treated with vehicle.

\section{Statistical analysis}

Minimum, maximum, median and range of all staining intensities were calculated. Differences between medians of staining indices were calculated using the Kruskal Wallis test for more than 2 independent variables. The number of endometriosis-like lesions developed in CAMs after treatment with an MMP inhibitor and the control CAMs treated with vehicle were compared using $\chi^{2}$ tests. P-values $<0.05$ were considered statistically significant.

\section{Results}

MMP and TIMP expression in menstrual endometrium, experimental endometriosis in the chorioallantoic membrane and in human peritoneal and deep invasive endometriosis

The staining index (SI) for MMP and TIMP expression was used to compare the MMP expression between experimental endometriosis in the CAM and human endometriosis. Differences in SI were found between endometriosis-like lesions in the CAM and human endometriosis in 3 out of 16 MMPS and TIMPS. Expression of MMP-1 ( $p<0.05),-16 \quad(p<0.05)$ and TIMP-3. $(p<0.01)$ was significantly lower in human endometriosis compared to experimental endometriosis in the CAM as shown in Figure 1a. No differences; were found between the SIs of menstrual endometrium and the endometriosis-like lesions in the CAM.

A majority of the studied MMPs and TIMPs. was expressed in the examined tissues, except MMP-8 which was absent in peritoneal endometriosis, and MMP-14 which was absent in all tissues. Representative examples of MMP staining are presented in Figure 2.

Effect of inhibition of MMP activity on endometriosis-like lesion formation in the chorioallantoic membrane

MMP inhibitor III was selected to inhibit the activity of MMPs $-1,-2,-3,-7$, and -13 , in order to evaluate its effect on the formation of endometriosis-like lesions in the CAM. This choice was based on the observation that MMPs $-1,-2,-3,-7,-11,-13$, -15 , and -23 were the most abundantly expressed MMPs in menstruall endometrium 
(Figure 1b). For MMPs $-11,-15$ and -23 no inhibitors were available. After 72 hours, endometriosis-like lesions were present in $32 \%$ of CAMs to which the MMP inhibitor was administered, whereas endometriosis-like lesions were observed in $76 \%$ of control CAMs $(p<0.05)$.
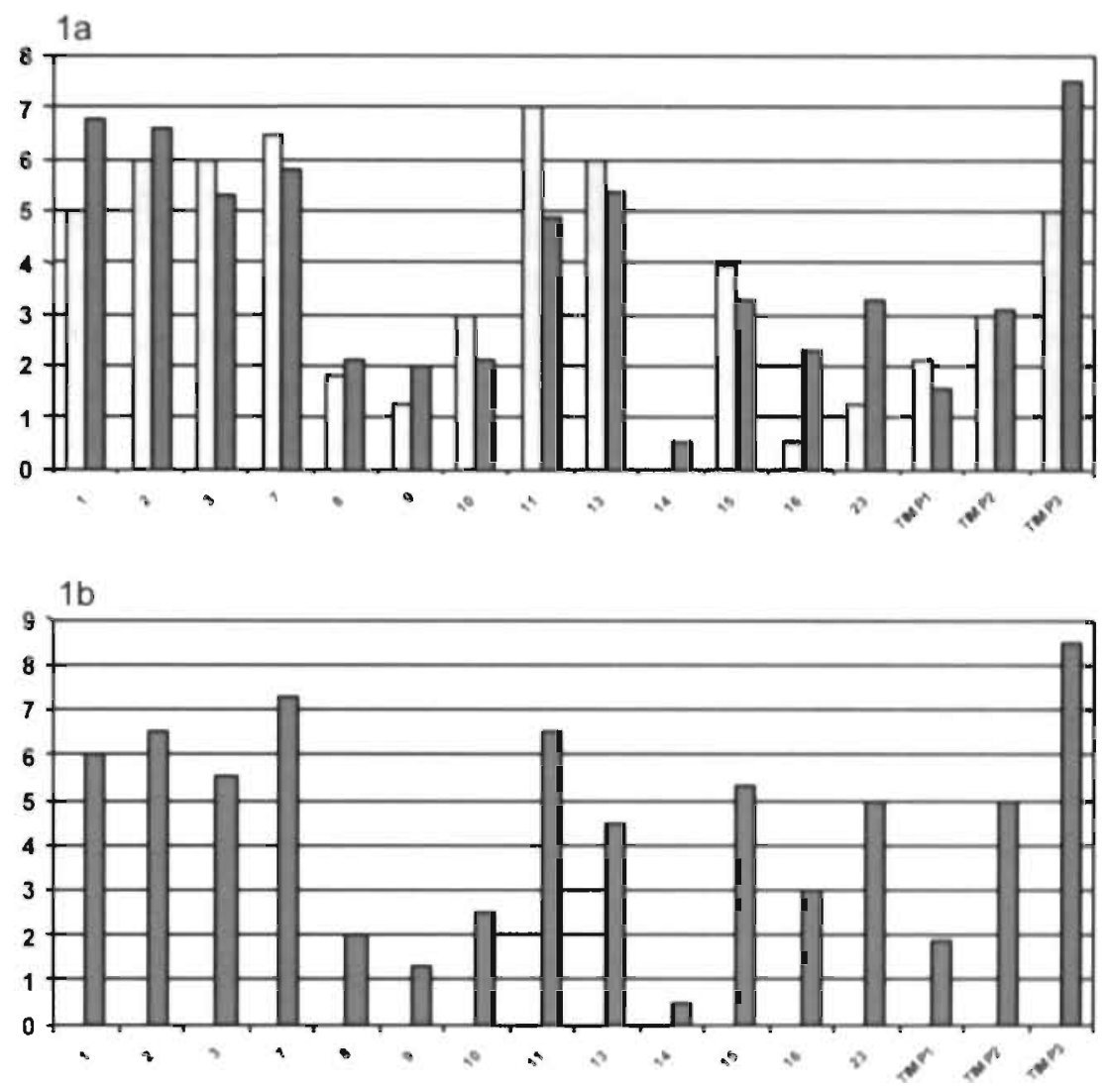

MMP type

Figure 1 Staining indices of human endometnosis (light grey bars) and endometnosis-like lesions in the CAM (dark grey bars) (A), and of menstrual endometrum (B) Staining indices were. determined exclusively in stromal cells for all MMPs and TIMPs except for MMP.7. in which staining indices were determined for epithelial cells 


\section{Discussion}

In this study we demonstrate for the first time the expression of the collagenases MMP-8 and -13, the stromelysin MMP-10, the membrane type-MMPs MMP-15 and -16 , and MMP-23 in human endometrium and in endometriosis. Inhibition of MMP activity impairs the development of early endometriotic lesions in the CAM model.

In order to investigate whether the CAM was suitable to study expression and function of MMPs in endometriosis, we initially compared the MMP expression profile of peritoneal and deep invasive endometriosis with that of endometriosis-like lesions in CAMs. The expression profiles turned out to be very similar. In menstrual endometrial tissue, MMPs $-1,-2,-3,-7,-11,-13,-15$ and -23 showed the relatively highest expression levels, indicated by the staining index.

Inhibition of the majority of these MMPs led to significant inhibition of endometriosislike lesion formation in CAMs. This indicates that MMPs are involved in endometriosis-like lesion development and that the CAM model is a useful tool to evaluate the involvement of MMPs in the initial steps of lesion formation of endometrial tissue. Lesion formation in the CAM was not completely prevented by the inhibitors used. This suggests that other MMPs or other mechanisms contribute to successful implantation of endometrium. Alternatively, it is possible that the inhibitor did not completely abolish all MMP activity.

Until recently MMPs were thought to function primarily as regulators of ECM composition and structure and to facilitate cell migration and invasion by removing barriers such as collagen. It is now becoming evident that MMPs cleave a variety of substrates that are not ECM components (Stamenkovic, 2003). Therefore, MMPs may be implicated in the regulation of (latent) growth factors, cytokines, angiogenesis, invasion, tissue organization and cell survival (Stamenkovic, 2003). The high expression of various MMPs in the endometriotic lesions may indicate the presence of an alternative self-sustaining mechanism of the endometriotic tissue, next to the local production of estrogens (Gurates and Bulun, 2003). 


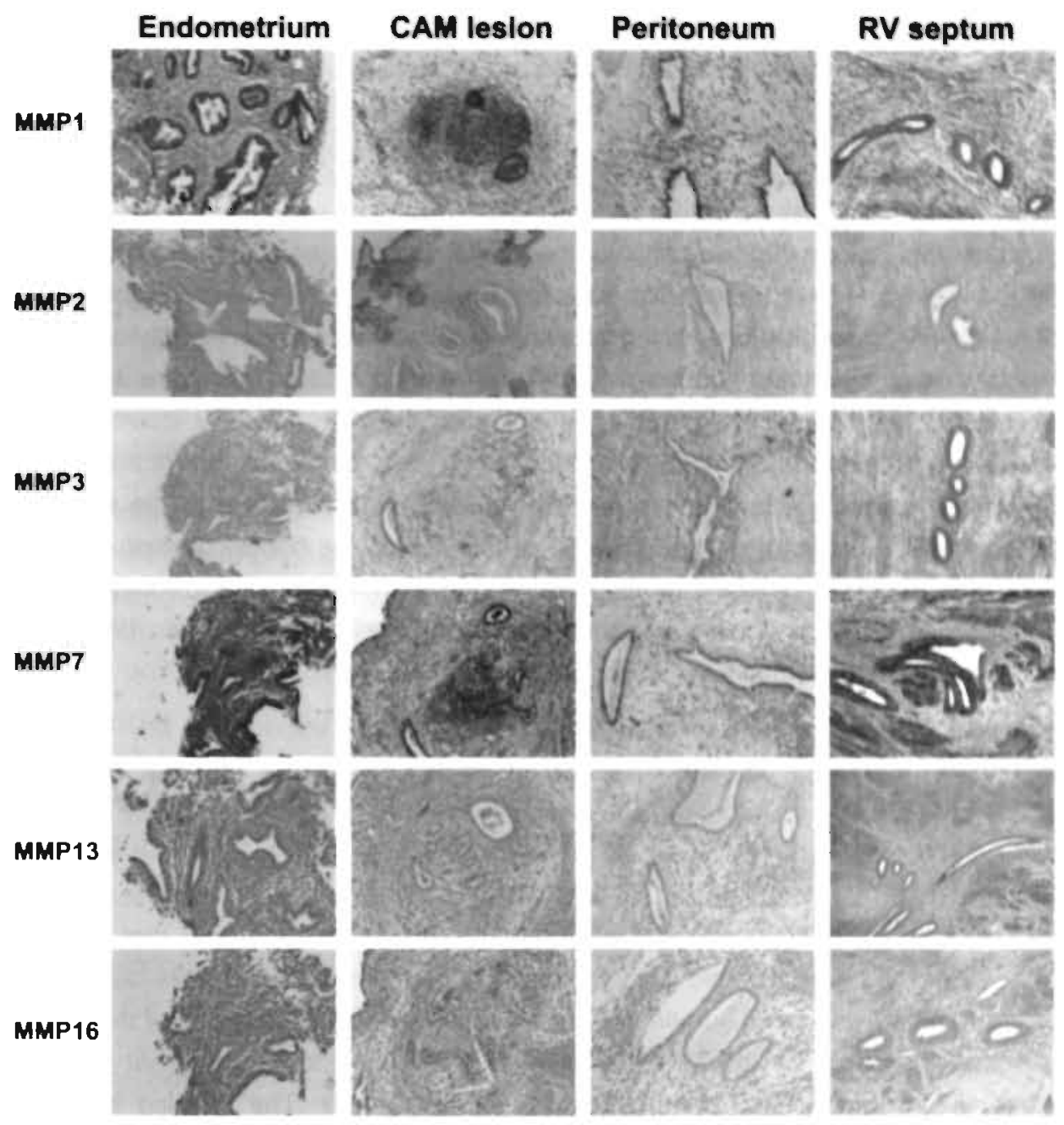

Figure 2. Representative examples of immunohistochemical staining of MMPs in menstrual endometrium. CAM lesions, peritoneal endometriosis and deep invasive endometriosis.

Transplantation of menstrual endometrium onto the CAM did not lead to upregulation of MMP expression in the endometriosis-like lesions that developed in CAMs. Apparently, the MMP expression in the endometrial tissue itself is an important determinant in the process of lesion formation, and not the local environment. This is in agreement with the study of Osteen and co-workers who stated that misregulation of the paracrine mediators of MMPs in the eutopic endometrium may be a central discriminating factor for the propensity of endometrium to implant ectopically, as a consequence of -endogenous or exogenous- steroid exposure, environmental toxin exposure, immunological 
disturbances or genetic predisposition (Osteen et al., 2002). This is also supported by the observation that members of all MMP subclasses as well as all TIMPs were present and that there were no dramatic differences in the expression of MMPs in eutopic and ectopic endometrium, and in experimentally induced endometriosis-like lesions in CAMs.

To date, the immunohistochemica! study of a large series of MMPs was hampered by the limited availability of antibodies applicable for staining paraffin-embedded tissue. In this study we have used all antibodies that were commercially available. Special care was taken to quantify the expression and to minimize bias and variability. Since the active forms of MMPS and TIMPS are usually located in the stromal compartments of tissues, we focussed on the presence of MMPS and TIMPS in the stroma. However, substantial MMP staining was observed in the epithelial cells as well. The expression of MMPs in epithelial cells is not uncommon and has been described earlier in endometrial epithelial cells (Henriet et al., 2002), human keratinocytes (Pilcher et al., 1997) and marnmary epithelium (Witty et al., 1995). The significance of these epitheliai MMPs is not yet known.

The presence of the collagenases MMP-8 and -13 , the stromelysin MMP-10, the membrane type-MMP-15 and -16, and of MMP-23 was not reported before in endometrium and in endometriosis. but has been described in a variety of other tissues and processes (Balbin et al. 1999; Pendas et al., 1999; Pilcher et al., 1999; Rechtman et al., 1999; Sorsa et al., 1999; Velasco et al., 1999; HernandezBarrantes et al., 2002; Leeman et al., 2002). The present study shows that MMP-13 and -23 are highly expressed in menstrual endometrium, endometriosis-like lesions in the CAM as well as in human endometriosis. As MMP-13 was one of the MMPs effectively inhibited by the MMP inhibitor, it is tempting to suggest that MMP-13 plays a role in the early pathogenesis of endometriosis. The staining index for MMP-9 and MMP-14 was low, in menstrual endametrium as well as in human and experimental endometriosis. Ueda and co-workers did not find high MMP-9 and -14 expression in endometrium from women without endometriosis. However, in contrast to our findings, they detected high expression levels in ectopic endometrium from endometriosis patients (Ueda et al., 2002). The expression of MMPs $-1,-2,-3,-7,-11$ and TIMPs $-1,-2$, and -3 is in accordance with previous. reports (Osteen et al., 1996. 1999. 2002; Sillem et al., 1998; Sharpe-Timms and Cox, 2002; Table 2). Based on the present study and literature reports, we conclude that a combined action of MMPs of all subclasses may be responsible for the development of endometriosis.

In summary, we have assessed the expression of a broad range of MMPS and TIMPs in human endometrium and endometriosis, and in experimentally induced 
endometriosis-like lesions. The expression patterns of MMPs in these tissues appear to be similar. Also, it has been shown that inhibition of most of the abundantly expressed MMPs in menstrual endometrial tissue effectively reduces endometriosis-like lesion formation in the CAMs. Therefore, the CAM model was found suitable to study MMP expression and function in lesion development in endometriosis. Our results indicate functional involvement of MMPs $-1,-2,-3,-7$ and -13 in this process, however, the involvement of other MMPs or mechanisms cannot be excluded.

\section{Acknowledgements}

The authors acknowledge Mrs. Jacqueline Schouten and Ms. Quirine Theunissen for excellent laboratory assistance and Mrs. L.aurence Colautti-Duijsens for her help with providing the chorioallantoic membrane model used for this study. 


\section{References}

Armstrong PB, Quigley JP and Sidebottom E (1982) Transepithelial invasion and intramesenchymal infiltration of the chick embryo chorioallantois by tumour cell lines. Cancer Res 42, 1826-1837.

Balbin M, Pendas AM, Uria JA, Jimenez MG, Freịe JP and Lopez-Otin C (1999) Expression and regulation of collagenase-3 (MMP-13) in human malignant tumours. APMIS, 107, 45-53.

Bruner KL, Eisenberg E, Yeaman GR, Anderson TA, McBean J and Osteen KG (2002) Steroid and cytokine regulation of matrix metalloproteinase expression in endometriosis and the establishment of experimental endometriosis in nude mice. J Clin Endocrinol Metab 87, 4782-4791

Bruner-Tran KL. Eisenberg E. Yeaman GR, Andersen TA, McBean J and Osteen KG (2002) Steroid and cytokine regulation of matrix metalloproteinase expression in endometriosis and the establishment of experimental endometriosis in nude mice. $J$ Clin Endocrinol Metab 87, 4782-4791.

Bruner KL, Matrisian LM, Rodgers WH, Gorstein F and Osteen KG (1997) Suppression of matrix metalloproteinases inhıbits establishment of ectopic lessions by human endometrium in nude mice. $J$ Clin Invest 99, 2851-2857

Chung HW, Lee JY, Moon H-S. Hur SE, Park MH, Wen Y and Polan ML. (2002) Matrix metalloproteinase2. membranous fype 1 matrix metalloproteinase, and tissue inhibitor of metalloproteinase-2 expresșion in ectopic and eutopic endometrium. Fertil Steril 78, 787-795.

Chung HW. Wen Y. Chun SH, Nezhat C, Woa BH and Lake Polan M (2001) Matrix metalloproteinase-9 and fissue inhibitor of metalloproteinase-3 mRNA expression in ectopic and eutopic endometrium in women with endometriosis: a rationale for endometriotic invasiveness. Fertil Steril 75, 152-159.

Giannopoulou E. Katsoris. P. Hatziapostolou M. Kardamakis D. Kotsaki E, Polytarchou C. Parthymou A. Papaioannou S and Papadimitriou E (2001) X-rays modulate extracellufar matrix in vivo Int J Cancer 94. $690-698$

Gilabent-Estelles J, Estelles A. Gilabert J, Castello R. Espana F. Falco C. Romeu A, Chirivella M. Zorio E and Aznar $J$ (2003) Expression of several components of the plasminogen activator and matrix metalloproteinase systems in endometriosis. Hum Reprod 18, 1516-1522

Gottschaik C: Malberg K, Arndt M. Schmitt J, Roessner A. Schultze D. Kleinstein J and Ansorge S (2000) Matrix metalloproteinases and TACE play a role in the pathogenesis of endometriosis. Adv Exp Med Biol 477, 483-485

Gurates B and Bulun SE (2003) Endometriosis: the ultimate hormonal disease. Semin Reprod Med 21. 125-134.

Henriet P. Cornet: PB. Lemoine P. Galant C. Singer CF, Cortoy. PJ. Eeckhout Y' and Marbaix E (2002) Circulating ovarian steroids and endometrial matrix metalloproteinases (MMPs). Anri $\mathrm{N} Y$ Acad Sci $955,119-138$

Hernandez-Barrantes S. Bernardo M. Toth M and Fridman R (2002) Regulation of membrane type-matrix metalloproteinases Sem Cancer Biol 12, 131-138

Hulboy DL, Rudolph LA and Matrisian LM (1997), Matrix metalloproteinases as mediators of reproductive function Molec Hum Reprod 3, 27-45

Kokorine I. Nisolle M. Donnez J, Eeckhout Y. Courtou PJ and Marbaix E (1997) Expression of interstitial collagenase (matrix melalloproteinase-1) is related to the activity of human endometriotic lesions. Fertil Steril $68,246-251$

Leeman MF, Curran S and Murray GI (2002) The structure, regulation, and function of human matrix metalloproteinase-13. Crit Rev Biochem Mol Biol 27', 149-166

Liu XJ. He YL and Peng DX (2002) Expression of metalloproteinase-9 in ectopic endometnum in women with endometriosis Di Yi JunYi Da Xue Xue Bao 22,467-469 
Maas JWM, Groothuis PG. Dunselman GAJ, De Goeil AFPM, Struijker Boudier HA.J and Evers JLH (2001) Deveiopment of endometnosis-like lesions after transplantation of human endometrial fragments onto the chick embryo chorioallantoic membrane Hum Reprod 16, 627-631

McCawley C and Matrisian CM (2001) Matrix metalloproteinases. they 're not just for matrix anymorel Curr Opin Cell Biol 13, 534-540

Mizumoto H. Saito T. Ashihara K, Nishimura M. Takehara M, Tanaka R, Ito E and Kudo R (2002) Expression of matrix metalloproteinases in ovarian endometriomas immunohistochemical study and enzyme immunoassay Life Sci 71, 259-273

Nap AW, Groothuis PG, Demir AY, Maas JWM. Dunseiman GAJ, De Goeil AFPM and Evers JLH (2003) Tissue integrity is essential for ectopic implantation of human endometrium in the chonoallantoic membrane assay Hum Reprod 18, 30-34

Nezhat FR and Kalir T (2002) Comparative immunohistochemical studies of endometriosis lesions and endometriotic cysts Fertil Steril 78, 820-824

Osteen KG. Bruner KL and Sharpe-Timms KL (1996) Steroid and growth factor regulation of matrix metalloproteinase expression and endometriosis Semin Reprod Endocrin 14, 247-255

Osteen KG. Keller NR. Feltus FA and Melner MH (1999) Paracrine regulation of matrix metalloproteinase expression in the normal human endometrium Gynecol Obstet Invest 48 suppl 1,2-13

Osteen KG. Bruner-Tran KL, Keller NR and Eisenberg E (2002) Progesterone-mediated endometrial maturation limits matrix metalloproteinase (MMP) expression in an inflammatory-like environment a regulatory system altered in endometriosis Ann N Y Acad Sci 955, 37-47

Pilcher BK. Dumin JA, Sudbeck BD. Krane SM, Welgus HG and Parks WC (1997) The activity of collagenase- 1 is required for keratinocyte migration on a type I collagen matrix J Cell Biol 137, 1445. 1457

Pilcher BK. Wang M, Qin X-J. Parks WC, Senior RM and Welgus HG (1999) Role of matrix metalloproteinases and their inhibitors in cutaneous wound healing and allergic contact hypersensitivity Ann N Y Acad Sci 878, 12-24

Ria R. Loverro G. Vacca A, Ribatti D, Cormio G, Roccaro AM and Selvaggi L (2002) Angiogenesis extent and expression of matrix metalloproteinase-2 and -9 agree with progression of ovarian endometriomas. Eur $\downarrow$ Clin Invest 32, 199-206

Rechtman MP. Zhang J and Salamonsen LA (1999) Effect of inhibition of matrix metalloproteinases on endometrial dẹcidualization and implantạtion in matẹd ratș J Reprod Fertill 117. 169-177

Sampson JA (1927) Peritoneal endometriosis due to menstrual dissemination of endometrial tissue into the peritoneal cavity: Am J Obstet Gynecol 14, 422-469

Scher CD. Haudenschild C and Klagsbrun M (1976) The chick chorioallantoic membrane as a model system for the study of tissue invasion by viral transformed cells Cell 8, 373-382

Schroyens W. Schroyens E and Bielunas J (1989) Different invasion capacity of NBT II and MDCK in the chick embryo chorioallantois Anticancer Res 9, 1665-1668

Sillem M. Prifti S. Neher M and Runnebaum B (1998) Extracellular matrix remodelling in the endometrium and its possible relevance to the pathogenesis of endometnosis Hum Reprod Update 4. 730-735

Sillem M. Prifti S, Koch A. Neher M. Jauckus, J and Runnebaum B (2001) Regulation of matrix metalloproteinases and their inhibitors in uterine endometrial cells of patients with and without endometriosis Eur J Obstet Gynecol Reprod Biol 95, 167-174

Sharpe-Timms KL and Cox KE. (2002) Paracrine regulation of matrix metalloproteinase expression in endometrosis Ann N Y Acad Sci 955.147-156

Sorsa T. Mantyla P. Ronka H. Kallı P. Kallis GB. Lundqvist C. Kunane DF, Salo T. Golub LM Teronen O and Tikanoja S (1999) Scientific basis of a matrix metalloproteinase-8: specific chair-side test for monitoring penodontal and pen-implant health and disease. Ann N Y Acad Sci 878. 130-140 
Spuijbroek MDEH, Dunseiman GAJ, Menhẹere PPCA and Evers JLH (1992) Early endometriosis invades the extracellular matrix. Fertil Steril 58, 929-933.

Stamenkovic, I (2003) Extracellular matrix remodelling: the role of matrix metalloproteinases. J Pathol 200. $448-464$.

Szamatowicz J, Laudanski P and Tomaszewska I (2002) Matrix metalloproteinase- 9 and tissue inhibitor of matrix metalloproteinase-1 a possible role in the pathogenesis of endometriosis. Hum Reprod 17. 284288.

Ueda M, Yamashita $Y$, Takehara M, Terai Y, Kumagai K, Ueki K, Kanda K, Yamaguchi H, Akise D, Hung $Y$ and Ueki M (2002) Survivin gene expression in endometriosis. J Clin Endocrinol Metab 87, 3452-3459.

Ueda M, Yamashita Y. Takehara M, Terai Y, Kumagai K, Ueki K, Kanda K, Hung YC and Ueki M (2002) Gene expression of adhesion molecules and matrix metalloproteinases in endometriosis. Gynecol Endocrinol 16, 391-402.

Velasco G. Pendas AM, Fueyo A, Knauper V, Murphy G and Lopez-Otin C (1999) Cloning and characterization of human MMP-23, a new matrix metalloproteinase predominantly expressed in reproductive tissues and lacking conserved domains in other family members. J Biol Chem 274, 45704576

Whittaker M and Ayscough A (2001) Matrix metalloproteinases and their inhibitors - current status and future challenges. Celltransmismisions 17, 3-14.

Witty JP, Wright JH and Matrisian LM (1995) Matrix metalioproteinases are expressed during ductal and alveolar mammary morphogenesis, and misregulation of stromelysin-1 in transgenic mice induces unscheduled alveolar development Mol Biol Cell 6, 1287-1303.

Witz CA, Montoya-Rodriguez IA, Cho S, Centonze VE, Bonewald LF and Schenken RS (2001) Composition of the extracellular matrix of the peritoneum J Soc Gynecol Investig 8, 299-304

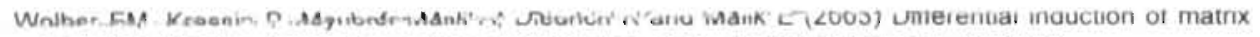
metalloproteinase-1 and -2 in ectopic endometrium. Reprod Biomed Online 6. 238-243.

Wenzi RJ and Heinzl H (1998) Localization of matrix. metalloproteinase-2 in uterine endometrium and ectopic implants Gynecol Obstet Invest 45, 253-257. 


\section{Chapter 4}

Anti-angiogenic agents prevent the development of endometriosis in the chicken chorioallantoic membrane

Annemiek W. Nap, Patrick G. Groothuis, Arjan W. Griffioen, Johannes L.H. Evers, and Gerard A.J. Dunselman 


\section{Abstract}

\section{Objective}

To assess whether inhibition of angiogenesis by anti-angiogenic therapy inhibits the development of endometriosis, assuming that angiogenesis is essential in its pathogenesis.

\section{Design}

Prospective study to determine the effects of the angiostatic compounds anti-hVEGF, TNP-470, endostatin and anginex on the vascularisation and on endometriosis-like lesion formation in the chicken choriọallantoic mẹmbrane (CAM) model.

\section{Setting}

Tertiary care medical center and university research laboratory.

Animals: day 10 chicken embryo's onto which human eñdometrium was transplanted. Interventions: Regular administration of angiostatic compounds to the CAMss for 72 hours.

\section{Main outcome measures}

Vascular density indices, endometriosis-like lesion formation and morphology of endometriosis-like lesions

\section{Results}

After transplantation of human endometrium onto the CAM, vessel densities increased and endometriessis-like lesions developed in the CAM. Administration of angiostatic agents caused significantly decreased vessel densities in the CAM after transplantation of endometrium. Endometriosis-like lesion formation was significantly impaired after treatment with anti-angiogenic agents, and significantly more necrosis was present in endometriosis-like lesions treated with inhibitors of angiogenesis

\section{Conclusion}

Inhibition of angiogenesis effectively interferes with the vascularisation and the formation of endometriosis-like lesions in the CAM, demonstrating that endometriosis is dependent on angiogenesis. Angiostatic agents may be promising as future therapeutic options for endometriosis. 


\section{Introduction}

Endometriosis is one of the most frequently encountered gynaecological problems (Gazvani and Templeton, 2002). It is defined as the presence of endometrium outside the uterine cavity, and supposedly is the result of the implantation of retrogradely shed endometrium during menstruation (Sampson, 1927). Similar to tumour implants that are not capable of growing beyond a volume of $3 \mathrm{~mm}^{3}$ unless they develop a new blood supply, ectopically implanted endometrium may trigger an angiogenic switch, activating angiogenesis within and around the tissue (Abulafia and Sherer, 1999). Circumstantial evidence in literature suggests that angiogenesis is a prerequisite for the development of endometriosis. Endometrium has angiogenic potential (Maas et al., 1999), increased angiogenesis is found around peritoneal implants (Nisolle et al., 1993), and increased endothelial cell proliferation has been observed in eutopic endometrium of endometriosis patients (Wingfield et al., 1995). Moreover, peritoneal fluid has an increased angiogenic activity in women with endometriosis compared to women without the disease (Oosterlynck et al., 1993). Angiogenesis is the formation of new blood vessels from pre-existing capillaries. It involves the proteolytic degradation of the extracellular matrix, proliferation and migration of endothelial cells, and the formation of a tubular network. Angiogenesis is essential in wound healing and in the female reproductive system in processes including the menstrual cycle and pregnancy.

Since angiogenesis may be essential in the pathogenesis of endometriosis, we hypothesize that inhibition of angiogenesis leads to inhibition of the development of endometriotic lesions. This hypothesis was tested in the chicken chorioallantoic membrane (CAM) model, which has been proven to be a suitable model to study the angiogenic properties of human endometrium (Maas ef al., 1999) as well as the development of endometriosis-like lesions (Maas et al., 2001a; Nap et al., 2003). We evaluated the vascularisation and endometriosis-like lesion formation after transplantation of human endometrium together with angiostatic agents on the CAM. Since vascular endothelial growth factor (VEGF) was demonstrated to be the predominant angiogenic factor in human endometrium (Charnock-Jones et al., 1993), we assessed the function of this growth factor by blocking it with a humanized VEGF antibody (anti-hVEGF). In addition to anti-hVEGF, we used 3 other angiogenesis inhibitors, the fungus derived antibiotic TNP-470 (Ingber et al., 1990), and the specific angiogenesis inhibitors endostatin (O'Reilly et al.. 1997) and anginex (Mayo et al., 1996; Griffioen et al., 2001; Van der Schaft et al., 2002). 


\section{Materials and Methods}

\section{Endometrial tissue}

Proliferative endometrium (days 5 to 11 of the menstrual cycle) was collected in 15 women by transvaginal biopsy using a sampling device (Gynotec, Malden, The Netherlands). Women were 25 to 42 years of age, they had regular menstrual cycles, and none had symptomatic endometriosis. Gynaecological pathology was found in none of the endometrial biopsies. The use of human endometrium was approved by the Institutional Ethical Review Committee of the University Hospital Maastricht. All women gave written informed consent. Immediately after collection, blood clots were removed, the endometrium was minced in small fragments of 1-2 $\mathrm{mm}^{3}$ and kept in serum-free DMEM/HAM's F12 culture medium. From each endometrial biopsy, tissue was embedded in paraffin and sectioned. Haematoxylin and Eosin (H\&E) staining was performed for histologic evaluation. The phase of the menstrual cycle was histologically confirmed by a pathologist.

\section{Reagents}

HuMV833, a humanized VEGF antibody (anti-hVEGF) was provided by Protein Design Labs (Fremont, USA). TNP-470 (AGM-1470) was purchased from Takeda Chemical Industries (Osaka, Japan). Endostatin was provided by Entremed Inc (Rockville, MD., USA). Anginex was synthesized (Griffioen et al., 2001) and provided by K.H. Mayo (Minneapolis, MN)

\section{Chorioallantoic membrane model}

Fertilised eggs of Lohman-selected White Leghorns were prepared as described previously (Nap et al., 2003). On day 7 of incubation, a $10 \mathrm{~mm}$ silicon ring was placed on the CAM to allow drug administration of $65 \mu$ quantities within the ring. On day 10 of incubation, an endometrium fragment of $1-2 \mathrm{~mm}^{3}$ was transplanted within the ring. Two hours after transplantation, anti-hVEGF $(3 \mathrm{mg} / \mathrm{kg} /$ day, $\mathrm{n}=22)$, TNP-470 (20 mg/ $/ \mathrm{kg}$, once every 2 days, $n=22)$, endostatin ( $2 \mathrm{mg} / \mathrm{kg} / \mathrm{day}, \mathrm{n}=10)$, anginex $(8 \mathrm{mg} / \mathrm{kg} / \mathrm{day} . \mathrm{n}=24)$ or vehicle $(65 \mu \mathrm{l}$ of saline $(\mathrm{NaCl}) /$ day. $n=10)$ were administered. For each reagent, the same treatment regimen was applied to 10 CAMs without endometrial fragment to study the effect of the reagent on CAM morphology and on its vascularisation. For the calculation of the right dose, the average weight of a chicken embryo after 10 days of incubation was taken.

Seventy two hours after transplantation of the endometrial fragment onto the CAM. color micrographs of the area within the ring were made as described previously (Maas et al., 2001b). Subsequently CAMs were fixed by injecting $1 \mathrm{ml}$ of $3.7 \%$ 
buffered formaldehyde on top of and $1 \mathrm{ml}$ under the CAM, and the area of the CAM containing the endometrial fragment was excised and embedded in paraffin. Paraffin sections $(4 \mu \mathrm{m})$ were cut from the entire specimen (150-200 sections) and sections were H\&E stained for histological evaluation.

\section{Analysis of angiogenesis and endometriosis-like lesion development in the CAM}

The vascular density index (VDI) was calculated by superimposing a circular grid containing 5 concentric circles on the image of the CAM and counting the number of intersections of the rings and the blood vessels (Maas et al., 2001b). Angiogenesis present in CAMs without endometrial fragment was defined as developmental angiogenesis. Angiogenesis occurring after transplantation of endometrium onto the CAM was defined as endometrium-induced angiogenesis.

Endometriosis-like lesions, studied microscopically on H\&E stained sections, were defined as the presence of human endometrial glands and endometrial stroma in the CAM mesenchyme (Maas et al., 2001a; Nap et al., 2003). Percentage of necrosis in endometriosis-like lesions was quantified using a microscope coupled to a computerized morphometry system (Quantimet 570, Leica, the Netherlands). Sections were evaluated twice under identical circumstances, and the average of the evaluations was taken.

\section{Statistical analysis}

Descriptive statistics (median, range and percentiles) were calculated for each experimental group, and compared using the non-parametric Mann-Whitney- $U$ test. Dichotomous variables were compared using $\chi^{2}$ tests. Correlations were calculated using Spearman correlation tests. P-values $<0.05$ were considered statistically significant. Vascular density indices were counted blindly, twice under identical circumstances, by 2 observers. The average of the counts was taken. Intra-observer and inter-observer variabilities were between 5 and $10 \%$.

\section{Results}

\section{Human endometrium is angiogenic}

Transplantation of human endometrium onto the CAM led to a strong angiogenic response in the chicken tissue, both at the level of vessel number as well as at the level of vessel architecture (Figure $1 \mathrm{a}$ and $1 \mathrm{~b}$ ), and to the formation of endometriosis-like lesions (Figure 2a), as we have demonstrated before (Maas et al., 1999; Nap et al., 2003). 

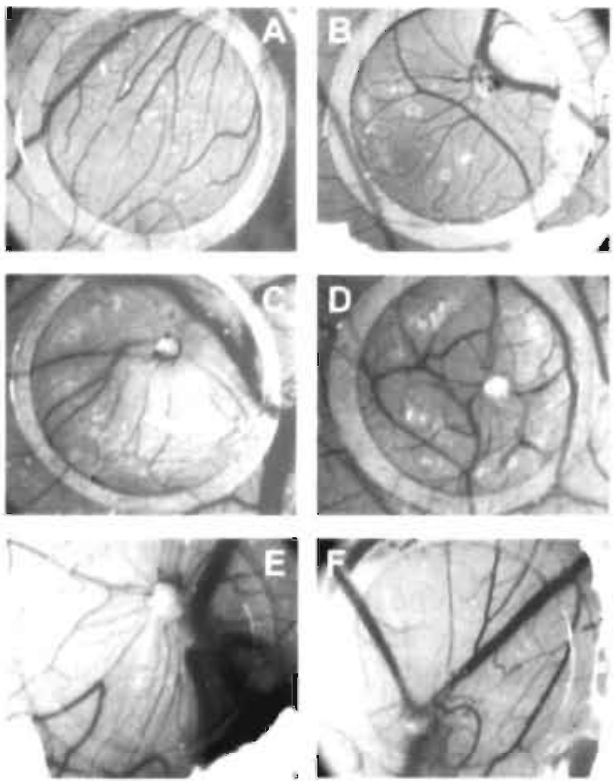
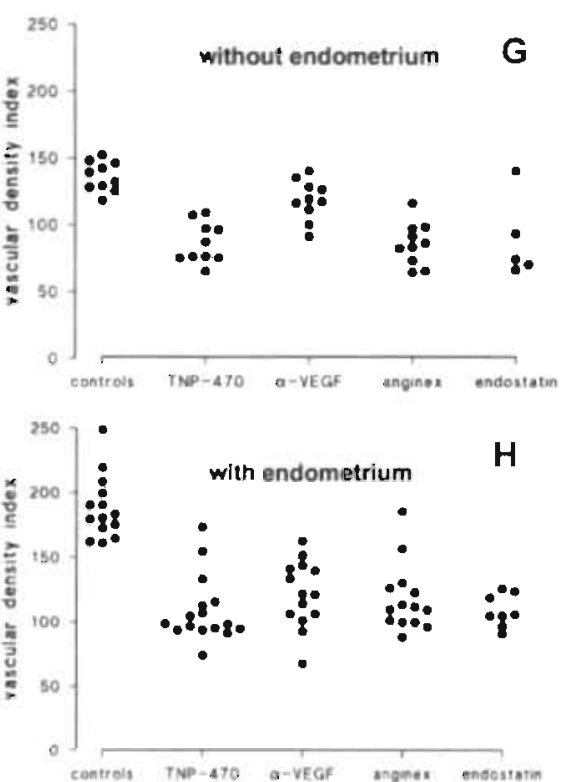

Figure 1 Vessel density and vessel architecture in CAMs after administration of angiostalic agents In ova photograph of a CAM on day 13 of development TA: Control CAM without transplanted human endometrial fragment, 18 Endometrium-induced angiogenesis (with transplanted human endometrial fragment) Note the significant increase in vascular density index in the CAM transplanted with an endometrial fragment The inhibitory effects on the vascularisation by anti-hVEGF (1C). TNP-470 (1D), endostatin (1E), and anginex (1F). The number of vessels is significantly decreased, and vessel architecture is disturbed after administration of angiostatic agents Panei $1 \mathrm{G}$ shows the inhibitory effect of the angrostatic agents on the vascular density index (VDI) in CAMs without transplanted endometrial fragment (developmental angiogenesis). Developmental angiogenesis is decreased after administration of TNP-470, endostatin and anginex, but not after administration of anti-hVEGF in panel H. VDi of endometrum-Induced angiogenesis is shown. All ängiostatic agents çause a significant decrease of the endometrium induced angiogenesis

Endometrium-induced angiogenesis in the CAM is suppressed by angiostatic agents. In order to study the significance of the angiogenic potential of endometrium in the formation of endometriosis-like lesions, several angiogenesis inhibitors, were selected for intervention treatments in the CAM model. Since VEGF-A has been demonstrated to be the predominant angiogenic factor (Charnock-Jones et al.: 1993), we studied the function of this growth factor by blocking it with a humanized VEGF-A antibody (anti-hVEGF). No effect of anti-hVEGF was observed in the vascularisation of CAMs without an endometrial fragment (Figure $1 \mathrm{~g}$ ). The efficient angiogenic response to the presence of transplanted human endometrium (Figure 1b) was significantly inhibited by treatment with this antibody. This was measured at the level of the vascular density index (VDI) (Figure $1 \mathrm{c}$ and $1 \mathrm{~h}$ ). In addition to antihVEGF, CAMs were treated with 3 other angiogenesis inhibitors, i.e. the fungus 
derived antibiotic TNP-470 (Figure 1d), and the specific angiogenesis inhibitors endostatin (Figure 1e) and anginex (Figure 1f). All 3 compounds significantly inhibited the developmental angiogenesis in the CAM by $45 \% \quad(p<0.05), 51 \%$ $(p<0.03)$, and $48 \%(p<0.01)$, respectively (Figure $1 \mathrm{~g})$.

The endometrium induced angiogenesis was inhibited as well by these angiogenesis inhibitors, by $43 \% \quad(p<0.05), 43 \% \quad(p<0.03)$, and $38 \% \quad(p<0.01)$, respectively (Figure $1 \mathrm{~h}$ ).

\section{Endometriosis-like lesion formation is prevented by angiostatic agents in the CAM model}

Transplantation of a human endometrial fragment onto the CAM resulted in the formation of endometriosis-like lesions in a majority of CAMs (Figure 2). In vehicle treated control CAMs, this was observed in 20 out of 24 CAMs (83\%).

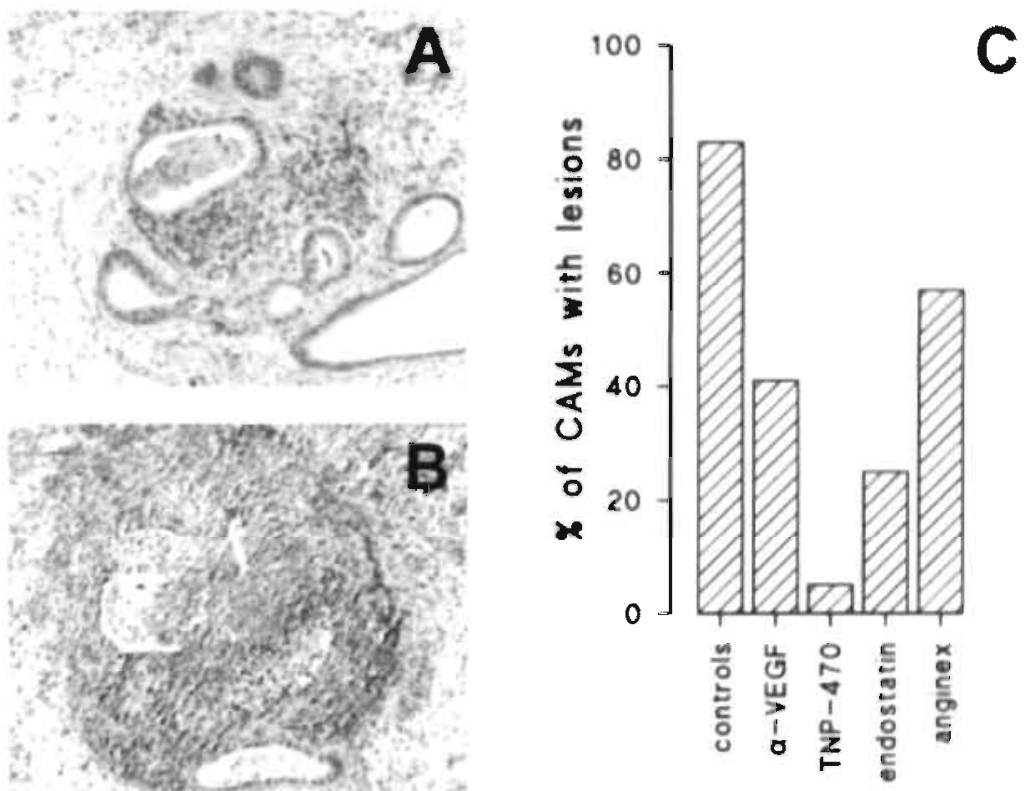

Figure 2 Formation and morphology of endometriosis-like lesions in CAMs after administration of angiostatic agents

Panel A șhows the morphology of an endometnosis-like lesion in a control CAM Normally developed human endometrial stroma and glands are present, and no necrosis is observed (H\&E staining) In pạnel $2 B$ an endometriosis-like lesion after treatment' with endostatin is shown Normal morphology is disturbed Note the massive amount of necrosis (H\&E staining) 2C. After administration of angiostatic agents the formation of endometnosis-like lesions in CAMs is significantly inhibited

Administration of the angiostatic agents significantly reduced endometriosis-like lesion formation. Anti-hVEGF reduced lesion formation to $41 \%(9 / 22, p<0.005)$. In 
CAMs treated with TNP -470 only 1 endometriosis-like lesion was observed in 22 CAMs $(5 \%, p<0.0001)$. In a majority of CAMs treated with TNP-470, a disturbed morphology of the surface of the CAMs was observed. In CAMs treated with endostatin, endometriosis-like lesion formation was reduced to $25 \%$, $(2 / 8, p<0.001)$, and anginex treatment resulted in 13 out of 23 CAMs containing endometriosis-like lesions $(57 \%, p<0.05)$. A significantly higher number of vessels was observed in CAMs in which an endometriosis-like lesion came to development, as compared to CAMs without a lesion $(p<0.05)$, indicating the dependence of endometriosis-like lesion formation on development of new vessels.

All endometriosis-like lesions were histologically evaluated. Unlike endometriosislike lesions in control CAMs, a significant part of endometriosis-like lesions in the CAMs treated with angiostatic agents showed necrotic morphology (Figure $2 \mathrm{~b}$ ). Treatment with anti-hVEGF, endostatin and anginex resulted in a necrotic area of $9.4 \%(p<0.05), 32 \%(p<0.01)$, and 16\% ( $p<0.01)$ of the endometriosis-like lesion respectively, compared to $4 \%$ of the endometriosis-like lesion in control CAMs. The single lesion that was found in the 22. TNP -470 treated CAMs consisted of a single gland surrounded by a small covering layer of stroma, and $7 \%$ of the lesion had a necrotic morphology. A strong negative correlation was found between the VDI and the percentage of necrosis $(R=-0.63, p<0.0001)$.

\section{Discussion}

In this study we demonstrate that anti-angiogenic agents are able to inhibit the vascularisation of endometrial implants and thus diminish the formation of endometriosis-like lesions in the chorioallantoic membrane (CAM).

Developmental angiogenesis in the growing CAM was significantly inhibited by TNP470, endostatin and anginex, whereas treatment with anti-hVEGF did not affect this embryological process. Because the anti-human VEGF antibody would only block human VEGF, no effects were expected in the CAM without human endometria; transplants. Indeed, no significant response in the CAM was observed. The efficient angiogenic response by transplanted human endometrium on the CAMs measured at the level of the VDI was strongly and significantly inhibited by treatment with antihVEGF and the other angiostatic agents, indicating that all applied agents effectively inhibited the endometrium-induced angiogenesis.

The use of angiogenesis inhibitors in the CAM led to a significantly impaired development of endometriosis-like lesions, which was considered to be caused by the inhibition of angiogenesis. An association between the VDI in CAMs and the 
number of endometriosis-like lesions was observed. CAMs without an endometriosis-like lesion showed a significantly lower VDI than CAMs with a lesion. In addition, endometriosis-like lesions in CAMs treated with anti-hVEGF, endostatin or anginex contained significantly more necrosis as compared to control CAMs. The negative correlation between the VDI in CAMs and the percentage of necrosis in endometriosis-like lesions supports the idea that a disturbed vascularisation as a consequence of the presence of the inhibitors is responsible for the necrosis in the CAMs.

In this ștudy, angiostatic agents which have not been used before in the CAM model for endometriosis, have been tested on their inhibitory effects on angiogenesis and endometriosis-like lesion formation. Vascular endothelial growth factor (VEGF) is a major player in angiogenesis based on its ability to induce vasodilatation and its. endothelial cell permeability increasing effect. (Ziche et al., 1997). In endometriosis, VEGF plays a pivotal role as well. VEGF-A content was significantly higher in the eutopic glandular epithelium of endometriosis patients during the late secretory phase as compared to that of women without endometriosis (Donnez et al., 1998). Moreover, in menstrual effluent as well as in peritoneal endometriotic lesions. VEGF-A was expressed (McLaren, 2000; Smith, 2001). In an animal study, it was demonstrated that inhibition of VEGF prevents endometriosis-like lesion formation in nude mice (Hull et al., 2003). Recently, a humanized anti-VEGF antibody, Avastin. was administered for the first time in man in the treatment of colorectal carcinoma, with satisfactory results (McCarthy, 2003). This approach of neutralizing VEGF provided the first proof-of-concept that anti-angiogenesis is applicable in man. The major role of VEGF in endometriosis may also predict success of Avastin in the treatment of endometriosis. In our study, anti-hVEGF selectively inhibited endometrium-induced angiogenesis and effectively inhibited endometriosis-like lesion formation.

TNP-470 (AGM-1470) is a representative of the first generation anti-angiogenic agents. It is a furnagiliin analogue and a naturally secreted antibiotic of Aspergillus Fumigatus Fresenius which inhibits endothelial cell proliferation in vitro, tumour induced angiogenesis in vivo, and tumour growth in mice (Ingber et al., 1990; Yamaoka et al., 1993; Bergers et al., 1999). TNP-470 is one of the most potent inhibitors of angiogenesis and has, been tested in clinical trials for treating a variety of malignancies. However, serious dose-related side effects limit the potential of TNP-470 (Bergers et al., 1999). In endometriosis, which is an invalidating but not a life-threatening disease, side effects are less acceptable than in potentially lethal malignancies. For this reason. TNP-470 may be less suitable as a potential therapy for endometriosis although it was the most potent inhibitor of endometriosis-like lesion formation in our study. However, the large decrease in endometriosis-like 
lesion formation in our study may well be caused by toxic effects of the TNP-470 on the CAM, as we observed a disturbed CAM morphology in a majority of CAMs.

Endostatin is a $20 \mathrm{kD} \mathrm{C}$-terminal fragment of collagen XVIII. It is a potent inhibitor of in vivo tumour angiogenesis. In mice, systemic administration of recombinant endostatin strongly inhibited angiogenesis, maintained metastases at a microscopic size, and regressed primary tumours. No re-growth of tumour, no evidence of drug resistance and no toxicity were observed (O'Reilly et al., 1997). The anti-angiogenic effect of endostatin seems to be mediated by inhibition of endothelial cell migration, as well as by induction of endothelial cell apoptosis (Dhanabal et al, 1999). We showed in the CAM model for endometriosis that endostatin inhibits angiogenesis as well as endometriosis-like lesion formation.

In the search for novel anti-angiogenic agents, a $\beta$-sheet forming cytokine-like peptide, anginex, was developed (Griffioen et al., 2001). Anginex acts by specifically blocking adhesion and migration of angiogenically activated endothelial cells, leading to apoptosis and ultimately to inhibition of angiogenesis in vitro and in vivo. Preliminary data indicate that anginex does not influence physiologic angiogenic responses in mice. Anginex may be a specifically acting anti-angiogenic agent for pathological angiogenesis. In the present study, anginex was used for the first time in a model for endometriosis, in which it effectively inhibited angiogenesis as well as endometriosis-like lesion formation.

For effective treatrnent of endometriosis by inhibition of angiogenesis, evidence is needed that not only the development of endometriosis is prevented as was shown in our study and in the study of Hull and co-workers (Hull et al., 2003), but that established endometriosis will be eradicated as well. Currently, we are investigating the effects of the anti-angiogenic agents tested in this study on established endometriosis-like lesions in nude mice. Eradication of established endometriosis by these agents will be promising for future possibilities of anti-angiogenic agents for the treatment of endometriosis. Moreover, angiostatic agents should act selectively in order to make them suitable for the treatment of endometriosis. Physiological angiogenesis required in processes in the female reproductive system should not be affected. As VEGF-A is the most importantly expressed angiogenic factor in human endometrium (Charnock-Jones et al., 1993), an anti-VEGF-A antibody might be suitable to inhibit endometriosis-specific angiogenesis. Anti-angiogenesis therapy will only be suitable for the treatment of endometriosis if the vasculature of the ectopicaily implanted endometrium can be inhibited selectively.

In conclusion, we have demonstrated that angiogenesis is a prerequisite for the development of endometriosis. Our data demonstrate that inhibitors of angiogenesis effectively interfere with the formation of endometriosis-like lesion formation. More 
studies are required to investigate whether anti-angiogenic agents not only can prevent the development of endometriosis, but may eradicate established endometriosis as well. Anti-angiogenic therapy should selectively target the ectopically implanted endometrium and should not interfere with physiological angiogenesis.

\section{Acknowledgements}

The authors wish to acknowledge Mr. Jacques Cleutjens for designing the Quantimet computer program for the characterization of endometriosis-like lesions, and Mrs. Jacqueline Schouten, Ms. Michelle Versleijen and Ms. Quirine Theunissen for excellent technical assistance. 


\section{References}

Abulafia O and Sherer DM (1999) Angiogenesis of the Endometrium. Obstet Gynecol 94,148-153.

Bergers G, Javaherian K, Lo KM, Folkman J and Hanahan D (1999) Effects of angiogenesis inhibitors on multistage carcinogenesis in mice. Science 284, 808-812.

Charnock-Jones DS, Sharkey AM, Rajput-Williams J, Burch D. Schofield JP, Fountain SA, Boocock CA and Smith SK (1993) Identification and localization of alternately spliced mRNAs for vascular endothelial growth factor in human uterus and estrogen regulation in endometrial carcinoma cell lines. Biol Reprod 48, 1120-1128.

Dhanabal M, Ramchandran R, Waterman MJF, Lu H, Knebelmann B. Segal M and Sukhatme VP (1999) Endostatin induces endothelial cell apoptosis. J Biol Chem 274. 11721-11726.

Donnez J. Smoes P. Gillerot S, Casanas-Roux F and Nisolle M (1998) Vascular endothelial growth factor (VEGF) in endometriosis: Hum Reprod 13, 1686-1690.

Gazvani R and Templeton A (2002) New considerations for the pathogenesis of endometriosis. Int J Gynaecol Obstet 76, 117-126.

Griffioen AW, van der Schaft DW. Barendsz-Janson AF, Cox A. Struijker Boudier HA, Hillen HF and Mayo $\mathrm{KH}(2001)$ Anginex, a designed peptide that inhibits angiogenesis. Biochem J 354, 233-242.

Hull ML, Charnock-Jones DS, Chan CLK, Bruner-Tran KL, Osteen KG, Tom BDT, Fan T.PD and Smith SK (2003) Antiangiogenic agents are effective against endometriosis. J Clin Endocrinol Metab 88, 28892899.

Ingber D. Fujita T, Kishimotg S, Sudo K, Kanamaru T, Brem H and Folkman J (1990) Synthetic analogues of fumagillin that inhibit angiogenesis and suppress tumour growth. Nature $348,555-557$.

Maas JWM, Groothuis PG. Dunselman GAJ, De Goeij AFPM. Struijker Boudier HAJ and Evers JLH (2001a) Development of endometriosis-like lesions after transplantation of human endometrial fragments onto the chick chorioallantoic membrane. Hum Reprod 16, 627-631

Maas JWM. Groothuis PG, Dunselman GAJ, De Goeij AFPM. Struijker Boudier HAJ and Evers JLH (2001b) Endometrial angiogenesis throughout the human menstrual cycle Hum Reprod 16, 1557 . 1561

Maas JWM, Le Noble FAC, Dunselman GAJ, De Goeij AFPM, Struijker Boudier HAJ and Evers JLH (1999) The chick chorioallantoic membrane as a model to investigate the angiogenic properties of human endometrium. Gynecol Obstet Invest 4, 108-112

Mayo KH. llyina $\mathrm{E}$ and Park H (1996) A. recipe for designing water-soluble, betasheet-forming peptides Protein Sci 5, 1301-1315.

McCarthy M (2003) Angiogenesis drug promising for metastatic colorectal cancer. Lancet 361,1959.

McLaren I (2000) Vascular endothelial growth factor and endometriotic angiogenesis. Hum Reprod Update $6,45-55$

Nap AW, Groothuis PG. Demir AY, Maas JWM. Dunselman GAJ, De Goeị AFPM and Evers JLH (2003) Tissue integrity is essential for ectopic implantation of human endometrium in the chicken chorioallantoic membrane. Hum Reprod 18, 30-34.

Nisolle M. Casanas-Roux F. Anaf V. Mine JM and Donnez J (1993) Morphometric study of the stromal vascularization in peritoneal endometriosis Fertil Steril 59, 681-684.

Oosterlynck DJ. Meuleman C. Sobis H. Vandeputte M and Koninckx PR (1993) Angiogenic activity of peritoneal fluid from women with endometriosis. Fertil Steril 59. 778-782

O'Reilly MS, Boehm T. Shing Y. Fukai N Vasios G. Lane WS. Flynn E, Birkhead JR, Olsen BR and Folkman $J(1997)$ Endostatin. an endogenous inhibitor of angiogenesis and tumour growth Cell 88 . 277-285 
Sampson JA (1927) Peritoneal endometriosis due to the menstrual dissemination of endometrial tissue into the peritoneal cavity. Am J Obstet Gynecol 14, 422-469

Smith SK (2001) Regulation of angiogenesis in the endometrium. TRENDS Endocrin Metab 12, 147-151.

Van der Schaft DWJ, Dings RPM, de Lussanet QR, van Eijk LI, Nap AW, Beets-Tan RGH, Wagstaff J, Mayo KH and Griffioen AW (2002) The designed cytokine-like peptide anginex targets tumour endothelial cells inhibiting angiogenesis and thereby tumour growth. FASEB J 16, 1991-1993.

Wingfield M, Macpherson A, Healy DL and Rodgers PA (1995) Cell proliferation is increased in the endometrium of women with endometriosis. Fertil Steril 64, 340-346.

Yamaoka M, Yamamoto T, Masaki T, Ikeyama S, Sudo K and Fujita T (1993) Inhibition of tumour growth and metastasis of rodent tumours by the angiogenesis inhibitor O-(chloroacetyl-carbamoyl) fumagillol (TNP-470; AGM-1470). Cancer Res 53, 4262-4267.

Ziche M, Morbidellt L. Choudhuri R, Zhang HT, Donnini S, Granger HJ and Bicknell R (1997) Nitric oxide synthase lies downstream from vascular endothelial growth factor-induced but not basic fibroblast growth factor-induced angiogenesis. J Clin Invest 99, 2625-2634 


\section{Chapter 5}

\section{Anti-angiogenesis therapy for endometriosis}

Annemiek W. Nap, Arjan W. Griffioen, Gerard A.J.

Dunselman, Jessica C.A. Bouma-ter Steege,

Victor L.J.L. Thijssen, Johannes L.H. Evers, and Patrick G. Groothuis 


\section{Abstract}

Endometriosis is defined as the presence of endometrial glands and stroma outside the uterine cavity and is one of the most frequently encountered benign problems in gynaecology. Assuming that angiogenesis, the formation of new capillaries from pre-existing blood vessels, is of pivotal importance in the pathogenesis of endometriosis, inhibition of angiogenesis by angiostatic therapy may interfere with the development of endometriotic lesions. In the treatment of endometriosis patients, prevention of endometriotic lesion development only will not be sufficient as a therapy, but treatment options have to be developed aimed at interfering with establishecl lesions. We evaluated the effect of the angiostatic compounds anti-hVEGF, TNP-470, endostatin, and anginex on growth of established endometriotic lesions in the nude mouse model. The angiostatic compounds significantly decreased microvessel densities and inhibited established endometriotic lesions. We confirm that human endometrium is highly angiogenic and suggest that VEGF-A is the most important angiogenesis promotory factor in both proliferative endometrium and in the biology of endometriosis. Our data demonstrate that inhibitors of angiogenesis effectively interfere with the maintenance and growth of endometriosis, which shows that endometriosis is dependent on angiogenesis. This suggests that the use of angiostatic agents may be promising as a therapy for endometriosis. 


\section{Introduction}

Endometriosis, defined as endometrium outside the uterine cavity, is found primarily in the peritoneum, the ovary and the rectovaginal septum. Women suffering from endometriosis may present with chronic pelvic pain, dysmenorrhea, dyspareunia, and subfertility. The prevalence of endometriosis in women with pelvic pain and/or subfertility is estimated between $20 \%$ and $90 \%$, thereby being one of the most frequently encountered benign gynaecological problems (Gazvani and Templeton, 2002). Endometriosis supposedly is the result of the implantation of retrogradely shed endometrium during menstruation (Sampson, 1927). Endometrium has the capacity to adhere, attach and implant ectopically (Koks et al., 1999; Maas et al., 2001a). For the survival of endometrium in an ectopic location, the acquisition of an adequate blood supply is essential. Endometrium has angiogenic potential (Maas et al., 2001b) and endometriotic lesions are larger in areas with a rich blood supply (Nisolle et al., 1993). This suggests that angiogenesis is a prerequisite for the development of endometriosis.

Angiogenesis is a sequence of events that is fundamental to a broad array of physiological events in the body including embryogenesis, the menstrual cycle and wound healing. Angiogenesis is also involved in pathological situations such as tumour growth, atherosclerosis, chronic inflammation and endometriosis (Griffioen and Molema, 2000). The use of angiostatic agents promises to provide a new therapeutic option for some of these pathoiogic processes. The search for inhibitors of angiogenesis has mainly concentrated on controlling 2 of the processes involved in angiogenesis: endothelial cell (EC) growth and EC adhesion (Folkman, 1985; Molema and Griffioen, 1998; Thompson et al., 1999). Targeting drugs to ECs may hold promise for treatment of endometriosis because ECs are more accessible than other cells to pharmacologic agents delivered via the blood. In addition, ECs are genetically stable and thus are not easily mutated into drug resistant variants (Molema and Griffioen, 1998).

Assuming that angiogenesis is of pivotal importance in the pathogenesis of endometriosis, angiostatic compounds may interfere with the development of endometriotic lesions, as was illustrated recently (Hull et al., 2003). However, in clinical practice, women will present with established endometriosis. In order to treat women who suffer from this disease, prevention of the development of new lesions only will not be sufficient as a therapy, but treatment options have to be developed which are aimed at inhibition of maintenance and growth of established lesions. Therefore, the aim of this study was to evaluate whether the angiostatic compounds anti-human vascular endothelial growth factor-A (anti-hVEGF). TNP-470, endostatin 
and anginex, acting in a broad array of angiogenic mechanisms, were effective inhibitors of established endometriotic lesions. In order to test the effect of these anti-angiogenic agents for this purpose, we used the nude mouse model. Human endometrium can be transplanted into nude mice, and endometriotic lesions which are macroscopically and microscopically similar to human endometriotic lesions come to development (Zamah et al., 1984; Bruner et al., 1997; Nisolle et al., 2000; Grìmmer et al., 2001; Hull et al., 2003). In our study, endometriotic lesions were allowed to establish during 3 weeks. After this period, administration of angiostatic agents was initiated. We studied the number of endometriotic lesions after 2 weeks of treatment with angiostatic agents, and evaluated microvessel densities in the lesions.

We demonstrate that angiogenesis is a prerequisite for the maintenance and growth of endometriosis, and that angiostatic compounds effectively inhibit established endometriotic lesions. This indicates that the use of angiostatic compounds may be promising as a therapy for endometriosis.

\section{Materials and Methods}

\section{Endometrial tissue}

Proliferative endometrium (days 5 to 11 of the menstrual cycie) was collected in 8 . women having ovulatory cycles (25 to 32 days) and undergoing laparoscopy for benign conditions by transvaginal biopsy using a sampling device (Gynotec, Malden, The Netherlands). Women were 25 to 42 years of age, and indications for laparoscopy were abdominal pains, tubal testing, and sterilization. No gynaecological pathology was, found in any of the endometrial biopsies. The use of human endometrium was approved by the Institutional Ethical Review Committee of the University Hospital Maastricht. All women gave written informed consent. After collection, bload was removed and endornetrium was kept in serum-free DMEM/HAM's F12 culture medium. For each endometrial biopsy. Haematoxylin and Eosin (H\&E) staining was performed. Tissue integrity was evaluated and the day of the menstrual cycle (cycle day) was histologically confirmed by a pathologist.

\section{Real-time RT-PCR}

In order to investigate the angiogenic profile of proliferative human endometrium, real-time RT-PCR was performed. Total RNA was isolated from human proliferative endometrial tissue using the RNeasy RNA isolation kit (Qiagen) according to the supplier's protocol. One column DNAse treatment with the RNase-free DNAse set (Qiagen) was used to remove any genomic DNA. The purity and integrity of the 
RNA was checked by gel electrophoresis according to standard procedures. One $\mu g$ total RNA was reverse transcribed for 1.5 hours at $42^{\circ} \mathrm{C}$ with $600 \mathrm{U}$ of M-MLV reverse transcriptase (Promega) in $20 \mu \mathrm{L}$ of $1 \mathrm{x}$ first strand buffer (Promega), and 1 $\mathrm{mM}$ dNTPs in the presence of $40 \mathrm{U}$ RNase inhibitor RNasin (Promega) and $0.5 \mu \mathrm{g}$ random primers (Promega). Real-time RT-PCR was carried out in an ABI PRISM 7700® Sequence Detection System apparatus (Applied Biosystems) on $30 \mathrm{ng}$ CDNA in a $25 \mu \mathrm{L}$ volume containing 1x SYBR® Green PCR master mix (Applied Biosystems), and $500 \mathrm{nM}$ of the forward and the reverse primer using the following PCR profile: 10 minutes at $95^{\circ} \mathrm{C}$, followed by 50 cycles of 15 seconds at $95^{\circ} \mathrm{C}$ and 1 minute at $60^{\circ} \mathrm{C}$. Primers used for real-time RT-PCR were targeted against betaactin (B-Actin), cyclophillinA (cycloA), VEGF-A,-B,-C, and -D, angiopoietin 1, 2, and 3 (ANG-1, -2, -3), basic fibroblast growth factor (bFGF), placental growth factor (PIGF), VEGF-receptors 1, 2 and 3 (VEGF-R1, VEGF-R2, VEGF-R3), neuropillin 1 and 2 (NRP-1, NRP-2), and tyrosine kinase receptors 1 and 2 (Tie-1 and Tie-2). The parameter $\mathrm{Ct}$ (Cycle threshold) was defined as the cycle number at which the fluorescent signal passed a fixed value and the expression of each target gene was normalized to the expression of the control genes.

\section{Reagents}

HuMV833, a humanized VEGF-A antibody (anti-hVEGF, provided by Protein Design. Labs, Fremont, USA), TNP-470 (AGM-1470, provided by Takeda Chemical Industries, Osaka, Japan), endostatin (provided by Entremed Inc., Rockville „MD.), and anginex (Griffioen et al., 2001) were used. As TNP-470 is a strong gleneral angiogenesis inhibitor we used this agent as a positive control for angiostasis.

\section{Nude mouse model}

57 female mice (Swiss, nu/nu, Charles River, Maastricht, Netherlands) were individually housed in autoclaved cages and bedding, in laminar-flow filtered hoods. The animal room was maintained at $26^{\circ} \mathrm{C}$ with a $12-\mathrm{h}$ light/12- $\mathrm{h}$ dark cycle, and mice were fed ad libitum with autoclaved laboratory rodent chow and acidified water. All handling, was done in laminar-flow filtered hoods. A mixture of ketamin/xylazin (100 $\mathrm{mg} / \mathrm{kg}$ ketamin, and $10 \mathrm{mg} / \mathrm{kg}$ xylazin, Eurovet, Bladel, Netherlands). subcutaneously injected in a volume of $0.1 \mathrm{ml} / 10 \mathrm{gram}$ bodyweight was used to anaesthetize mice before invasive procedures, using sterile instruments. The Maastricht University Ethical Review Committee for Animal Experiments approved the use of mice for this study.

At. the age of 5 weeks, sterile 60-day release capsules containing $18 \mathrm{mg} 17 \beta$ oestradiol (Innovative Research of America, Sarasota, FL, USA) were placed subcutaneously in the neck of each animal. According to the manufacturer's 
information, capsules provide continuous release of oestradiol at serum concentrations of 150 to $250 \mathrm{pmol} / \mathrm{l}$, in the range of physiological levels in mice during the estrous (Bronson and Desjardins, 1974). This stable physiological level of estrogen promotes the growth of the transplanted human endometrium and eliminates inter-mouse differences related to various stages of the estrous.

Four days after the insertion of the estrogen pellet, an entrance was made to the peritoneal cavity in the midline in the lower abdomen with an 18-G needle, and with the help of a pipette 10 fragments of fresh human endometrium in $200 \mu$ of sterile phosphate buffered saline (PBS) were inoculated intraperitoneally in order to mimic the situation after retrograde menstruation in women. An other entrance was made subcutaneously through the skin in the flank and 10 fragments of fresh human endometrium were pipetted subcutaneously in order to enlarge the probability of recovery. Endometrial fragments were $1-2 \mathrm{~mm}^{3}$ in size. Endometriotic lesions were equally found in both locations; suggesting that both subcutaneous and intraperitoneal inoculation of human endometrial fragments result in formation of endometriotic lesions in nude mice.

To sludy normal lesion development and vascularisation in time, 2 control mice were sacrificed by cervical dislocation, 1, 2, 3 and 4 weeks after implantation of the endometrial fragments.

To study the effect of angiostatic agents on established endometriotic lesions and their vascularisation, the other mice were divided into 5 groups: a control group $(n=15)$ and 4 groups that received anti-angiogenic agents anti-hVEGF $(n=11)$, TNP$470(n=4)$, endostatin $(n=9)$, or anginex $(n=10)$. Three weeks after implantation of endometrial fragments, administration of angiostatic agents was initiated. AntihVEGF ( $3 \mathrm{mg} / \mathrm{kg} /$ day) and TNP-470 (20 mg/kg every 2 days) were administered subcutaneous!y. Endostatin (2 $\mathrm{mg} / \mathrm{kg} /$ day) and anginex ( $8 \mathrm{mg} / \mathrm{kg} /$ day) were administered by mini osmotic pumps (Alzet, DURECT Corporation, Cupertino, CA, USA) placed subcutaneously on the back of the animals. To control mice, $100 \mu \mathrm{l}$ of normal saline was administered daily, subcutaneously. Five weeks after implantation of the endometrial fragments, all mice were sacrificed.

\section{Analysis of endometriotic lesions and vascularisation in nude mice}

To evaluate endometriotic lesions and vascularisation, the abdominal skin was opened and the abdonninal subcutaneous region, the peritoneum and visceral organs were examined under a surgery microscope. Uterus and lesions with possible endometriosis were removed, fixed in 10\% buffered formalin and embedded in paraffin. Paraffin sections $(4 \mu \mathrm{m})$ were cut from the entire specimen (150-200 sections) and sections were H\&E stained or used for 
immunohistochemistry. Histology of endometriotic lesions was evaluated by a pathologist specialized in gynaecology and a laboratory animal pathologist.

The number of von Willebrand Factor (vWF) stained vessels (as described below) in the lesion was counted under 200x magnification, and the number of vessels per $\mathrm{mm}^{2}$ lesion was calculated. Under identical circumstances, the number of mature vessels surrounded by a-smooth muscle actin (aSMA) positive cells (as described below) was calculated. To calculate the number of newly developed vessels, the number of aSMA stained vessels was subtracted from the number of vWF stained vessels. Each lesion was examined twice, and the average of the counts was taken.

\section{Immunostaining}

Immunostaining for VEGF on human endometrium was performed using an antibody against VEGF (polyclonal, 1:200, Novocastra Laboratories LTD, Newcastle upon Tyne, UK). Human origin of endometriotic lesions was confirmed by immunostaining using an antibody against pancytokeratin (MNF 116, monoclonal, 1:500, DAKO, Glostrup, Denmark), specifically staining human epithelial cells. Blood vessels were stained by immunohistochemistry using an antibody against von Willebrand Factor (VWF) (polyclonal, 1:1000, DAKO, Giostrup, Denmark), and smooth muscle cells surrounding mature vessels were stained using an antibody against $\alpha$-smooth muscle actin (aSMA)-FITC (monoclonal, 1:3000, Sigma, Saint Louis, Missouri, USA). Antibody binding was visualised with Envision (anti-VEGF, MNF 116, vWF) or with anti-FITC.HRP (aSMA) labeled secondary antibody, and 3,3'-diaminobenzidin (DAB) as a chromogen. Sections were counterstained with haematoxylin and mounted with coverslips.

\section{Statistical analysis}

Descriptive statistics (median, range and percentiles) were calculated for each experimental group. Differences in number of endometriotic lesions as well as differences in microvesse! densities between groups of mice were compared ușing the non-parametric Mann-Whitney- $U$ test. P-values $<0.05$ were considered statistically significant. Microvessel densities were counted blindly, twice by 1 observer, and 1 time by a secand observer under identical circumstances. The average of the counts was taken. Intraobserver and interobserver variabilities were between $5-10 \%$. 


\section{Results}

\section{Human endometrial tissue is highly angiogenic}

The angiogenic profile of proliferative endometrial tissue was investigated by quantitative real time RT-PCR (qRT-PCR, Figure 1a). VEGF-A was found to be the predominant angiogenic factor. This was confirmed by detection of VEGF at the protein level with immunohistochemistry (Figure 1b, 1c). GRT-PCR revealed that bFGF and angiopoietin-2 expressions were also relatively high, whereas VEGF-B and $-C$, PIGF and angiopoietin-1 were expressed at low levels. VEGF-D and angiopoietin-3 were virtually absent. Interestingly, whereas VEGF-R1 and -2 were expressed moderately, neuropillin-1 was the predominantly expressed angiogenesis receptor in the endometrial tissue (Figure 1a).
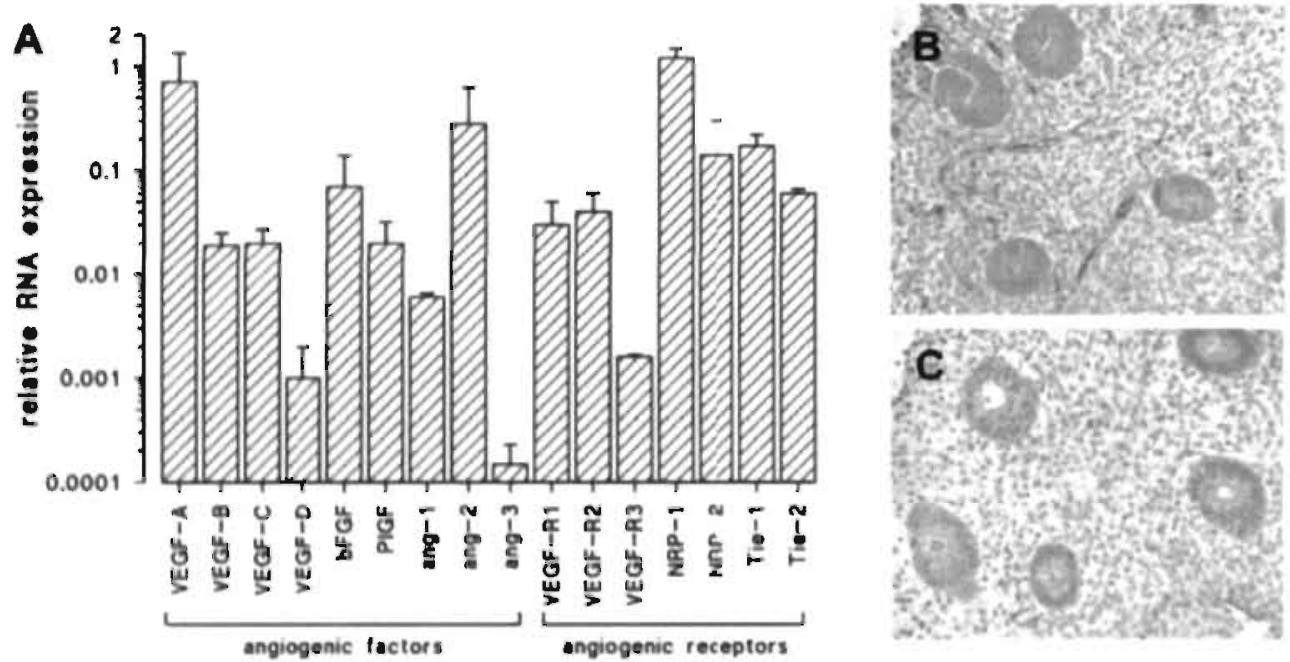

Figure r. Angiogenesis profile of human endometrium

a: Quantitative real-time RT-PCR for endothelial growth factors. b: Immunostaining for human VEGF in proliferative human endometrium shows that VEGF is expressed abundantly c: Negative control staining in the same proliferative human endometrial specimen (both magnification 200x).

\section{Development of endometriosis in mice is inhibited by angiostatic agents}

Human endometrial fragments injected subcutaneously and in the peritoneal cavity of estrogen suppleted athymic mice gave rise to endometriotic lesions in both locations in $>95 \%$ of mice. In a longitudinal study, 2 or 3 lesions were found in each mouse when mice were sacrificed 1,2, 3 or 4 weeks after inoculation, with an 
average of 2.5 lesion per mouse (not significant). This indicates that engraftment of endometrium results in quick and stable development of endometriotic lesions. In time, an increase in microvessel density was observed, when determined by vWFstaining, going up from 5 vessels $/ \mathrm{mm}^{2}$ lesion after 1 week (range 3-8) to 13.5 vessels $/ \mathrm{mm}^{2}$ lesion after 5 weeks (range $6-41, \mathrm{p}<0.005$ ).
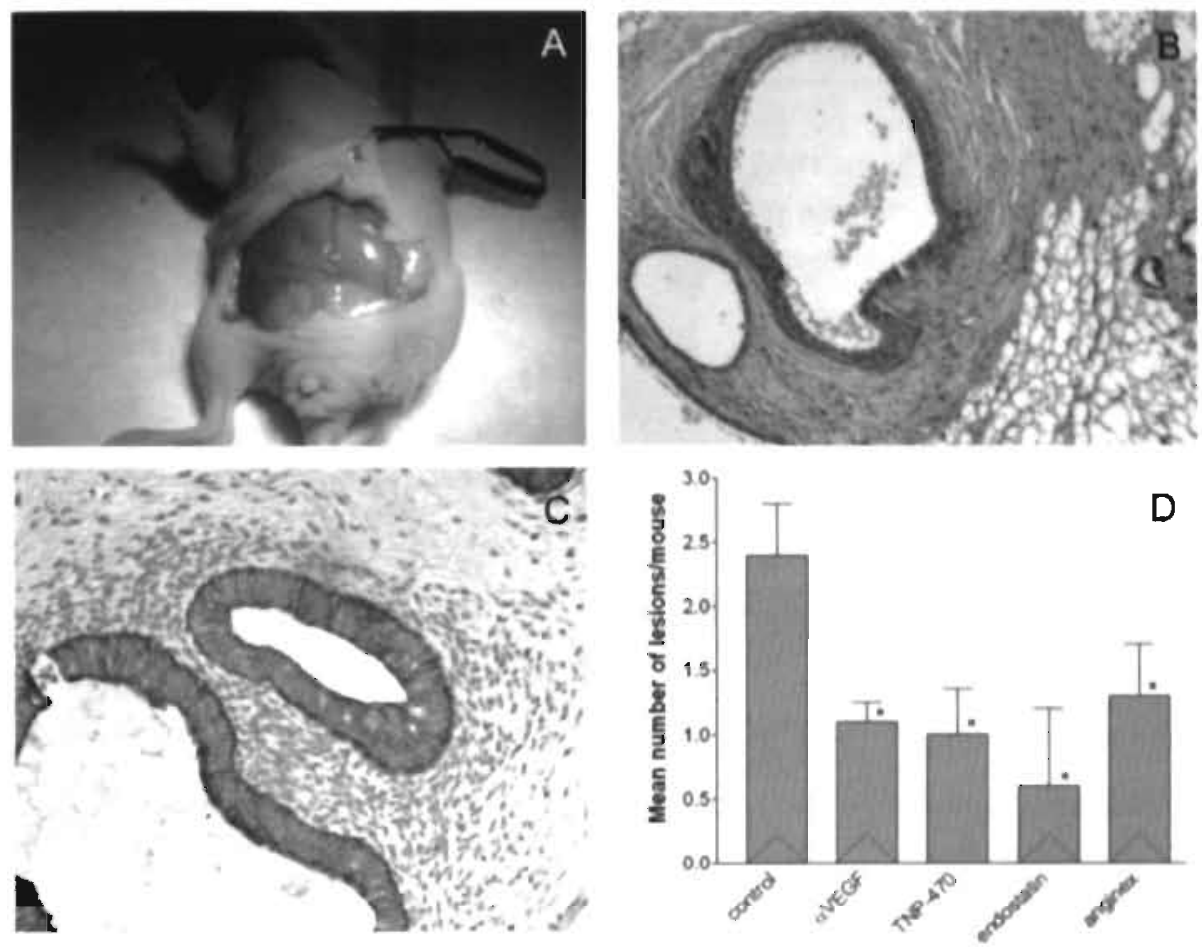

Figure 2. Formation and morphofogy or endometriotic lesions in nude mice after administration of angiostatic agents.

a: Intraperitoneal lesion in nude mouse (control). The endometriotic lesion is visible through the peritoneum, forming white nodules in the mouse abdomen. $b$ : Representative cross section of a subcutaneous endometriotic lesion in a nude mouse (H\&E staining). Nore the hererogeneous morphology of the endometrium with tubal metaplasia surrounded by fibrosis, and highly cylindrical epithelium covered with typical endometrial stroma (control mouse, magnification 200x). Panel c shows endometrial glands stained with a specific human pancytokeratin antibody (MNF 116) in a peritoneal endometriotic lesion, showing that the endometriotic lesion is of humarr origin (control mouse, magnification 300x). Panel d: number of endometriotic lesions in nude mice after treatment with angiostatic agents 
Table 1. Numbers of VWF stained vessels, of mature aSMA stained vesse/s, and the difference between \WF and aSMA stained vessels in endometriotic lesions in nude mice per $\mathrm{mm}^{2}$ of lesion.

\begin{tabular}{lccc}
\hline & $\begin{array}{c}\text { WWF stained vessers } \\
\text { Average (range) }\end{array}$ & $\begin{array}{c}\text { aSMÄ stained vessels } \\
\text { Average (range) }\end{array}$ & $\begin{array}{c}\text { vWF+ aSMA-vessels } \\
\text { Average (range) }\end{array}$ \\
\hline contro! & $15.4(1-52)$ & $9.9(\uparrow-29)$ & $5.7(0-30)$ \\
anti-hVEGF & $8.6(1-18)^{*}$ & $6.3(1-17)$ & $2.5(0-8)^{*}$ \\
endostatin & $5.3(3-8)^{\circ}$ & $5.0(2-8)$ & $0.0(0)^{*}$ \\
anginex & $5.9(3-10)^{*}$ & $5.4(3-9)$ & $1.0(0-9)^{*}$ \\
\hline
\end{tabular}

" $p<0.05$ compared to control.

WF

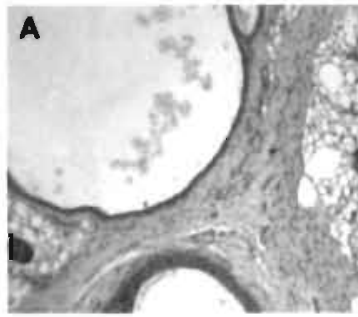

controi

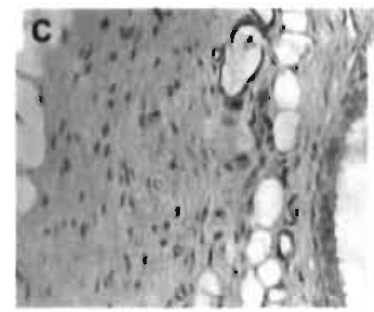

endostatin

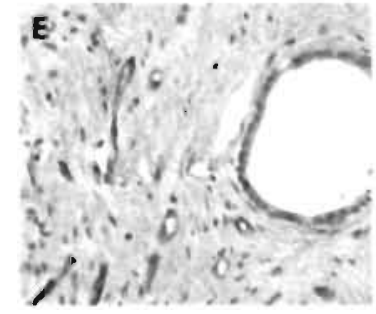

$\alpha S M A$
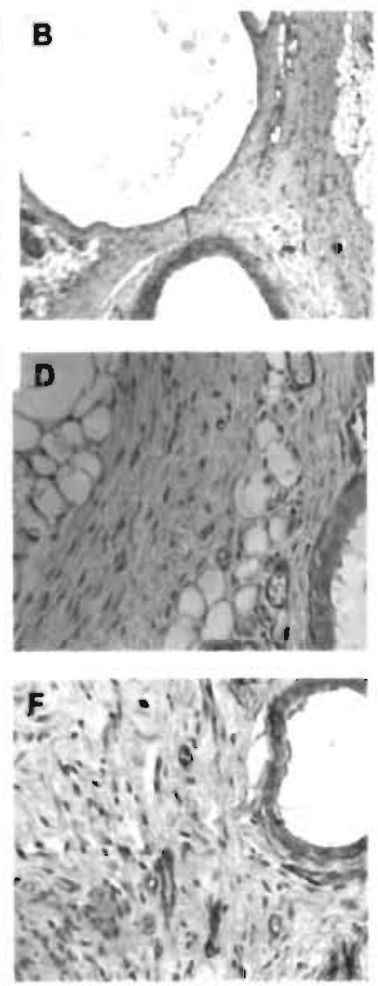

Figure 3. VWF and aSMA staining of vessels in endometnotic lesions in nude mice. In control mice all vessels are wWF-positive (3a, 3c), but not all are aSMA-positive (3b, 3d). indicating that mature as well as newly formed vessels are present in endometnotic lesions in control mice $3 a$ and $3 b$ show an overview of a representafive endometriotic lesion (magnification 200x) In panel $3 c$ and $3 d$ detailed representative pictures are given, in which vWF-positive and aSMA-negative vessels are present (magnification $300 \mathrm{x}$ ) in mice treated with endostatin, all WWF-positive vessels (3e) are aSMA-positive (3f), indicating that only mature vessels remain and that no new vessels come to development as a consequence of treatment with anti-angiogenic agents (magnification $300 \mathrm{x}$ ) 
After 5 weeks, in control mice an average of 2.5 lesion was present. Treatment with anti-hVEGF resulted in a significant decrease in the number of lesions observed per mouse $(p<0.05$. Figure $2 d)$. This indicates that VEGF is a key player in the endometrium derived signals. In addition to anti-hVEGF, mice were treated with 3 other angiogenesis inhibitors, i.e. the fungus derived antibiotic TNP-470 (Ingber et al., 1990), and the specific angiogenesis inhibitors endostatin (O'Reilly et al., 1997) and anginex (Griffioen et al., 2001; Mayo et al., 1996; Van der Schaft et al., 2002). All 3 compounds significantly inhibited the number of endometriotic lesions present in mice $(p<0.05$, Figure $2 d)$.

Morphology was assessed by a laboratory animal pathologist and by a pathologist specialized in gynaecology. A pancytokeratin staining specific for human epithelium confirmed the human origin of the endometriotic lesions (Figure 2c). All endometriotic lesions showed a heterogeneous morphology. Part of the lesions presented as tubal metaplasia (endosalpingeosis) consisting of metaplastic epithelium, surrounded by fibrotic tissue instead of stroma. This morphology equals morphology often seen in rectovaginal endometriosis in women. Other parts of the lesions contained more typical highly cylindrical endometrial epithelium surrounded by stroma (Figure 2b), as is typical for peritoneal endometriosis in women. Histology did not differ between the groups, and no relation was found between histology and vascular density of the lesion.

\section{Anti-angiogenic agents suppress neovascularisation in lesions in nude mice}

Microvessel density, determined on the basis of VWF positive vessels was suppressed in endometriotic lesions in mice treated with angiostatic agents $(p<0.05$, Table 1), as compared to conitrol mice. Endostatin was found to be the most effective inhibitor of microvessel density. Both competition of VEGF and treatment with anginex led to reduction of the microvessel density. Similar results were observed for endometriotic lesions in mice treated with TNP-470, but these results were left out of Table 1 due to the low number of lesions. When vessel density was determined using SMA antibodies, quantifying mature vessels, no differences were observed between the treatment groups. Enumeration of the number of $\mathrm{WWF}^{*}$ aSMA vessels, which can be considered the newly formed vessels, revealed a suppressed appearance in all groups treated with angiogenesis inhibitors $(p<0.05$, Table 1). Figure 3 shows the difference in vWF and aSMA stained vessels in an endometriotic lesion in mice. 


\section{Discussion}

The aims of the present study were to assess whether maintenance and growth of endometriotic lesions are dependent on angiogenesis and whether angiogenesis inhibition is a therapeutic possibility for endometriosis. The current data demonstrate that maintenance and growth of endometriosis are strongly dependent on angiogenic processes, and that angiostatic agents are able to inhibit established endometriotic lesions. These data were obtained from an in vivo human xenograft animal model using angiogenesis inhibitors for intervention.

Real time RT-PCR analysis of proliferative endometrium demonstrated that VEGF-A is the most abundantly expressed angiogenic factor in human endometrium, which suggests a pivotal role of VEGF in endometrium biology, and which confirms earlier results by others (Charnock-Jones et al. 1993; Fujimoto et al., 1999; Sharkey et al. 2000; Taylor et al., 2002; Hull et al., 2003). Although the expression of VEGF was present in both epithelial and stromal cells of the endometrium, a dominant expression was observed in the microvessels within the endometrial tissue. The presence of both VEGFR-1 and -2 as well as the extremely high expiression of neuropillin-1, which is a co-receptor of VEGF-A, supports the fact that VEGF-A is the most important angiogenic factor in endometrial tissue.

In a recently published study. the effect of angiogenesis inhibition was studied in nude mice. VEGF-A inhibitors were administered immediately after implantation of cultured human endometrial fragments (Hull et al., 2003). The authors observed impaired lesion formation, and they concluded that angiostatic agents may be effective in the treatment of endometriosis. However, angiostatic agents were applied immediately after implantation of human endometrium, when endometriotic lesions had not yet developed. Therefore, development of endometriotic lesions was prevented in this study, but no therapy for established endometriotic lesions was applied. In our study we used uncultured human endometrium in order to avoid adverse effects. Moreover, we initiated angiostatic treatment 3 weeks after implantation of human endometrial fragments. In these 3 weeks, endometriotic lesions were allowed to establish. Start of angiostatic therapy after endometriotic lesions have established seems to be a more realistic study design, since in the clinical situation, treatment is initiated in women after endometriosis has been diagnosed, at which moment endometriotic lesions have already been present for a period of time.

We applied not only an anti-hVEGF strategy but also a number of angiostatic agents affecting a broader array of angiogenesis mechanisms. Not only anti-hVEGF, but TNP-470, endostatin and the newly developed anti-angiogenic agent anginex furned 
out to effectively interfere with established endometriotic lesions as well. We found that the number of endometriotic lesions after 5 weeks of incubation was significantly lower in mice treated with angiostatic agents compared to the control group. The observed effects are ascribed to the anti-angiogenic capacity of these agents. Interestingly, physiological angiogenesis in the mice appeared not to be affected by the angiogenesis inhibitors. Surgery in mice was performed without bleeding complications later on, and no differences were observed in visual aspects of wound healing between control mice and mice treated with angiostatic agents. Moreover, the vascularisation of the uteri of mice in different groups did not differ (data not shown). These observations suggest that normal angiogenesis was not affected by the application of angiostatic agents.

The morphology of endometriotic lesions in all treatment groups was diverse, with typical endometrial glands and stroma, as well as tubal metaplasia with large cysts and flattened epithelium. The observed morphology was similar to the morphology that is often seen in endometriosis in women. We found no relation between the morphology and the vessel density of the lesions.

Vessel density, based on staining with VWF antibody was significantly lower in mice treated with angiostatic agents compared to control mice "even though the number of aSMA positive, mature vessels did not differ between the groups. This indicates that the vessels that have regressed were the newly developed ones, and not the smooth muscle cell-protected, mature vessels. Apparently, development of new blood vessels remains of pivotal importance for the maintenance and growth of endometriosis. This is aiso obvious from clinical observations, where newly developed, red peritoneal endometriotic lesions are vascularised by many small blood vessels with mitotically active endothelial cells. (Nisolle et al., 1993), and relatively small numbers of smooth muscle cell-protected adult blood vessels (Matsuzaki et al., 2001). With age, the lesions evolve into black, hemorihagic lesions, with larger blood vesseis (Nisolle ef al., 1993), that have a higher vessel maturation index, suggesting that the number of smooth muscle cell-protected bilood vessels has increased. However, unprotected vessels remain piresent (Matsuzaki et al., 2001). Therefore, angiostatic therapy may delay the progression of established endometriosis.

To date, endometriosis is hormonally treated, aimed at achieving a hypo-estrogenic state. Hormonal therapy only suppresses symptoms, but will not eradicate the ectopic implant. Moreover, there are significant side effects. Long term hormonal therapy, therefore, is not an attractive option. Alternatively, endometriosis can be treated surgically. Conservative surgery consists of ablation of endometriotic lesions, resulting in pain relief but symptoms may recurr in time in a majority of 
women. Radical surgery includes removal of the uterus and/or the ovaries, giving more permanent symptom relief, but resulting in the end of reproductive life. An effective therapeutic agent for endometriosis would be a compound that not only prevents development of endometriotic lesions, but that also would be effective against growth of established lesions. In cancer, ECs have been shown to play a pivotal role in tumour cell survival and growth. In analogy with tumour growth, enclometriosis is shown to be highly dependent on angiogenesis, which makes the achievements in the field of cancer research applicable to endometriosis. Recently, breaking results have been achieved with Avastin, a humanized anti-VEGF antibody. This approach of neutralizing VEGF provided the first proof-of-concept that anti-angiogenesis is applicable in man (Ferrara, 2002; McCarthy, 2003). The major role of VEGF in endometriosis may predict the success of Avastin in endometriosis.

In conclusion, we have shown that angiogenesis is a prerequisite for the maintenance and growth of endometriosis. Our data demonstrate for the first time that different kinds of inhibitors of angiogenesis effectively interfere with established endometriotic lesions. Therefore, we favor anti-angiogenesis therapy to be put forward for clinical testing for endometriosis. When symptoms of endometriosis have been treated by hormones or by surgery, anti-angiogenic agents may be applied in order to eradicate residual and/or microscopic endometriosis.

\section{Acknowledgements}

The authors wish to acknowledge Mrs. Marion Gijbels, animal pathologist, and Mrs. Nathalie Sieben, gynaecological pathologist, for evaluation of the morphology of the mouse sections, Mr. Jacques Cleutjens for designing the Quantimet computer progiram for the characterization of endometriotic lesions, and Mrs. Jacqueline Schouten and Ms. Quirine Theunissen for excellent technical assistance. 


\section{References}

Bronson FH and Desjardins C (1974) Circulating concentrations of FSH, LH, estradiol, and progesterone associated with acute, male-induced puberty in female mice Endocrinology 94, 1658-1668

Bruner KL. Matrisian LM, Rodgers WH, Gorstein F and Osteen KG (1997) Suppression of matrix metalloproteinases. inhibits. establishment of ectopic lesions by human endometrium in nude mice. J Clin Invest 99. 2851-2857

Charnock-Jones DS. Sharkey AM, Rajput-Williams J. Burch D. Schofield JP. Fountain SA. Boocock, CA and Smith SK (1993) Identification and Iocalization of alternately spliced mRNAs for vascular endothelial growth factor in human uterus and estrogen regulation in endometrial carcinoma cell lines Biol Reprod 48, 1120-1128

Ferrara N (2002) Role of vascular endothelial growth factor in physiologic and pathologic angiogenesis therapeutic implications Semin Oncol 29 (suppl 16). 10-14

Folkman J (1985) Tumour angiogenesis. Aḍv Cancer Res 43, 175-203

Fujimoto J. Sakaguchi H, Hirose R. Wen H and Tamaya T (1999) Angiogenesis in endometriosis and angiogenic factors. Gynecol Obstet Invest 48(suppl 1), 14-20

Gazvani R and Templeton A (2002) New considerations, for the pathogenesis of endometriosis Int J Gynaecol Obstet. 76, 117-126

Griffioen AW and Molema G (2000) Angiogenesis Potentials for pharmacologic intervention in the treatment of cancer, cardiovascular diseases, and chronic inflammation Pharmacological Reviews 52. 237.268

Griffioen AW, van der Schaft DW, Barendsz-Janson AF, Cox A. Struijker Boudier HA, Hillen HF and Mayo $\mathrm{KH}$ (2001) Anginex, a designed peptide that inhibits angiogenesis Biochem J 354, 233-242

Grümmer R. Schwarzer F. Bainczyk K. Hess-Stumpp H. Regidor P.A. Schindler AE and Winterhager E (2001) Peritoneal endometnosis: validation of an in-vivo model Hum Reprod 16, 1736-1743

Hull ML. Charnock-Jones DS, Chan CLK, Bruner-Tran KL. Osteen KG. Tom BDM, Fan TD and Smith SK (2003) Antiangiogenic agents are effective inhibitors of endometriosis. J Clin Endocrinol Metab 88. 2889-2899

Ingber D. Fujita T. Kishimoto S, Sudo K, Kanamaru T. Brem H and Folkman J (1990) Synthetic analogues of fumagillin that inhibit angiogenesis and șuppreșs tumoụr growth. Nature 348, 5̦55-557

Kọs CAM, Groothuis PG. Dunselman GAJ. De Goein AFPM and Evers JLH (1999) Adhesion of shed menstrual tissue in an in vitro model using amnion and peritoneum a light and electron microscopic ștudy Hum Reprod 14, 816-822

Maas JWM. Groothuis PG. Dunseimanı GAJ. De Goeij AFPM. Struijker Boudier HAJ and Evers JLH (2001a) Development of endometriosis-like lesions after transplantation of human endometrial fragments onto the chick chonoallantoic membrane Hum Reprod 16, 627-631

Maas JWM, Groothuis PG, Dunseimani GAJ, De. Goeij AFPM. Struijker Boudier HAJ and Evers JLH. (2001b) Endometrial angiogenesis throughout the human menstrual cycle Hum Reprod 16, 1557. 1561

Matsuzaki S. Canis M. Murakami T. Dechelotte P. Bruhat MA and. Okamura K (2001) Immunohistochemical analysis of the role of angiogenic status in the vasculature of peritoneal endometriosis Fertil Stenl 76, 712-716

Mayo KH. llyina $E$ and Park H (1996) A. recipe for designing water-soluble, betasheef-forming peptides Protein Sci $5.1301-1315$

McCarthy M (2003) Angiogenesis drug promising for metastatic colorectal cancer Lancet 361. 1959 


\section{Chapter 5}

Molema G and Griffioen AW (1998) Rocking the foundations of solid tumour growth by attacking the tumour's blood supply. Immunol Today 19, 392-394.

Nisolle M, Casanas-Roux F. Anaf V, Mine JM and Donnez J (1993) Morphometric study of the stroma! vascularization in peritoneal endometriosis. Fertil Steril 59, 681-684.

Nisolle M. Casanas-Roux F and Donnez: J (2000) Early-stage endornetriosis: adhesion and growth of human menstrual endometrium in nude mice. Fertil Steril 74, 306-312.

O'Reilly MS, Boehm T, Shing Y, Fukai N, Vasios G, Lane WS, Flynn E, Birkhead JR, Olsen BR and Folkman J (1997) Endostatin: an endogenous inhibitor of angiogenesis and tumour growth. Cell 88 , 277-285

Sampson JA (1927) Peritoneal endometriosis due to the menstrual dissemination of endometrial tissue into the peritoneal cavity Am J Obstet Gynecol 14, 422-469.

Sharkey AM, Day K, McPherson A. Malik S, Licence D. Sinith SK and Charnock-Jones DS (2000) Vascular endothelial growth factor expression in human endometrium is regulated by hypoxia. $\mathrm{J}$ Clin Endocrinol Metab 85, 402-409

Taylor RN, Lebovic, DI and Mueller MD (2002) Angiogenic factors in endometriosis. Ann New York Acad Sciences 955, 89-100

Thompson WVD, LI WW and Maragoudakis M (1999) The clinical manipulation of angiogenesis: pathology. side-effects, surprises and opportunities with novel human therapies. J Pathol 187, 503-510.

Van der Schafi DW, Dings RP, De Lussanet QG, Van Eijk LI, Nap AW, Beets-Tan RG, Bouma-Ter Steege JC. Wagstaff J, Mayo KH and Griffioen AW (2002) The designer anti-angiogenic peptide anginex targets tumour endothelial cells and inhibits tumour growth in animal models. FASEB J 16. 1991-1993.

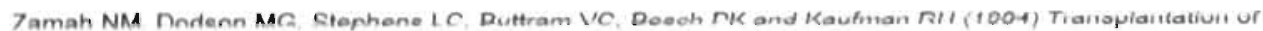
normal and ectopic human endometrial tissue into athymic nude mice. Am J Obstet Gynecol 149, 591597. 


\section{Chapter 6}

\section{Use of oral contraceptives prevents ectopic implantation of endometrium in the chicken chorioallantoic membrane}

Annemiek W. Nap, Patrick. G. Groothuis,

Chamindie Punyadeera-Mylonas.

Ludger Klein-Hitpass, Johannes L.H. Evers and Gerard A.J. Dunselman 


\section{Abstract}

\section{Background}

Innate differences exist in the endometrium between women with and without endometriosis. Oral contraceptives (OC) may be involved in the pathogenesis of endometriosis because of their effect on the endometrium. It was hypothesized that $\mathrm{OC}$ use affects the ability of endometrium to implant ectopically.

\section{Methods}

Endometrium from women using $O C$ and menstrual endometrium (ME) from normal cycling women was transplanted onto the chicken chorioallantoic membrane (CAM), and endometriosis-like lesion formation was evaluated. Microarray gene expression profiling was performed to identify differentially expressed genes in the endometrium from these 2 groups of women.

\section{Results}

Endometriosis-like lesions were formed after transplantation of $O C$ exposed endometrium in $33 \%$ of CAMs and after transplantation of ME in 76\% of CAMs ( $p<0$ 05). Gene expression profiling showed a marked decrease in the expression of genes encoding for various matrix metalloproteinases, members of the transforming growth factor- $\beta$. (TGF- $\beta$ ) superfamily and regulators of angiogenesis in $O C$ exposed endometrium.

\section{Conclusion}

OC use affects the endometrium, rendering it less potent to implant ectopically. 


\section{Introduction}

Endometriosis is defined as the presence of endometrial glands and stroma outside the uterus, predominantly within the peritoneal cavity. It presumably develops as a result of the ectopic implantation of endometrium, which has entered the peritoneal cavity via the Fallopian tubes during menstruation (Sampson, 1927). Endometriosis is one of the most commonly encountered benign problems in gynaecology. causing dysmenorrhoea, dyspareunia and chronic pelvic pain, and is associated with subfertility. Retrograde menstruation occurs to some extent in almost all cycling women, but not all of them develop symptomatic endometriosis. It has been suggested that the eutopic endometrium of women with endometriosis fundamentally differs from that of women without endometriosis in structure, proliferation, apoptosis, immune components, cell adhesion molecules, proteases and their inhibitors, steroid and cytokine production and responsiveness, gene expression and protein production (reviewed by Sharpe-Timms, 2001). Thus, innate differences in the eutopic endometrium between women may cause some to develop endometriosis whereas others do not.

Oral contraceptives (OC) are not only involved in the treatment of endometriosisassociated pain but might be instrumental in its pathogenesis as well. The endometrium of women using OC might have a diminished chance to implant ectopically as compared to the endometrium of normal cycling women. Conceivably. one explanation for this is the lower amount of tissue, which is shed by women using $O C$ during their withdrawal bleeding. A second explanation might be the changes in the endometrium per se as a result of the exposure to the OC. The steroid hormones in OC have a different concentration and composition compared to the cyclical hormonal influence on the endometrium of the normal menstrual cycle. OC use results in an arrest of glandular proliferation and eventually endometrial atrophy. Anovulation, decidualization, amenorrhoea and the establishment of a steady estrogen-progesterone milieu may contribute to disease quiescence, and the subsequent relief of symptoms (Deligdisch, 2000; Vercellini et al., 2003).

In this study, the hypothesis was tested that endometrium of women using OC has a reduced capacity to implant ectopically and form endometriotic lesions. To this end, endometrium was collected from women having normal menstrual cycles and from women using OC, and transplanted onto the chicken chorioallantoic membrane (CAM). The CAM is a suitable model to study the development of endometriosis-like lesions (Maas et al., 2001; Nap et al., 2003). Endometriosis-like lesion formation was evaluated in CAMs transplanted with the OC exposed endometrium and with 
the ME. Furthermore, we attempled to elucidate potential mechanisms contributing to the expected difference in the potential of the endometria to implant ectopically. Gene expression profiling was performed in which differentially expressed genes in $O C$ exposed endometrium as compared to ME were identified.

\section{Materials and methods}

\section{Human endometrium}

Endometrium was collected from women undergoing laparoscopy for benign conditions by transvaginal biopsy using a sampling device (Gynotec, Malden, The Netherlands). We collected endometrium from women using the monophasic oral contraceptive Microgynon ${ }^{\circ} 30$, containing $30 \mu \mathrm{g}$ of ethinyloestradiol and $150 \mu \mathrm{g}$ of levonorgestrel (Schering BV. Weesp. The Netherlands), and endometrium during the menstrual phase of the cycie (cycledays 1 to 3 ) from women with ovulatory cycles. In these women no endometriosis could be visualised. Ten biopsies of OC exposed endometrium and 10 biopsies of menstrual endometrium (ME) were used for the experiments in the CAM, and 2 biopsies of OC exposed endometrium and 2 biopsies of ME for the gene array analysis. The use of human endometrium was approved by the Institutional Ethical Review Committee of the University Hospital Maastricht. All women participating in the study gave their written informed consent.

Immediately after collection, blood clots were removed and the endometrium was minced in fragments of $1-2 \mathrm{~mm}^{3}$ and placed in serum-free DMEM/HAM's F12 culture medium supplemented with $2 \mathrm{mmol} / \mathrm{l} \mathrm{L}$-glutamine, $100 \mathrm{IU} / \mathrm{ml}$ penicillin, 100 $\mu \mathrm{g} / \mathrm{ml}$ streptomycin, and $2.5 \mu \mathrm{g} / \mathrm{ml}$ amphotericin B (all from Gibco Life Technologies, Breda, The Netherlands). Part of the endometrium samples was used for transplantation onto the CAM, and 2 samples were immediately snap frozen for RNA isolation. Endometrial tissue was embedded in paraffin, sectioned and stained with Haematoxylin \& Eosin (H8.E) for histological evaluation of the tissue integrity. The menstrual endometrium was dated according to the clinical information about the start of the last menstrual cycle.

\section{Chorioa!lantoic membrane model}

Fertilised eggs of Lohman-selected White Leghorns were incubated and prepared as described previously (Nap et al., 2003). Endometrium was carefully minced in fragments of 1-2 $\mathrm{mm}^{3}$ and $t$ fragment was transplanted onto each CAM. Endometrium exposed to OC was transplanted onto 52 CAMs, and ME: was transplanted onto 86 CAMs (Table 1. Figure 1). 
Table 1 Number of CAMs with endometriosis-hike lesions related to total number of CAMs per biopsy in menstrual endometnum (ME) and in OC exposed endometrum (OC). In brackets median and. range

CAMs with lesion / total number of CAMs (ME) $(7.5 ; 4-15)$

\section{$4 / 4$}

$10 / 11$

$4 / 4$

$4 / 5$

$10 / 15$

$5 / 14$

$10 / 10$

$13 / 15$

$3 / 4$

2/4
CAMs with lesion / total number of CAMs (OC) $(4.5 ; 2-10)$

217

$1 / 2$

$2 / 5$

$2 / 8$

$1 / 3$

$3 / 10$

$0 / 2$

$1 / 3$

$3 / 8$

$2 / 4$

Total $17 / 52$
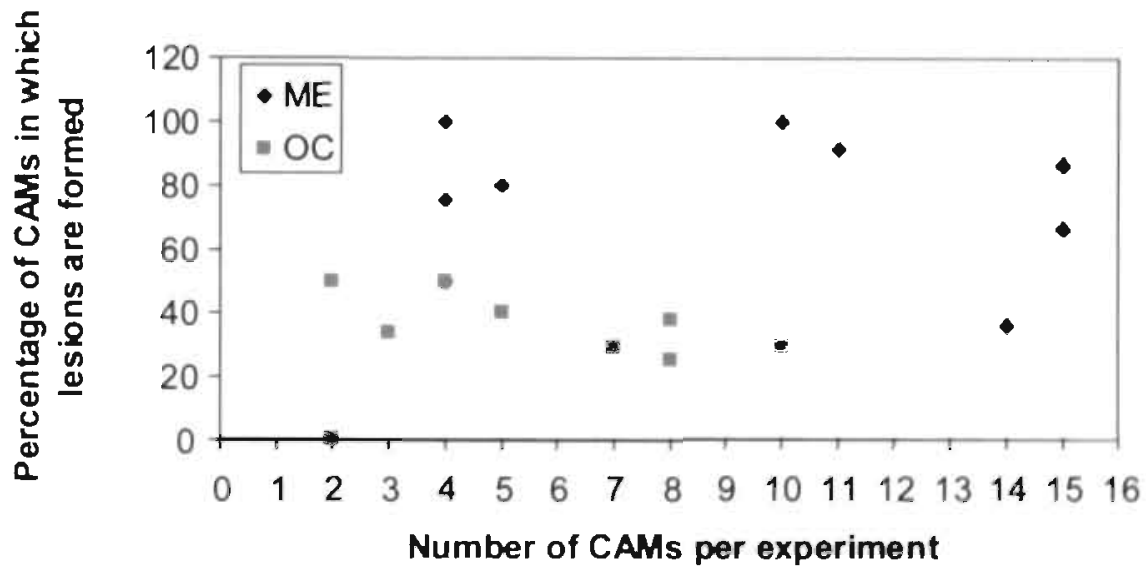

Figure 1 The number of CAMs transplanted with endometrium from 1 endometrial biopsy and the percentage of CAMs in which endometriosis-like lesions developed Irrespective of the number of CAMs transplanted with endometrium from one endometrial biopsy, in all but one experiments the percentage of endometnosis-like lesions was higher in the group of the menstrual endometrium

CAMs with the transplanted endometrium were incubated for 72 hours. To monitor endometriosis-like lesion formation, CAMs were fixed in $3.7 \%$ buffered 
formaldehyde, and the area of the CAM containing the endometrial fragment was excised and embedded in paraffin. From the entire specimen, paraffin sections

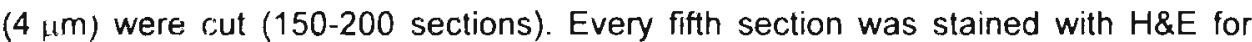
histological evaluation.

\section{RNA isolation}

Total RNA was; isclated from explants using the SV total RNA isolation kit (Promega, USA) according to the manufacturer's protocol, except that the concentration of DNase-1 was doubled and the incubation time extended to 45 minutes during the DNase treatment to completely remove genomic DNA. Total RNA was eluted from the column in $50 \mu \mathrm{l}$ RNase-free water and stored at $-70^{\circ} \mathrm{C}$ until further analysis. The quality of the RNA samples was determined by evaluating the $18 \mathrm{~S}$ and 28S RNA bands under UV light, after agarose gel electrophoresis and ethidium bromide staining. A GAPDH PCR was performed to test for genomic DNA contamination of the isolated RNA.

\section{Oligonucleotide microarray analysis}

For microarray analyses we used the Affymetrix GeneChip platform employing a standard protocol for sample preparation and microarray hybridization, as detailed previously (Dürig et al., 20,03). Briefly, total RNA was converted into doublestranded cDNA using an oligo-deoxythymidine (oligo-dT) primer containing the T7 RNA polymerase binding site (5'-GCATTAGCGGCCGCGAAATTAATACGACTCACTATAGGGAGA-(dT) ${ }_{24} \mathrm{~V}-3^{\prime}$ ) (MWG Biotech, Munich, Germany) for first strand synthesis. After generation of double-stranded cDNA from the first-strand CDNA, biotinylated CRNA was synthesized by in vitro transcription using the BioArray High Yield RNA Transcript Labeling Kit (Enzo Diagnostics, New York, New York, USA). Labeled cRNA was purified on RNeasy columns (Qiagen. Hilden, Germany), fragmented and hybridized to HG-U133A microarrays (Affymetrix, Santa Clara, California, USA). The arrays were washed and stained according to the manufacturer's recommendation and finally scanned in a GeneArray scanner 2500 (Agilent, Palo Alto, California, USA).

\section{Microarray data processing}

Array images were processed to determine signals and detection calls (present, absent, marginal) for each probeșet using the Affymetrix Microarray Suite 5.0 software (MAS 5.0; statistical algorithm). Scaling across all probe sets of a given array to an average intensity of 1000 was performed to compensate for variations in the amount and quality of the cRNA samples and other experimental variables of non-biological origin. Pairwise cross comparisons of the 2 samples of menstrual 
endometrium and the samples of the OC endometrium were carried out with MAS 5.0, which calculates the signal $\log 2$ ratio (Change) and significance (Change p-value) of each change in gene expression based on a Wilcoxon ranking test. Probesets exhibiting a signal $\log 2$ ratio $>1.0$ and a change p-value $<0.0065$ or a signal $\log 2$ ratio $\leq 1.0$ and a change p-value $>0.935$ (corresponding to 2 -fold up- or down-regulation) were identified by filtering using the Affymetrix Data Mining Tooll 3.0. Those passing these cut-offs in all 4 cross comparisons were considered as differentially expressed.

\section{Real-time PCR}

To generate cDNA, total RNA $(1 \mu \mathrm{g})$ was incubated, with random hexamers $(1 \mu \mathrm{g} / \mu \mathrm{l}$; Promega, Madison, WI, USA) at $70^{\circ} \mathrm{C}$ for $10 \mathrm{~min}$. The samples, were chilled on ice for $5 \mathrm{~min}$. A reverse transcriptase (RT)-mix consisting of $5 \times$ RT-buffer $(4 \mu \mathrm{l}), 10 \mathrm{mM}$

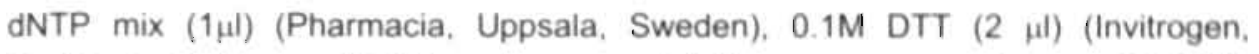
Carlsbad, California, USA) and superscript II reverse transcriptase (200U/ $\mu$ l) (Invitrogen) was added and the samples were incubated at $42 \mathrm{C}$ for 1 hour. Heating the samples at $95 \mathrm{C}$ for $5 \mathrm{~min}$ then inactivated reverse transcriptase. The cDNA was stored at $-20 \mathrm{C}$ until further use. Fifty nanogram of cDNA template was used in each real-time PCR reaction.

Endometrial bleeding associated factor (EBAF) and matrix metalloproteinase (MMP)-26 primers and probes were purchased from Perkin-Elmer Applied Biosystems as pre-developed assays. Human cyclophyllin A (Hs 99999904-m1) was used as an endogenous control to normalize for the differences in the amount of total RNA added to each reaction.

All PCR reactions were performed using an ABI Prism 7700-sequence detection system (Perkin-Elmer, Boston, MA, USA). The thermal cycling conditions comprised an initial decontamination step at $50^{\circ} \mathrm{C}$ for $2 \mathrm{~min}$, a denaturation step at $95^{\circ} \mathrm{C}$ for 10 min and 40 cycles at $95^{\circ} \mathrm{C}$ for $15 \mathrm{sec}$ and $60^{\circ} \mathrm{C}$ for $1 \mathrm{~min}$. Experiments were performed in duplicate for each sample. Quantitative values were obtained from the threshold cycle number $(\mathrm{Ct})$, at which the increase in the signal associated with exponential growth of PCR products is first detected with the ABI Prism 7700 sequence detector software (Perkin-Elmer). As the targets and cyclophyllin $A$ have similar amplification efficiencies, we used the comparative $\mathrm{Ct}$ method (delta delta $\mathrm{Ct}$ ) to perform relative quantification of our target genes. For details, see user bulletin \#2 for the ABI PRISM 7700 Sequence. Detection System, available at: http://www.uk1.unifreiburg.de/core/facility/tagman/user_bulletin_2.pdf.

Briefly, the difference in the number of cycles, $\Delta \mathrm{Ct}$, was determined as the difference between the target gene and cyclophyllin A within each experiment. Next, 
the $\triangle \Delta \mathrm{Ct}$ was calculated between the treated and control samples within each experiment. The fold change was calculated as $F C=2^{-\triangle \Delta C_{T}}$

\section{Statistical analysis}

Differences between the number of endometriosis-like lesions in the CAMs transplanted with $O C$ endometrium and these with ME were calculated using $x^{2}$ tests. P-values $<0.05$ were considered statistically significant.

\section{Results}

\section{Morphology of human endometrium}

The microscopic appearance of endometrium exposed to oral contraceptives (OC) differed from that of menstrual endometrium (ME). The morphology of the OC exposed endometrium was characterized by the presence of small glands with apical snouts (Figure 2b, arrow). The ME was heterogeneous in morphology, and endometrial degeneration was present. Glands were irregularly shaped (Figure 2). Assessment by a gynaecopathologist revealed no major morphological differences within the group of the OC exposed endometrium or within the ME group.
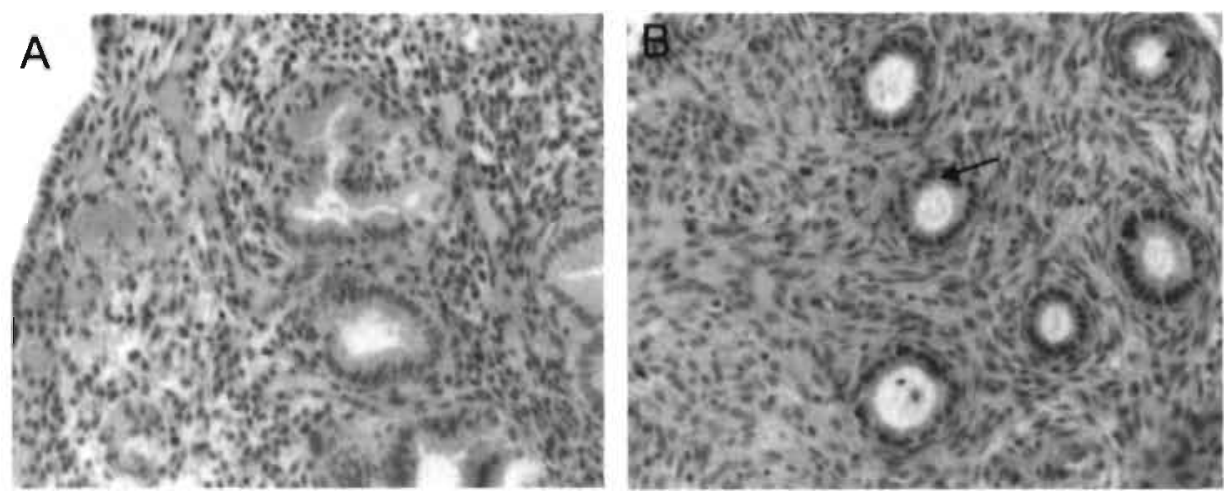

Figure 2. The morphology of menstrual endometrium (2A) and of endometrium exposed to Oral Contraceptives (OC) (2B). H\&E staining. Note the apical snouts in the OC exposed endometrium (arrow)

Endometrium exposed to oral contraceptives has an impaired capacity to form endometriosis-like lesions in the CAM

After seventy-fwo hours of incubation, endometriosis-like lesions were observed in $33 \%$ of CAMs (17 out of 52 ) after transplantation of OC exposed endometrium and 
in $76 \%$ of CAMs (65 out of 86 ) after transplantation of $M E(p<0.05$; Figure 3 ). Table 1 and Figure 1 show the percentage of CAMs with an endometriosis-like lesion and the number of CAMs per experiment.
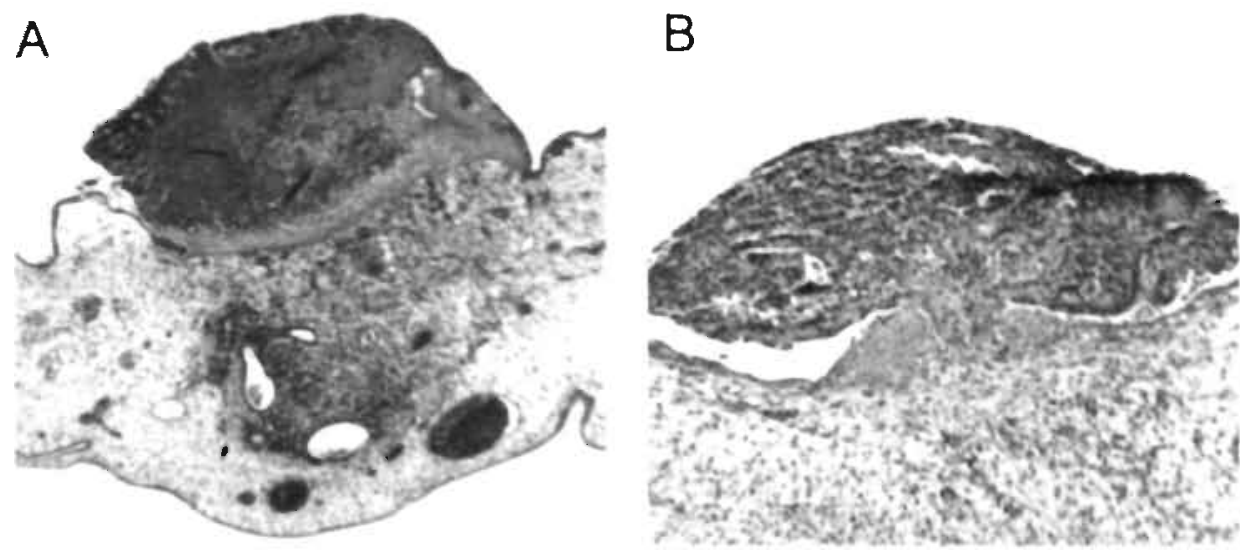

Figure 3. Endometriosis-like lesion in CAM onto which menstrual endometrium has been transplanted (3A), and CAM without a lesion, transplanted with endometrium exposed to oral contraceptives (3B), both after 72 hours of incubation

\section{Expression profiles of endometrium exposed to oral contraceptives and of menstrual endometrium}

When comparing the gene expression patterns of $\mathrm{OC}$ exposed endometrium to ME, a number of distinct differences emerged. Of the more than 12,000 genes analyzed: 143 gene transcripts were expressed $>2$-fold higher in ME, and 144 gene transcripts were expressed >2-fold lower in ME as compared to OC exposed endometrium (Appendix 2)

Table 2 presents the characteristics of 20 gene transcripts that were selected based on their relevance with regard to the potential involvement in ectopic implantation of endometrium. Inhibin $\beta A$ was the gene transcript with the highest expression in ME as compared to OC exposed endometrium, with an average fold change of 177.5 . whereas MMP-26 was the transcript with the lowest expression in ME, with an average fold change of 0.1 .

\section{Real-time PCR}

Two genes were selected to validate the findings of the microarray analysis with real-time PCR. These genes were endometrial bleeding associated factor (EBAF) and matrix metallioproteinase (MMP)-26. The expression of EBAF was 164-fold 
higher in the ME samples, whereas the expression of MMP-26 was 7.8-fold lower in the ME as compared to the $\mathrm{OC}$ exposed endometrium, using real-time PCR.

Table 2. Relative expression of gene transcripts in endometrium exposed to oral contraceptives compared to menstrual endometrium: a selection of relevant transcripts involved in ectopic implantalion of human endometrium. The ratio of mRNA levels of menstrual endometrium as compared to OC exposed endometrium is expressed as average (AVG) fold change. An AVG fold change of 177.5 means that the expression is 177.5 times higher in ME as compared to OC. exposed endometrium.

\begin{tabular}{|c|c|c|}
\hline Gene Symbol & Title & AVG Fold Change \\
\hline INHBA & inhibin, beta $A$ & 177.5 \\
\hline |GFBP| & insulin-like growth factor binding protein 1 & 80.3 \\
\hline MMP10 & matrix metalloproteinase 10 & 42.7 \\
\hline EBAF & endometrial bleeding associated factor & 24.7 \\
\hline BMP2 & bone morphogenetic protein 2 & 14.6 \\
\hline HLA & interleukin 1, alpha & 9.8 \\
\hline EDNRB & endothelin receptor type B & 8.1 \\
\hline TIMP3 & tissue inhibitor of MMP 3 & 8.0 \\
\hline IGFBP3 & insulin-like growth factor binding protein 3 & 6.7 \\
\hline FGF2 & fibroblast growth factor 2 & 3.6 \\
\hline PLAT & plasminogen activator, tissue & 3.6 \\
\hline TGFB2 & transforming growth factor, beta 2 & 3.4 \\
\hline THBS2 & thrombospondin 2 & 3.4 \\
\hline ENG & endoglin & 29 \\
\hline MMP27 & matrix metalloproteinase 27 & 2.8 \\
\hline MMP2 & matrix metalloproteinase 2 & 2.8 \\
\hline TNFAIP2 & $\begin{array}{l}\text { fumour necrosis factor, alpha-induced } \\
\text { protein } 2\end{array}$ & 2.5 \\
\hline EDNRA & endothelin receptor type A & 0.5 \\
\hline IGF 1 & insulin-like growth factor 1 (somatomedin C) & 0.2 \\
\hline MMP26 & matrix metalloproteinase 26 & 0.1 \\
\hline
\end{tabular}

\section{Discussion}

For many years oral contraceptives (OC) have been used to suppress symptoms associated with endometriosis. and currently many gynaecologists consider these 
drugs as the first line of therapy for the medical treatment of women with endometriosis (Winkel, 2003). As most OC have a predominant progestational effect, eventually resulting in an inactive and atrophic endometrium, women using OC shed only a small amount of endometrium during withdrawa! bleeding. Conceivably, this limits the chance to develop endometriosis. Increased amounts of retrograde menstruation have been associated with a higher risk of developing the disease (Sanfilippo et al., 1986; Darrow et al.., 1993; D'Hooghe et al., 1994). We hypothesized that apart from generating less endometrium available for ectopic implantation, $\mathrm{OC}$ induce changes in the endometrium, making the endometrium less potent to implant ectopically. Indeed, the experiments in the chorioallantoic membrane (CAM) model demonstrate that the capacity to develop endometriosislike lesions decreased more than $50 \%$ in the group of the OC exposed endometrium as compared to the group of the menstrual endometrium (ME). The CAM model that was used is particularly reliable to test this hypothesis, since the influence of the amount of tissue transplanted can be corrected and accounted for. The differences found are consequently not the result of the amount of tissue but of differences induced in the endometrium by the use of the hormones in the OC. In an attempt to. explain the observed difference in the capacity to form endometriosis-like lesions in the CAM, microarray gene expression profiling was performed. This lechnique allows a hypothesis-free way to explore the molecular mechanisms of endometriosis and to identify genes abnormaily expressed and possibly responsible for the. development of the disease (Taylor et al., 2002a).

In the present study differentially expressed genes were identified in OC exposed endometrium compared to ME, suggesting that the use of OC indeed changes the innate characteristics of the endometrium. Of the 287 differentially expressed gene transcripts, 20 genes are potentially involved in the ectopic implantation of endometrium. Strikingly, these genes were all associated directly or indirectly with either angiogenesis or with extracellular matrix: (ECM) remodelling. The most. markediy downregulated gene in OC exposed endometrium was inhibin $\beta A$, a member of the TGF- $\beta$ superfamily. Other members of the TGF- $\beta$ superfamily which were downregulated in OC exposed endometrium, were EBAF, bone morphogenetic protein (BMP)-2 and TGF- $\beta-2$. Members of the TGF- $\beta$ superfamily have been implicated in basically all aspects of tissue repair, including angiogenesis, the regulation of cell replication and differentiation, cellular migration, and in: ECM deposition and remodelling (Godkin and Dore, 1998; Chin et al., 2004). Although inhibin has been demonstrated to be present in the cystic fluid of ovarian endometriomas (Reis et al., 2001), in the follicular fluid (Akande et. al., 2000) and in the peritoneal fluid (Florio et al. , 1998) of women with endometriosis, and EBAF is. abundantly present in the endometrium of subfertile endometriosis patients 
(Tabibzadeh et al., 2000), the exact role of TGF- $\beta$ in endometriosis is unclear until now. Osteen and co-workers suggested that in endometriosis, it may function as a mediator of MMP expression in concert with progesterone (Osteen et al., 2003).

Besides members of the TGF- $\beta$ superfamily, other angiogenic factors were downregulated in OC exposed endometrium as compared to ME. We found a low expression of angiogenic factors which have been reported to be important in endometrial angiogenesis including the insulin-like growth factor binding proteins (IGFBP) -1 and -3 (Giudice and Irwin, 1999), and thrombospondin (Seki et al., 2001). A high expression of thrombospondin was associated with an angiogenic phenotype in endometrial cancer (Seki et al., 2001), suggesting that thrombospondin is associated with abnormal angiogenesis. Downregulation in OC exposed endometrium was also observed of angiogenic factors supposedly involved in endometriosis, including fibroblast growth factor (FGF) (Fujimoto et al., 1999), and endoglin (Kim et al., 2001). FGF induces angiogenesis in endometrium together with vascular endothelial growth factor (VEGF). Endoglin interacts with members of the TGF- $\beta$ superfamily, including BMP-2. (Barbara et al., 1999), indicating that the different angiogenic factors reported here are acting in concert with each other

Finallys the angiogenic factor endothelin receptor type B (EDRNB) was suppressed in $O C$ exposed endometrium. Endothelin-1 (ET-1) acts on this receptor, thereby regulating vasoconstriction, but it also modulates tumour angiogenesis by inducing VEGF (Bagnato and Spinella, 2003). As VEGF is a predominant angiogenic factor in human endometrium (Taylor et al., 2002b). appropriate regulation of this factor may be pivotal in both regulation of the menstrual cycle and in the development of endometriosis. Recent studies performed by our group confirmed that angiogenesis is essential in the development of endometriosis, and that VEGF is a major angiogenic factor in the endometrium (Nap et al, 2004). The current study shows that gene transcripts, which are acting in the process of angiogenesis, are downregulated in OC exposed endometrium as compared to ME, indicating that $\mathrm{OC}$ exposed endometrium is less angiogenic. This implies that $\mathrm{OC}$ exposed endometrium after entering the abdominal cavity during the withdrawal bleeding and after attachment to the peritoneal surface is less able to attract bloodvessels and hence will not survive in this ectopic location.

Gene transcripts associated with ECM remodelling are matrix metalloproteinases (MMPs) -2, - 10, -27, and Tissue Inhibitor of MMP (TIMP) -3, which were all lower expressed in $\mathrm{OC}$ exposed endometrium as compared to $\mathrm{ME}$. In previous studies in the CAM model, inhibition of MMP activity impaired endometriosis-like lesion formation (Nap et al., 2004), indicating that MMPs are pivotal in the process of ectopic implantation. The lower expression of MMPs in OC exposed endometrium 
may be explained by the effective inhibition of MMPs by progesterone (Osteen et al., 1996). Moreover, our microarray analysis revealed a downregulation in OC exposed endometrium of IL-1 and of TNF-a-induced protein. Bruner-Tran and coworkers demonstrated that progesterone limits the effects of proinflammatory cytokines, which are potent stimulators of the MMP expression during menstruation (Bruner-Tran et al., 2002). Although the cellular and molecular mechanisms by which progesterone blocks this proinflammatory cytokine action have not been elucidated, progesterone is critical to maintaining the appropriate balance between MMPs and TIMPs within the endometrium (Bruner-Tran et al., 2002).

Transplantation of OC exposed endometrium still resulted in the formation of endometriosis-like lesions in $33 \%$ of CAMs. This means that mechanisms. responsible for endometriosis-like lesion formation are still active. The array studies revealed that gene transcripts involved in angiogenesis including insulin-like growth factor 1 and endothelin receptor type A, as well as these encoding for the extracellular matrix mediating MMP-26 were even higher expressed in OC exposed endometrium as compared to menstrual endometrium. This may explain why endometriosis-like lesion formation still remains possible to a certain extent despite the use of OC.

The present microarray profiling study was performed with a limited number of endometrial biopsies. This carries the risk of drawing general conclusions based upon the characteristics of endometrium of individuals. This risk has been decreased as much as possible by cross comparing both biopsies in 1 group to both biopsies in the other group, and only taking into account results which were significantly different in all 4 comparisons. It has to be emphasized at this point that the relevant upregulated and downregulated genes identified in this study need to be investigated and confirmed in newly collected endometrial biopsies, to make the conclusions drawn more robust. Finally, one has to be aware of the fact that information from gene expression by its very nature does not give information on the expression on the protein level.

In conclusion, the use of OC reduces the capacity of the human endometrium to implant in an ectopic location. The use of OC causes an inhibition in the endometrium of the expression of gene transcripts which are prerequisites for the development of endometriosis, specifically those encoding for genes involved in angiogenesis and ECM remodelling. This effect is conceivably due to the progesterone component in OC. Therefore the use of OC not only diminishes pain symptoms in women with endometriosis, using OC might also be instrumental in reducing the risk to develop the disease. In future studies, the molecular mechanisms related to the findings of the present study should be investigated. 


\section{Acknowledgements}

The authors wish to acknowledge Mrs. Jacqueline Schouten for excellent technical assistance, and Mrs. Nathalie Sieben, gynaecopathologist, for the morphological assessment of the endometrial biopsies. Mr. Rick Kamps is acknowledged for his great work on the microarray analysis. 


\section{References}

Akande AV, Asselin J, Keay SD. Cahill DJ, Muttukrishna S, Groome NP and Wardle PG (2000) Inhibin A. inhibin B and activin A in follicular fluid of infertile women with tubal damage. unexplained infertility and emdometriosis. Am J Reprod immunol 43, 61-69

Bagnato A and Spinella F (2003) Emerging role of endothelin-1 in tumour angiogenesis. Trends Endocrinol Metab 14. 44-50

Barbara NP. Wrana JL and Letarte M (1999) Endoglin is an accessory protein that interacts with the signaling receptor complex of multiple members of the transforming growth factor-beta superfamily $J$ Biol Chem 274, 584-594

Bruner-Tran KL, Eisenberg E, Yeaman GR, Anderson TA, McBean J and Osteen KG (2002) Steroid and cytokine regulation of matrix metalloproteinase expression in endometriosis and the establishment of experimental endometriosis in nude mice J Clin Endocrinol Metab 87. 4782-4791

Chin D. Boyle GM, Parsons PG and Coman WB (2004) What is transforming growth factor beta (TGF- $\beta$ ) ? Br J Plastic Surg 57, 215-221

Darrow SL, Vena JE, Batt RE, Zielezny MA. Michalek AM and Selman S (1993) Menstrual cycle characteristics and the risk of endometriosis Epidemiology 4, 135-142'

DHooghe TM, Bambra CS, Suleman MA, Dunselman GAJ, Evers JLH andi Koninckx PR (1994) Development of a model of retrograde menstruation in baboons (Papio anubis) Fertil Stent 62, 635638

Deligdisch L (2000) Hormonal pathology of the endometrium Mod Pathol 13, 285-294

Dueng J. Nueckel H, Huettmann A, Kruse E. Hoelter T, Halfmeyer K, Fuehrer A, Rudolph R, Kalhori N. Nusch A, Deaglio S, Malavasi F, Moeroey T. Klein-Hitpass L and Duehrsen U (2003) Expression of ribosomal and translation-associated genes is correlated with a favorable clinical course in chronic lymphocytic leukemia Blood 101, 2748-55

Godkin JD and Dore JJ (1998) Transfroming growth factor and the endometrium. Rev Reprod 3, 1-6

Florio P. Luisi S, Vigano P. Busacca M. Fadalti Mt. Genazzani AR and Petraglia F (1998) Healthy women and patients with endometriosis show high concentrations of inhibin $A$, inhibin. $B$, and activin $A_{1}$ in peritoneal fluid throughout the menstrual cycle Hum Reprod 13, 2606-2611

Fujimoto J. Sakaguchi H. Hirose R. Wen H and Tamaya T (1999) Angiogenesis in endometriosis and angiogenic factors. Gynecol Obstet Invest 48 supp! 1, 14-20

Giudice LC and Irwin JC. (1999) Roles of the insulinlike growth factor family in, nonpregnant human endometrium and at the decidual trophoblast interface Semin Reprod Endocrinol 17. 13-21

Kim SH. Choi YM. Chae HD. Kim KR. Kim CH and Kang BM (2001) Increased expression of endoglin in the eutopic endometrium of women with endometriosis Fertil Stenl 76, 918-922

Maas JWM. Groothuis PG. Dunselman GAJ. De Goeij AFPM. Struijker Boudier HAJ and Evers. JLH. (2001) Development of endometriosis-like lesions after transplantation of human endometrial fragments onto the chick chorioallantoic membrane Hum Reprod 16, 627-631

Nap AW. Dunseiman GAJ. De Goeij AFPM. Evers JLH and Groothuis PG (2004) Inhibiting MMP activity prevents the development of endometriosis. in the chicken chorioallantoic membrane model Hum Reprod 19, 2180-2187

Nap AW. Griffioen AW, Dunselman GAJ, Bouma-ter Steege JCA. Thijssen VL.JL. Evers JLH and Groothuis PG (2004) Antiangıogenesis therapy for endometriosis. J Clin Endocrin Metab 89, 1089-1095

Nap AW. Groothuis PG, Demir AY, Maas JWM Dunseiman GAJ De Goeij AFPM and. Evers JLH (2003) Tissue integrity is essential for ectopic implantation of human endometrium in the chicken chorioallantoic membrane Hum Reprod, 18,30-3.4 
Osteen KG, Bruner KL and Sharpe-Timms KL. (1996) Steroid and growth factor regulation of matrix metalloproteinase expression and endometriosis. Semin Reprod Endocrin 14, 247.255.

Osteen KG, Igarashi TM and Bruner-Tran KL (2003) Progesterone action in the human endometrium: induction of a unique tissue environment which limits matrix metalloproteinase (MMP) expression . Front Biosci 8, d78-86.

Reis FM, Di Blasio AM, Florio P. Ambrosini G. Di Loreto C and Petraglia F (2001) Evidence for local production of inhibin $A$ and activin $A$ in patients with ovarian endometriosis. Fertil Steril 75, 367-373.

Sampson JA (1927) Peritoneal endometriosis due to menstrual disșemination of endometrial tissue into the peritoneal cavity. Am J Obstet Gynecol 14, 422-469.

Sanfilippo JS, Wakim NG, Schikler KN andl Yussman MA (1986) Endometriosis in association with uterine anomaly. Am J Obstet Gynecol 154, 39-43.

Seki N. Kodama J, Hashimofo 1, Hongo A Yoshinouchi M and Kudo T (2001) Thrombospondin-1 and -2 messenger RNA expression in normal and neoplastic endometrial tissues: correlation with angiogenesis and prognosis. Int J Oncol 19, 305-310.

Sharpe-Timms KL (2001) Endornetrial anomalies in women with endometriosis. Ann N Y Acad Sci 943 , $131-147$

Tabibzadeh S, Mason JM: Shea W. Cai Y, Murray MJ and Lessey B (2000) Dysregulated expression of ebaf, a nove! molecular defect in the endometria of patients, with infertility. J Clin Endocrinol Metab 85. 2526-2536.

Tayior RN, Lundeen SG and Giudice LC (2002a) Emerging role of genomics in endometriosis research. Fertile Steril 78, 694-698

Taylor RN, Lebovic Dl and Mue!ler MD (2002b) Angiogenic factors in endometriosis. Ann New York Acad Sciences 955: 89-100

Vercellini P. Fedele L. Pietropaolo G, Frontino G. Somigliana E and Crosignani PG (2003) Progestogens for endometriosis: forward to the past Hum Reprod Update 9, 387-396

Winkel CA (2003) Evaluation and management of women with endometriosis. Obstet Gynecol 102. 397. 408 


\section{Chapter 7}

\section{General Discussion}




\section{General Discussion}

Of the multiple theories put forward to explain the origin of endometriosis, most evidence points to the retrograde transplantation theory. According to this theory, endometriosis in the abdomen is the result of the ectopic implantation of endometrium, which has entered the peritoneal cavity via the Fallopian tubes during menstruation (Sampson, 1927). Little information is available about the actual events occurring during the period between the moment of the arrival of the endometrial tissue in the abdomen and the first appearance of endometriotic implants. In order to implant, the endometrial fragment must be viable, adhere to the peritoneum, degrade the extracellular matrix, invade, acquire a blood supply, and survive. To gain more insight in the behaviour of endometrial tissue under ectopic conditions, we employed two model systems: the ex vivo chicken embryo chorioallantoic membrane (CAM) model and the in vivo nude mouse model. The influence of the architecture of the endometrial tissue, of the matrix metalloproteinases (MMPs), of the process of angiogenesis, and of the steroid hormone exposure of the endometrium on the initial stages of endometriotic lesion formation were evaluated individually. The results of the studies and their possible clinical implications will be discussed in this chapter.

The CAM model is easily accessible and cheap. Since the immune system of the chicken does not function until day 17 of development, it is possible to transplant human endometrium onto the CAM and to study the behaviour of this tissue in an ectopic environment. The extracellular matrix constitution of the CAM is similar to that of the peritoneum, the structure onto which the endometrium is supposed to attach prior to the implantation of the endometrial fragment. Both peritoneum and CAM contain the collagen types I and IV, laminin, and fibronectin (Giannopoulou et al., 2001; Witz et al., 2001). However, the CAM only partially reflects processes in the human peritoneum, because the peritoneurn is exposed to hormones and local intra-abdominal environmental influences, including factors from the immune system, which are absent in the CAM. This may be considered a drawback of the CAM model. On the other hand, the lack of exposure to these local factors in the CAM does allow the study of individual processes that may contribute to lesion development without interference of the immune system.

In contrast to human amnion membranes and peritoneum that have been used to study adhesion of endometrial cells and tissue (Groothuis et al.. 1998; 1999), the CAM model allows the study of invasive behaviour and angiogenic potential of cells (Scher et al., 1976; Armstrong et al., 1982). In endometriosis research, the CAM model has mainly been used for observational studies. Our group demonstrated that 
transplantation of human endometrial fragments onto the CAM induces angiogenesis and results in the formation of endometriosis-like lesions in the CAM mesenchyme (Maas et al., 1999; 2001). A vascular density index (VDI) system was validated for the quantification of the number of vessels in the CAM (Maas et al., 1999). Recently, the expression of angiopoietins-1 and -2 (Drenkhahn et al., 2004) and MMP-1 and -2 (Wolber et al., 2003) by ectopic endometrium transplanted onto the CAM has been demonstrated. In the present thesis $s_{v}$ the CAM model has been used for intervention studies in order to investigate different mechanisms potentially involved in the development of endometriosis.

The interaction between stroma and epithelium is essential for the normal functioning of endometrial tissue (Buchanan et al., 1999). Therefore, it was postulated that the endometrial tissue architecture is an important determinant of the behaviour of the endometrium during the process of implantation. In previous studies in our laboratory it was shown that single endometrial cells isolated from menstrual effluent were not invasive when transplanted on the CAM, whereas the transplantation of intact tissue fragments. of human endometrium resulted in the development of endometriosis-like lesions in the CAM mesenchyme (Maas et al., 2001). In the study presented in this thesis, dispersed menstrual endometrial cells did not invade the epithelium of the CAM, whereas biopsied endometrial tissue from all phases of the menstrual cycle and larger endometrial fragments manually picked from antegradely shed menstrual effluent led to the development of endometriosislike lesions. These findings are in accordance with the observations of Sillem and co-workers who demonstrated in a cynomolgus monkey model that collagenase. digestion of endometrial tissue fragments prior to transplantation reduced their ability to implant ectopically (Sillem et al., 1996). We conclude that tissue integrity. and architecture are important for the ectopic implantation of endometrium. This supports the clinical observation that women shedding larger, intact enclometrial fragments in their menstrual effluent are more prone to develop endometriosis (Darrow et ail., 1993).

Immunohistochemical staining performed in the study presented in this thesis showed that almost all MMPs, which are enzymes involved in extracellular matrix degradation, are expressed in peritoneal endometriosis and endometriosis of the rectovaginal space. There is still discussion whether the MMPs in endometriosis are expressed as a. cause or as a. consequence of the disease, and whether they are. functionally involved in the pathogenesis of endometriosis. The establishment of a functional role of MMPs is crucial to understand the relevance of the presence of these proteins in endometriotic lesions. This was evaluated in the CAM model. Immunohistochemical stạining of menstrual endometrial tissue which was transplanted onto the CAM, and of the endometriosis-like lesions formed from this 
endometrium revealed that there was no change in the expression level of MMPs during endometriosis-like lesion formation. Inhibiting MMP activity with an inhibitor of MMP's (metalloproteinase inhibitor, MPI) $-1,-2,-3,-7$ and -13 significantly reduced the number of endometriosis-like lesions that developed in the CAM. As specific inhibitors are only available for a few MMPs, an MPI has been selected which inhibits the MMPs that were most prominently expressed in the menstrual endometrium. The results of this experiment suggest that the MMPs which were inhibited by this MPI are crucial in the formation of the endometriosis-like lesions. However, in a limited number of CAMs, endometriosis-like lesions were still formed despite the administration of the MPI. This indicates that other MMPs, which were not inhibited, may also play a role in the formation of endometriosis, or, that other compensatory mechanisms are operative. Since MMPs are known to interact with, activate or inhibit each other, it is only possible to elucidate their exact role in the process of the early pathogenesis of endometriosis by selective silencing or inactivation. In animal studies, different MPIs showed promising results in inhibiting tumour progression (Zervox et al., 2000; Bello et al., 2002), as well as endometriotic lesion formation (Bruner et al., 1997). Thus far, however, clinical results have been disappointing (reviewed in Coussens et al., 2002).

In the present thesis evidence is provided to support the contention that angiogenesis is a prerequisite for the development of endometriosis-like lesions, as inhibition of angiogenesis in the CAM inhibited the vascularisation and impaired endometriosis-like lesion formation. The presence of nucleated, avian erythrocytes in the vessels in and around the endometriosis-like lesions shows that the vessels are of avian origin. Grümmer and co-workers demonstrated that the new blood vessels formed in endometriosis-like lesions in the nude mouse are of murine origin (Grümmer et al., 20101). This finding is in accordance with the origin of the blood supply in malignant tumours, which is also obtained from the host environment (Taraboletti and Giavanni, 2004). Apparently, blood vessels from the surrounding tissue are feeding the endometrium in the ectopic location, and inhibiting these vessels may prevent the endometrium from surviving in an ectopic location.

The CAM is fully developed on day 10 of incubation, and from that moment onwards human endometrial tissue can be transplanted onto the CAM. Seven days later the inmune system of the chick starts to function and transplanted human tissue will be rejected (Seto, 1971). Therefore, the CAM is not suitable to study growth of the endometriosis-like lesion after its initial development. In order to be able to study the role of the vasculature in endometriosis after implantation of the endometrial fragment and the development of the endometriotic lesion, a different model system had to be selectedl. Primates with a menstrual cycle and endometriosis, such as the cynomolgus monkey or the baboon, would be most appropriate to study. However. 
the possibilities of using primates for research are limited due to ethical and financial considerations. Instead, mainly rodents have been used for the in vivo study of the pathogenesis of endometriosis. But as rodents do not shed endometrium, they do not develop endometriosis. Hence, endometriosis-like lesions have been induced experimentally. The immunodeficient status of nude mice makes it possible to transplant human endometrium and induce endometriosis (Zamah et al., 1984: Bergqvist et al., 1985). Transplanted endometrium develops into endometriosis-like lesions that have morphological characteristics of human endometriosis (Nisolle et al., 2000). The nude mouse model has been validated for the study of endometriosis over extended periods of time (Grümmer et al., 2001), and is therefore useful for intervention studies (Bruner et al., 1997; Hull et al., 2003). A possible drawback of this model is that the local chronic inflammatory response as has been described in human endometriosis is lacking in experimentally induced endometriosis in nude mice because of the deficient immunesystem.

In the study presented in this thesis, uncultured human endometrium was transplanted into nude mice, endometriotic lesions were allowed to develop and subsequently anti-angiogenic agents were administered. Part of the lesions that had developed disappeared and neo-vascularisation was impaired, indicating that established lesions are dependent on angiogenesis in order to survive. Side effects of the angiostatic agents appeared to be limited, as wound healing was normal in all mice, and the body weight as well as the weight of the uterus did not differ between the groups of mice. Moreover, vascularisation of the uterus was not impaired after the administration of anti-angiogenic agents. The results of the studies presented in this thesis regarding the interference with angiogenesis in endometriosis indicate that angiostatic therapy may be promișing in order to prevent? new endometriosis, to treat established endometriosis, and to prevent recurrence of the disease after surgical or hormonal treatment. Avastin, an angiostatic agent which has alreacly been applied successfully in cancer patients. (Rini et al:, 2004) should be considered for the treatment of endometriosis.

Endometrium that has been exposed to exogenous steroid hormones in vivo, e.g. by the use of oral contraceptives (OC) was shown ta have a reduced capacity to form endometriosis-like lesions in the CAM. Prolonged progesterone exposure of the endometrium prior to transplantation apparently impairs endometriosis-like lesion formation. To gain more insight in the underlying mechanisms, gene expression profiles of menstrual endometrium and OC exposed endometrium were compared. Various matrix metalloproteinases and angiogenic factors were expressed at lower levels in the endometrium exposed to $O C$ as compared to menstrual endometrium. These results support the earlier findings in this thesis that MMPs and angiogenesis are pivotal to the development of endometriosis. 
In synthesis, the abundance of MMPs and VEGF in menstrual endometrial fragments facilitates implantation of these fragments and creates their bloodsupply after implantation. Steroid hormone exposure impairs the potential of human endometrium to form endometriotic lesions by affecting the expression of gene transcripts involved in matrix remodelling and angiogenesis. Based on these findings it is postulated that tissue integrity, matrix remodelling, angiogenesis and steroid hormone regulation work in concert in the complicated process of ectopic implantation of endometrium.

\section{Future perspectives}

Irrespective of the obvious drawbacks, we consider both the ex vivo CAM model and the in vivo nude mouse model reliable models for the study of different aspects of the development of endometriosis and for evaluation of the efficacy of new agents to treat endometriosis. Interesting agents might be metalloproteinase inhibitors (MPIs), novel angiostatic agents, selective progesterone receptor modulators (SPRMs), and non-steroidal anti-inflammatory drugs (NSAIDs), including cyclooxygenase-2 (COX-2) inhibitors. Agents achieving satisfying results in the CAM model and in nude mouse experiments may subsequently be tested in primate models, and eventually in clinical studies.

The study of angiostatic therapy in mice as presented in this thesis has to be extended before application in women can be considered. The effects of angiostatic agents on fertility and outcome of pregnancy should be investigated, in order to see whether these agents can be given safely to women in their fertile years. Effects of angiostatic agents on the fertility of the mice, on pregnancy duration, number of animals born, number of animals alive and development of the animais could be endpoints of this sludy.

The effect of adjuvant angiostatic therapy for established endometriotic lesions in mice that have been treated surgically or hormonally, should be investigated. Angiostatic adjuvant treatment might eventually lead to a more effective suppression, or prevention of recurrence, of endometriosis in women.

Gene expression profiling may be a promising way to identify mechanisms involved in the pathogenesis of endometriosis. Studies should be undertaken in order to confirm the results of the study in the present thesis. Prospectively collected human endometrium should be tested for the expression of the identified genes. In combination with laser capture micro-dissection, which allows selection of individual cells or groups of cells, gene expression programs, may be studied during the initiation and progression of ectopic implantation of endometrium. Recent studies using gene array technology comparing endometriosis and endometrial tissue 
demonstrated differentially expressed genes encoding for tumour suppression (Arimoto et al., 2003) and for cell cycle regulation (Lebovic et al., 2002).

Human antibodies selectively targeting angiogenic vessels may be promising for the immunotherapy of endometriosis and can help to elucidate the molecular mechanisms regulating angiogenesis in the disease. Using a phage display library on endometriosis-specific angiogenesis, antibodies may be isolated which target the vasculature of the endometriosis lesions. The selected antibodies might turn out to be useful tools for diagnostic imaging, as prognostic markers, and as therapeutic targets.

The CAM model and the nude mouse model have unique properties which can be used to investigate new questions raised by the present thesis. Complete inhibition of endometriotic lesion formation was not observed after administering angiostatic agents or MMP inhibitors, or after the transplantation of endometrium that had been exposed to steroids in vivo. This suggests that these mechanisms act logether, or that other mechanisms may be involved. The complex way in which these mechanisms act in concert has to be investigated. This can be done by inhibiting one mechanism and study the effect of this inhibition on other mechanisms possibly involved. In addition, other mechanisms, particularly those related to chronic inflammation have to be assessed. In order to mimic the human situation as closely as possible, future studies should preferably be performed in a primate model for endometriosis. 


\section{References}

Absenger Y, Hess-Stumpp H, Kreft B, Krātzschmar J, Haendler B, Schûtze N, Regidor P-A and Winterhager E (2004) Cyr61, a deregulated gene in endometriosis. Molec Hum Reprod 10, 399-407.

Arimoto $T$, Katagiri T, Oda $K$, Tsunoda $T$, Yasuhi T, Osuga $Y$, Yoshikawa H, Nishii O, Yano T, Taketani $Y$ and Nakamura $Y$ (2003) Genome-wide cDNA microarray analysis of gene-expression profiles involved in ovarian endometriosis. Int J Oncol 22, 551-560

Armstrong PB, Quigley JP and Sidebottom E (1982) Transepithelial invasion and intramesenchymal infiltration of the chick embryo chorioallantois by tumour cell lines. Cancer Res, 42, 1826-1837

Bello L. Giussani C, Carrabba G. Pluderi M. Lucini V. Pannacci M. Caronzolo D. Tomei G, Villani R. Scaglione F. Carroll RS and Bikfalvi A (2002) Suppression of malignant glioma recurrence in a newly developed animal model by endogenous inhibitors. Clin Cancer Res 8, 3539-35.48

Bergqvist A, Jeppson S and Kullander S (1985) Human endometrium transplanted into nude mice. Histologic effects of various steroid hormones. Am J Pathol 119, 336-344.

Bruner KL, Matrișian LM, Rodgers WH, Gorstein F and Osteen KG (1997) Suppression of matrix metalloproteinases inhibits establishment of ectopic lesions by human endometrium in nude mice. J Clin Invest 99, 2851-2857

Buchanan DL. Setiawan T. Lubahn DB, Taylor JA, Kurita T, Cunha GR and Cooke PS (1999) Tissue compartment-specific estrogen receptor-aipha participation in the mouse uterine epithelial secretory response Endocrinology 140, 484-491

Coussens LM. Fingleton B and Matrisian LM (2002) Matrix metalloproteinase inhibitors and cancer: trials and tribulations Science 295, 2387-2392

Darrow SL, Vena JE, Batt RE. Zielezny MA. Michalek AM and Selman S (1993) Menstrual cycle characteristics and the risk of endometriosis Epidemiology 4 . 135-142

Drenkhahn M. Gescher DM. Wolber EM. Meyhofer-Malik A and Malik E (2004) Expression of angiopoietin 1 and 2 in ectopic endometrium on the chicken chorioallantoic membrane. Fertil Stenl 81 suppl 1,869875

Giannopoulou E, Katsoris P. Hatziapostolou M. Kardamakis D, Kotsaki E, Polytarchou C, Parthymou A. Papaioannou S and Papadimitriou E (2001) X-rays modulate extracellular matrix in vivo. Int J Canceer $94.690-698$

Groothuis PG, Koks CAM. De Goeij AFPM, Dunselman GAJ. Arends JW and Evers JLH (1998) Adhesion of human endometrumi to the epithelial lining and extracellular matrix of amnio in vitro an electron microscopic study Hum Reprod 13, 2275-2281

Groothuis PG. Koks CAM. De Goeij AFPM, Dunselman GAJ. Arends JW and Evers JLH (1999) Adhesion of human endometrial fragments to peritoneum in vitro Fertil Steri! 71, 1119-1124

Grümmer R. Schwarzer F. Bainczyk. K. Hess-Stumpp H. Regidor P-A, Schindler AE and Winterhager E (2001) Peritoneal endometriosis validation of an in-vivo model Hum Reprod 16. 1736-1743

Hull ML. Charnock-Jones DS, Chan CLK, Bruner-Tran KL. Osteen KG, Tom BDM, Fan TD and Smith SK (2003) Antiangiogenic agents are effective inhibitors of endometriosis J Clin Endocr Metab 88. 28892899

Lebovic Di, Baldocchi RA, Mueller MD and Taylor RN (2002) Altered expression of a cell-cycle suppressor gene, Tob- 1 , in endometnotic cells by cDNA array analyses Fertil Steril 78, 849-854

Maas JWM. Le Noble FAC, Dunselman GAJ, De Goej AFPM, Struijker Boudier HAJ and Evers JLH (1999) The chick chorioallantoic membrane as a model to investigate the angiogenic properties of human endometrium Gynec Obstet Invest 4. 108-112 
Maas JWM. Groothuis PG, Dunseiman GA.J. De Goeil AFPM, Struijker Boudier HAJ and Evers JL.H (2001) Development of endometriosis-like lesions after transplantation of human endometrial fragments onto the chick embryo chorioallantoic membrane Hum Reprod 16, 627-631.

Nisolle M. Casanas-Roux F and Donnez J (2000) Early-stage endometriosis adhesion and growth of human menstrual endometrium in nude mice Fertil Steril 74 :306-312

Rini BI. Halabi S, Taylor J, Small EJ and Schilsky RL (2004) Cancer and Leukemia Group B 90206: a randomised phase III trial of interferon-alpha or interferon-alpha plus anti-vacsular endothelial growth factor antibody (bevacizumab) in metastatic renal cell carcinoma. Clin Cancer Res 10, 2584-2586.

Sampson JA (1927) Peritoneal endometriosis due to the menstrual dissemination of endometrial tissue into the peritoneal cavity Am J Obstet Gynecol 14, 422-469.

Scher CD. Haudenschild C and Klagsbrun M (1976) The chick chorioallantoic membrane as a model system for the study of tissue invasion by viral transformed cells Cell 8, 373-382

Seto $F$ (1971) Allograft reactivity in chick embryo's. J Exp Zool 177, 343-352

Sillem M. Hahn U. Coddington CC $3^{\prime \prime}$, Gordon K, Runnebaum B and Hodgen GD (1996) Ectopic growth of endometrium depends on its structural integrity and profeolytic activity in the cynomolgus monkey (Macaca Fascicularis) model of endometriosis Fertil Steril 66, 351-353

Taraboletti G and Giavazzi R (2004) Modelling approaches for angiogenesis Eur J Cancer 40, 881-889

Witz CA, Montoya-Rodriguez IA, Cho S, Centonze VE, Bonewald LF and Schenken RS (2001) Composition of the extracellular matrix of the peritoneum. J Soc Gynecol Investig 8. 299-304

Wolber EM. Kressin P. Meyhofer-Malik A. Diedrich K and Malik E (2003) Differential induction of matrix metalloproteinase 1 and 2 in ectopic endometrium Reprod Biomed Online 6. 238-243.

Zamah NM, Dodson MG, Stephens LC, Buttram VC jr. Besch PK, Kaufman RH (1984) Transplantation of normal and ectopic human endometrial tissue into athymic nude mice. Am J Obstet Gynecol 149, 591 . 597

Zervox EE, Franz. MG, Salhab KF, Shafil AE, Menendez J, Gower WR and Rosemurgy AS (2000) Matrix metalloproteinase inhibition improves survival in an orthotopic model of human pancreatic cancer J Gastrointest Surg 4, 614-619 


\section{Summary}

Endometriosis, the presence of endometrium outside the uterus, is one of the most frequently' encountered benign problems in gynaecology. Pathologists and gynaecologists have been puzzled about the phenomenon of ectopic endometrium since its first description, and until now the pathogenesis is still poorly understood. This thesis aims to shed light on different aspects of early endometriotic lesion formation.

In Chapter 1 the prevailing theories regarding the pathogenesis of endometriosis are summarized. Eventsi in early endometriotic lesion formation are described in detail, focussing on invasion, on the role of matrix metalloproteinases (MMPs) and on angiogenesis. In addition, the hypothesis and aims of this thesis are formulated

In Chapter 2 the influence of tissue integrity on the success of infiltration and endometriosis-jike lesion formation in the chicken chorioallantoic membrane (CAM) model is clescribed. Endometriosis-like lesion formation was evaluated after transplantation of endometrium of the menstrual and non-menstrual phase of the cycle. Biopsied endometrial fragments and fragments of shed menstrual endometrium that were larger than $1 \mathrm{~mm}^{3}$ in size infiltrated the CAM and formed endometriosis-like lesions 72 hours after transplantation. Transplantation of single menstrual endometrial cells did not result in endometriosis-like lesion formation.

112 This study suggests that an intact tissue architecture of endometrium, which consists of arganized glandular epithelium and stroma, is crucial for the ability of endometriurn to form lesions:

In Chapter 3 the suitability of the CAM model for evaluating expression and function of MMPs during early endometriotic lesion formation is describeci. The expression of MMPs in menstrual endometrium, in human endometriosis, and in endometriosislike lesions in the CAM model was investigated using immunohistochemical staining. Almost all MMPs investigated were expressed in endometrium as well as in human endometriosis and in endometriosis-like lesions in the CAM. No significant: differences were present in the expression of the majority of the MMPs investigated when comparing human endometriosis and endometriosis-like lesions in the CAM. This indicates that the MMP expression profile of human endometriosis reflects that of experimentally induced endometriosis in the CAM. Thereafter, MMP function in early lesion formation was studied by application of an inhibitor of MMP activity after transplantation of endometrium onto the CAM. The application of the MMP-inhibitor resulted in significant impaired endometriosis-like lesion formation. This study 
demonstrates that the CAM model can be used to evaluate the involvement of MMPs in the development of lesions, and that MMPs are important in the pathogenesis of endometriosis.

In Chapter 4 the effect of the angiostatic agents TNP-470, anti-human VEGF, endostatin and anginex on endometriosis-like lesion development in the CAM model is described. The angiostatic agents were applied onto the CAM after transplantation of human endometrial fragments. Vascularisation of the CAMs, endometriosis-like lesion formation in CAMs and morphology of the endometriosislike lesions were assessed 72 hours after transplantation of the tissue onto the CAM. The vascularisation of the CAMs was significantly impaired as a result of administration of angiostatic agents, as was endometriosis-like lesion formation. The percentage of necrosis in endometriosis-like lesions was significantly higher in CAMs onto which angiostatic agents were applied. This study strengthens the concept that angiogenesis is a prerequisite for the development of endometriosis lesions.

In Chapter 5 a study is presented using angiostatic agents to investigate the importance of angiogenesis in endometriotic lesions which already have developed. referred to as established endometriosis. To this end, human endometrial fragments were transplanted subcutaneously and intra-abdominally in nude mice and allowed to develop into endometriosis lesions for 3 weeks. Then the angiostatic agents were administered for a period of 2 weeks. The number of endometriotic lesions was significantly lower in mice treated with angiostatic agents. In these mice, a significantly lower number of newly formed vessels was present in the lesions compared to contro! mice to which no angiostatic agents had been administered. The number of mature, smooth muscle cell protected vessels did not differ between the groups, indicating that the vessels that regressed were the newly developed ones. These results suggest that angiogenesis is pivotal for the maintenance of endometriotic lesions, and that angiostatic therapy may be promising as a future treatment option for women with endometriosis.

In Chapter 6 characteristics of endometrium exposed to oral contraceptives (OC) were compared to those of menstrual endometrium. Human OC exposed endometrium and menstrual endometrial fragments were transplanted onto the CAM, and endometriosis-like lesion formation was evaluated. Exposure to $O C$ caused an impaired capacity to develop endometriosis-like lesions in the CAM. In order to find an explanation for the different behaviour of OC exposed endometrium and menstrual endometrium after transplantation onto the CAM, microarray gene expression profiling was performed to identify differentially expressed genes. This analysis revealed a marked decrease in the expression of genes encoding for 


\section{Summary}

various matrix metalloproteinases, members of the TGF- $\beta$ superfamily and regulators of angiogenesis in OC exposed endometrium as compared to the expression of genes in menstrual endometrium. Conceivably, the progesterone component in $O C$ is responsible for the effect on the endometrium, rendering it less suitable for implantation in ectopic locations.

In Chapter 7 the results of this thesis are discussed. Perspectives for future studies are given. 


\section{Samenvatting}

Endometriose. gedefinieerd als de aanwezigheid van endometrium buiten de uterus, is een van de meest voorkomende goedaardige afwijkingen in de gynaecologie. Pathologen en gynaecologen hebben zich het hoofd gebroken over het fenomeen van ectopisch endometrium sinds de eerste beschrijving ervan, maar de pathogenese van endometriose is nog niet volledig achterhaald. In dit proefschrift worden verschillende aspecten van deze pathogenese belicht.

In Hoofdstuk 1 worden de gangbare theorieèn omtrent de pathogenese van endometriose samengevat. De stappen in het ontstaan van de endometrioselaesie worden in detail beschreven, waarbij de nadruk wordt gelegd op de rol van invasie. van matrix metalloproteinases (MMPs) en op die van angiogenese. Tevens worden de hypothese en doelstellingen van dit proefschrift geformuleerd.

In Hoofdstuk 2 wordt de invloed van een intacte weefselstructuur van het endometrium op het succes van infiltratie en het ontstaan van endometriose beschreven in het chorioallantoìs membraan (CAM) model van de kip. Het ontstaan van endometriose-achtige laesies werd geëvalueerd na transplantatie van endometrium van de menstruele fase en van de niet-menstruele fase van de cyclus. Gebiopteerde stukjes endometrium en fragmenten van afgescheiden menstrueel endometrium die groter waren dan $1 \mathrm{~mm}^{3}$ infiltreerden het CAM en vormden endometriose-achtige laesies 72 uur na het. opbrengen van het endometrium. Opbrengen van individuele cellen van menstrueel endometrium resulteerde niel in vorming van endometriose-achtige laesies. Deze studie malakt aannemelijk dat een intacte weefselstructuur van het endometrium, dat bestaat uit georganiseerd klierbuisepitheel en stroma, cruciaal is voor het vermogen van endometrium om laesies te vormen.

In Hoofdstuk 3 wordt beschreven dat het CAM model geschikt is om de expressie en functie van MMPs bij het ontstaan van endometriose te evalueren. De immunohistochemische expressie van MMPs in menstrueel endometrium " in humane endometriose en in endometriose-achtige laesies in het CAM model werd onderzocht. Bijna alle onderzochte MMPs kwamen tot expressie in endometrium, in humane endometriose en in endometriose-achtige laesies. Er waren geen significante verschillen wanneer de expressie van MMPs in humane endometriose vergeleken werd met die in endometriose-achtige laesies in het CAM. Dit wijst erop dat het MMP expressiepatroon van humane endometriose bij benadering gelijk is aan dat van experimentele endometriose. De functie van MMPs in de vroege 
ontwikkeling van endometrioselaesies werd onderzocht door een MMP remmer toe te dienen na transplantatie van humaan endometrium op het CAM. De toediening van een MMP remmer resulteerde in een significante vermindering van de vorming van endometriose-achtige laesies.

Deze studie toont aan dat het CAM model geschikt is voor de evaluatie van de betrokkenheid van MMPs in de ontwikkeling van endometriose en dat MMPs van belang zijn in het ontstaan van endometriose.

In Hoofdstuk 4 wordt het effect beschreven van de angiostatische middelen TNP470, anti-humaan VEGF, endostatine en anginex op de ontwikkeling van endometriose-achtige laesies in het CAM model. De angiostatische middelen werden toegediend na transplantatie van humane endometriumfragmenten op het CAM. De vascularisatie van de CAMs, de vorming van endometriose-achtige laesies en de morfologie van de laesies werden beoordeeld 72 uur na transplantatie van hel weefsel op het CAM. De vascularisatie van de CAMs en de vorming van endometriose-achtige laesies in de CAMs was significant verminderd als gevolg van de toediening van angiostatische middelen. Necrose in de endometriose-achtige laesies was significant hoger in CAMs waaraan angiostatische middelen waren toegediend. Deze studie versterkt de eerder gevonden aanwijzingen dat angiogenese een voorwaarde is voor de ontwikkeling van endometrioselaesies.

In Hoofdstuk 5 wordt een studie gepresenteerd waarin gebruik gemaakt wordt van angiostatische middelen om het belang van angiogenese te onderzoeken in al langer bestaande endometriose. Daartoe werden humane endometrium fragmenten getransplanteerd onderhuids en in de buikholte van immunodeficiënte (naakte) muizen. Na 3 weken ontstonden endometrioselaesies. Vervolgens werden gedurende 2 weken angiostatische middelen toegediend. Het aantal endometrioselaesies was significant lager in muizen die behandeld werden met angiostatische middelen. In deze endometrioselaesies was een significant lager aantal nieuw ontwikkelde bloedvaten aanwezig vergeleken met de endometrioselaesies in muizen in de controlegroep die geen angiostatische middelen toegediend hadden gekregen. Het aantal mature, door pericyten beschermde bloedvaten was niet verschillend in de endometrioselaesies van beide groepen. Dit wijst erop dat de vaten die verdwenen de nieuw ontwikkelde vaten waren. Deze resultaten suggereren dat angiogenese essentieel is voor het voortbestaan van endometriose, en dat angiostatische therapie veelbelovend zou kunnen zijn als behandeling van endometriose.

In Hoofdstuk 6 worden eigenschappen van endometrium dat is blootgesteld aan orale anticonceptiva (pil endometrium) vergeleken met die van menstrueel endometrium. Pil endometrium en menstrueel endometrium werd getransplanteerd 
op het CAM, en het ontstaan van endometriose-achtige laesies werd onderzocht. Wanneer endometrium dat is blootgesteld aan de pil werd opgebracht op het CAM, kwamen minder endometriose-achtige laesies tot ontwikkeling. Om een verklaring te vinden voor het verschillende gedrag van pil endometrium en menstrueel endometrium na transplantatie op het CAM werd microarray genexpressie analyse uitgevoerd om genen te identificeren die op verschillende wijze tot expressie komen. Deze analyse toonde aan dat er in pil endometrium een belangrijke vermindering is in de expressie van een aantal genen coderend voor verscheidene MMPs, leden van de transforming growth factor (TGF) $\beta$ familie en regulatoren van angiogenese vergeleken met menstrueel endometrium. Het is aannemelijk dat de progesteroncomponent in de pil verantwoordelijk is voor dit effect op het endometrium, waardoor het minder goed in staat is om op een ectopische plaats te implanteren.

In Hoofdstuk 7 worden de resultaten van deze thesis bediscussieerd en worden perspectieven voor toekomstige studies gegeven. 


\section{Abbreviations}

\begin{tabular}{|c|c|}
\hline ANG & angiopoietin \\
\hline bFGF & basic fibroblast growth factor \\
\hline BMP-2 & bone morphogenetic protein-2 \\
\hline $17-\beta H S D$ & $17-\beta$ hydroxysteroid dehydrogenase \\
\hline CAM & chorioallantoic membrane \\
\hline $\operatorname{cox}$ & cyclooxygenase \\
\hline $\mathrm{Ct}$ & cycle threshold \\
\hline Cyclo-A & cyclophillin-A \\
\hline DAB & diaminobenzidin \\
\hline DMEM & Dulbecco's modified Eargle's medium \\
\hline DNA & decixy ribo nucleic acid \\
\hline EBAF & endometrium bleeding associated factor \\
\hline E-cadherin & epithelial cadherin \\
\hline EC & endothelial cell \\
\hline ECM & extracellular matrix \\
\hline EDRNB & endothelin receptor type B \\
\hline EGF & epidermal growth factor \\
\hline ET-1 & endothelin-1 \\
\hline GnRH & gonadotrophin releasing hormone \\
\hline HB-EGF & heparin binding-epidermal growth factor \\
\hline H\&E & haematoxylin and eosin \\
\hline ICAM-1 & intracellular adhesion molecule-1 \\
\hline IGFBP-1 & insulin-like growth factor binding protein-1 \\
\hline IL & interleukin \\
\hline MBP & myelin basic protein \\
\hline ME & menstrual endometrium \\
\hline MIF & macrophage inhibitory factor \\
\hline MMP & matrix metalloproteinase \\
\hline $\mathrm{MPI}$ & metalloprotteinase inhibitor \\
\hline MT-MMP & membrane type MMP \\
\hline MW & molecular weight \\
\hline NK cell & natural killer cell \\
\hline NRP & neuropilitin \\
\hline NSAID & non-steroidal anti inflammatory' drug \\
\hline $\mathrm{OC}$ & oral contraceptives \\
\hline
\end{tabular}




$\begin{array}{ll}\text { PAI } & \text { plasminogen activator inhibitor } \\ \text { PBS } & \text { phosphate-buffered saline } \\ \text { PDGF } & \text { platelet-derived growth factor } \\ \text { PGE }_{2} & \text { prostaglandin } E_{2} \\ \text { PIGF } & \text { placental growth factor } \\ \text { PI } & \text { protein inhibitor } \\ \text { PMN } & \text { polymorph nuclear neutrophils } \\ \text { qRT-PCR } & \text { quantitative reverse transcriptase polymerase chain reaction } \\ \text { RNA } & \text { ribo nucleic acid } \\ \text { SI } & \text { staining index } \\ \text { aSMA } & \alpha \text { smooth muscle actin } \\ \text { SPRM } & \text { selective progesterone receptor modulators } \\ \text { Tie } & \text { tyrosine kinase receptor } \\ \text { TGF- } \beta & \text { transforming growth factor- } \beta \\ \text { TIMP } & \text { tissue inhibitor of MMP } \\ \text { TNF- } \alpha & \text { tumour necrosis factor- } \alpha \\ \text { UPA } & \text { urokinase-type plasminogen activator } \\ \text { VDI } & \text { vascular density index } \\ \text { VEGF } & \text { vascular endothelial growth factor } \\ \text { VWF } & \text { von Willebrand Factor }\end{array}$


Appendix 1. Characteristics of antibodies against MMPs and TIMPS, used for immunohistochemical stainings as described in chapter 3. (Source: Oncogene, La Jolla, CA, USA).

\begin{tabular}{|c|c|c|c|c|c|c|c|c|c|}
\hline $\begin{array}{l}\text { MMPI } \\
\text { TIMP }\end{array}$ & $\begin{array}{l}\text { Antibody: } \\
\text { polyl } \\
\text { monocional }\end{array}$ & $\begin{array}{l}\text { Recognizes latentlactive } \\
\text { MMP }\end{array}$ & host & clone & isotype & dilution & $\begin{array}{l}\text { Incubation } \\
\text { over night / } \\
2 \text { hours } \\
\text { room } \\
\text { femperature }\end{array}$ & $\begin{array}{l}\text { Pres } \\
\text { sure } \\
\text { cook }+\%\end{array}$ & CAT-no \\
\hline 1 & 1 (mono) & Latent and active & mouse & 41-1E5 & $\lg G_{2}$ & $1: 400$ & On & * & IM35L \\
\hline 2 & 3 (mono) & Latent and active & mouse & $42 \cdot 5011$ & $\lg G_{1}$ & $1: 100$ & On & - & IM33L \\
\hline 3 & 2 (mono) & Latent and active & mouse & 148-1A3 & $\lg \mathrm{G}$, & $1: 20$ & On & + & IM45L. \\
\hline 7 & 2 (mono) & $\begin{array}{l}\text { Active (recognizes no pro- } \\
\text { MMP7) }\end{array}$ & mouse & $176-5512$ & $\lg G_{1}$ & $1: 100$ & On & + & IM47L \\
\hline 8 & 1 (mono) & Latent and active & mouse & $115-13 \mathrm{D} 2$ & $\lg G$ & $1: 20$ & On & - & IM38L \\
\hline 9 & 1 (mono) & $\begin{array}{l}\text { Latent and active (latent only } \\
\text { under reducing conditions); } \\
\text { inhibits enzymatic activity of } \\
\text { MMP.g }\end{array}$ & mouse & $6-68$ & $\lg G$, & 1.50 & On & - & IMO9L \\
\hline 10 & 3 (mono) & $\begin{array}{l}\text { Latent and active (under } \\
\text { reducing conditions) }\end{array}$ & mouse & VC3 & $\lg G$ & $1: 20$ & 2h RT & . & IM76 \\
\hline 11 & 2 (mono) & Latent and active & mouse & SL3-05 & $\lg G$, & $1: 100$ & On & - & IM86. \\
\hline 13 & 1 (mono) & Latent and active & mouse & $\begin{array}{l}181 . \\
15 A 12\end{array}$ & $\lg G$ & 1.50 & On & ? & IM44L. \\
\hline $\begin{array}{l}14 \\
\text { (MT 1. } \\
\text { MMP) }\end{array}$ & 3 (mono) & $\begin{array}{l}60 \text { and } 66 \mathrm{kDA} \text { forms of } \\
\text { MT1-MMP }\end{array}$ & mouse & \14-6G6 & $\lg G: 6$ & $1: 125$ & On & - & IM42L \\
\hline $\begin{array}{l}15 \\
\text { (MT2. } \\
\text { MMP) }\end{array}$ & 1 (mono) & $\begin{array}{l}68 \text { and } 62 \text { kDA forms of } \\
\text { MT2-MMP (dioes not react } \\
\text { with MT1-MMP or MT3- } \\
\text { MMP) }\end{array}$ & mouse & $162.22 \mathrm{G5}$ & $\lg _{w_{6}}$ & $1: 10$ & On & - & IM48L. \\
\hline $\begin{array}{l}16 \\
(\mathrm{MT3}- \\
\text { MMP) }\end{array}$ & 1 (mono) & $\begin{array}{l}60 \text { kDA human MT3-MMP } \\
\text { (does not cross-react with } \\
\text { human MT1-MMP or MT2. } \\
\text { MMP) }\end{array}$ & mouse & $117 \cdot 10 \mathrm{C} 6$ & $\lg G$ & $1: 10$ & $2 \pi R T$ & . & IMSOL \\
\hline 23 & 1 (poly) & Inhibited by TIMP-1 & rabbit & $?$ & $\lg G$ & 1.20 & On & + & PCA70 \\
\hline timp 1 & 1 (mono) & $\begin{array}{l}\text { TIMP. } 1 \text { is found in low } \\
\text { amounts in most cells and } \\
\text { tissues Reacts with } \\
\text { MMP-TIMP. } 1 \text { complexes }\end{array}$ & mouse & $7-6 \mathrm{C} 1$ & $\lg G$, & 1.60 & On & - & IM32L \\
\hline $\operatorname{timp} 3$ & 1 (mono) & $\begin{array}{l}\text { Recognizes glycosylated and } \\
\text { non-glycosylated TIMP. } 3 \text {, no } \\
\text { cross-reactivity seen with: } \\
\text { human TIMP. } 1 \text { or TIMP.2 }\end{array}$ & mouse & $130-13 \mathrm{H} 4$ & $\lg G_{1}$ & 150 & On & * & IM43L. \\
\hline
\end{tabular}


Appendix 2 Gene transcripts significantly higher expressed in menstrual endometrium as compared to endometrum exposed to oral contraceptives

\begin{tabular}{|c|c|c|c|}
\hline Category & Gene Symbol & Tite & $\begin{array}{l}\text { AVG Fold } \\
\text { Change }\end{array}$ \\
\hline $\begin{array}{l}\text { growth factors, hormones, } \\
\text { cylokines }\end{array}$ & INHBA & $\begin{array}{l}\text { inhibin, beta A (activin A, activin AB alpha } \\
\text { polypeptide) }\end{array}$ & 177.5 \\
\hline $\begin{array}{l}\text { growth factors. hormones. } \\
\text { cytokines }\end{array}$ & IGFBPI & insulin-tike growth factor binding protein 1 & 80.3 \\
\hline proteases, peptidases & SERPINB3 & $\begin{array}{l}\text { serine (or cysteine) proteinase inhibitor, clade B } \\
\text { (ovalbumin), member } 3\end{array}$ & 78.5 \\
\hline $\begin{array}{l}\text { matrix metalloproteinases, } \\
\text { ECM remodeling }\end{array}$ & MMP10 & matrix metalloproleinase 10 & 42.7 \\
\hline miscellaneous & KIAA1199 & KLAA1199 protein & 27.1 \\
\hline metabolism & CYP24A1 & $\begin{array}{l}\text { cylochrome P450, family } 24 \text {, subtamily A, } \\
\text { polypeptide } 1\end{array}$ & 25.2 \\
\hline $\begin{array}{l}\text { growth factors, hormones, } \\
\text { cytokines }\end{array}$ & EBAF & endometrial bleeding associated factor & 247 \\
\hline immunomodulators & PAEP & progestagen-associated endometrial protein & 14.1 \\
\hline metabolism & VNN1 & vanin ? & 13.4 \\
\hline metabolism & GPX3 & glutathione peroxidase 3 (plasma) & 13.3 \\
\hline $\begin{array}{l}\text { receptors, cell surface } \\
\text { molecules }\end{array}$ & KLRC3 & $\begin{array}{l}\text { killer cell lectin-like receptor subfamily C, member } \\
3\end{array}$ & 10.8 \\
\hline $\begin{array}{l}\text { growth factors, hormones, } \\
\text { cytokines }\end{array}$ & ILIA & interleukin 1, alpha & 9.8 \\
\hline miscellaneous, & DACT1 & dapper homolog 1. antagonist of beta-catenin & 9.5 \\
\hline transporter, carrier proteins & TCN1 & transcobalamin I & 9.5 \\
\hline $\begin{array}{l}\text { growth factors, hormones, } \\
\text { cylokines }\end{array}$ & BMP2 & bone morphogenetic protein 2 & 9.4 \\
\hline proteases, peptidases & SERPINB3 & $\begin{array}{l}\text { serine (or cysteine) proteinase inhibitor, clade B } \\
\text { (ovalbumin), member } 3\end{array}$ & 8.4 \\
\hline $\begin{array}{l}\text { receptors, cell surface } \\
\text { molecules }\end{array}$ & EDNRB & endothelin receptor type B & 8.1 \\
\hline transporter, carrier proteins & $\mathrm{KCND2}$ & $\begin{array}{l}\text { potassium voltage-gated channel, Shal-rẹlated } \\
\text { subfamily, member } 2\end{array}$ & 7.5 \\
\hline $\begin{array}{l}\text { receptors, cell surface } \\
\text { molecules }\end{array}$ & $\mathrm{T} 1 \mathrm{~A}-2$ & $\begin{array}{l}\text { lung type-l cell membrane-associated } \\
\text { glycoprotein }\end{array}$ & 73 \\
\hline $\begin{array}{l}\text { DNA/RNA proteins, } \\
\text { transcription factors }\end{array}$ & SOX4 & SRY (sex determining region Y)-box 4 & 6.7 \\
\hline $\begin{array}{l}\text { growth factors, hormones, } \\
\text { cylokines. }\end{array}$ & IGFBP3 & insulin-like growth tactor binding protein 3 & 67 \\
\hline
\end{tabular}




\begin{tabular}{|c|c|c|c|}
\hline Category & Gene Symbol & Title & $\begin{array}{l}\text { AVG Fold } \\
\text { Change }\end{array}$ \\
\hline $\begin{array}{l}\text { growth factors, hormones, } \\
\text { cytokines }\end{array}$ & NID2 & nidogen 2 & 6.6 \\
\hline ECMcell adhesion & EFEMP1 & $\begin{array}{l}\text { EGF-containing fibulin-like extracellular matrix } \\
\text { protein } 1\end{array}$ & 6.2 \\
\hline $\begin{array}{l}\text { receptors, cell surface } \\
\text { molecules }\end{array}$ & LRRC15 & leucine rich repeat containing 15 & 5.8 \\
\hline metabolism & SOD2 & superoxide dismutase 2, mitochondrial & 5.6 \\
\hline miscellaneous & LOC51334 & mesenchymal stem cell protein DSC54 & 5.5 \\
\hline $\begin{array}{l}\text { ion-binding proteins, metal-ion } \\
\text { regulators }\end{array}$ & FLJ13612 & $\begin{array}{l}\text { likely ortholog of neuronally expressed calcium } \\
\text { binding protein }\end{array}$ & 5.2 \\
\hline metabolism. & SDR1 & short-chain dehydrogenase/reductase 1 & 5.1 \\
\hline $\begin{array}{l}\text { matrix metalloproteinases; } \\
\text { ECM remodeling }\end{array}$ & TIMP3 & tissue inhibitor of metalloproteinase 3 & 4.8 \\
\hline $\begin{array}{l}\text { receptors, cell surface } \\
\text { molecules }\end{array}$ & KCNK3 & potassium channel, subfamily $K$, member 3 & 4.7 \\
\hline proteases, peptidases & SPINK1 & serine protease inhibitor, Kazal type 1 & 4.7 \\
\hline $\begin{array}{l}\text { DNA/RNA proteins, } \\
\text { transcription factors }\end{array}$ & TWIST1 & twist homolog 1 & 4.6 \\
\hline mẹtabolism & CYP3A5 & $\begin{array}{l}\text { cytochrome } \mathrm{P} 450 \text {, family } 3 \text {, subfamily A, } \\
\text { polypeptide } 5\end{array}$ & 4.5 \\
\hline signal transduction & - & $\begin{array}{l}\text { Homo sapiens mRNA full length insert cDNA } \\
\text { clone EUROIMAGE } 1630957\end{array}$ & 4.3 \\
\hline ECMcell adhesion & ASPN & asporin (LRR class 1) & 4.3 \\
\hline $\begin{array}{l}\text { cell cycle, proliferation, } \\
\text { apoptosis }\end{array}$ & GoS2: & putative lymphocyte G0/G1 switch gene & 4.3 \\
\hline transporter, carriẹ proteins & ABCA6 & $\begin{array}{l}\text { ATP-binding cassette, sub-family A (ABC1). } \\
\text { member } 6\end{array}$ & 4.3 \\
\hline $\begin{array}{l}\text { receptors, cell surface } \\
\text { molecules }\end{array}$ & CLECSF2 & C-type lectin, superfamily member 2 & 4.2 \\
\hline transporter, camier proteins & SLC12A8 & solute carrier family 12 member 8 & 4.1 \\
\hline ECMcell adhesion & LAMB3 & laminin, beta 3 & 4.1 \\
\hline $\begin{array}{l}\text { receptors, cell surface } \\
\text { molecules }\end{array}$ & ELTD1 & $\begin{array}{l}\text { EGF, latrophilin and seven transmembrane } \\
\text { domain containing } 1\end{array}$ & 41 \\
\hline $\begin{array}{l}\text { DNARNA proteins, } \\
\text { transcription tactors }\end{array}$ & HOP & homeodomain-only protein & 4.1 \\
\hline miscellaneous & - & - & 4.0 \\
\hline $\begin{array}{l}\text { receptors, cell surtace } \\
\text { molecules }\end{array}$ & KDR & kinase insert domain receptor & 40 \\
\hline
\end{tabular}




\begin{tabular}{|c|c|c|c|}
\hline Category & Gene Symbol & Tise & $\begin{array}{l}\text { AVG Fold } \\
\text { Change }\end{array}$ \\
\hline immunomodulators & KIR3DL2 & kiler cell immunogiobulin-like receptor & 3.9 \\
\hline metabolism & PRDM1 & PR domain containing 1 & 3.8 \\
\hline $\begin{array}{l}\text { cell cycle, proliteration. } \\
\text { apoptosis }\end{array}$ & CLKI & CDC-like kinase 1 & 3.8 \\
\hline $\begin{array}{l}\text { growth factors, hormones, } \\
\text { cylokines. }\end{array}$ & FGF2 & fibroblast growth factor 2 (basic) & 3.6 \\
\hline signal transduction & MAP3K4 & mitogen-activated protein kinase kinase kinase 4 & 3.6 \\
\hline proteases, peptidases & SERPINE2 & serine (or cysteine) proteinase inhibitor, clade $E$ & 3.6 \\
\hline proteases, peptidases & PLAT & plasminogen activator, tissue & 36 \\
\hline $\begin{array}{l}\text { DNARNA proteins, } \\
\text { transcription factors }\end{array}$ & BACH2 & $\begin{array}{l}\text { BTB and CNC homology 1, basic leucine zipper } \\
\text { transcription factor } 2\end{array}$ & 3.5 \\
\hline ECMcell adhesion & HABP2 & hyaluronan binding protein 2 & 35 \\
\hline proteases, peptidases & TFPI & tissue factor pathway inhibitor & 3.4 \\
\hline miscellaneous & MGC14376 & hypothetical protein MGC14376 & 34 \\
\hline metabolism & NOX4 & NADPH oxidase 4 & 3.4 \\
\hline miscellaneous & $\cdots$ & - & 3.4 \\
\hline ECMcell adhesion & THBS2 & thrombospondin 2 & 3.4 \\
\hline $\begin{array}{l}\text { growth factors, hormones, } \\
\text { cytokines }\end{array}$ & TGFB2 & transforming growth factor, beta 2 & 3.4 \\
\hline $\begin{array}{l}\text { receptors, cell surface } \\
\text { molecules }\end{array}$ & EMP1 & epithelial membrane protein 1 & 3.3 \\
\hline $\begin{array}{l}\text { growth factors, hormones, } \\
\text { cytokines }\end{array}$ & LIF & leukemia inhibitory factor & 3.3 \\
\hline transporter, carrier proteins & SLC22A4 & solute carnier family 22, member 4 & 3.2 \\
\hline signal transduction & AXL & AXL receptor tyrosine kinase & 3.2 \\
\hline $\begin{array}{l}\text { DNARNA proteins, } \\
\text { transcription factors }\end{array}$ & SFRS6 & splicing factor, arginine/serine-rich 6 & 3.1 \\
\hline metabolism & FADS3 & fatty acid desaturase 3 & 31 \\
\hline miscellaneous & ANKRD10 & ankynn repeat domain 10. & 3.0 \\
\hline $\begin{array}{l}\text { receptors, cell surface } \\
\text { molecules }\end{array}$ & TM4SF1 & transmembrane 4 superfarnily member 1 & 3.0 \\
\hline signal transduction & PKIG & protein kinase inhibitor gamma & 30 \\
\hline signal transduction & CBLB & $\begin{array}{l}\text { Cas-Br-M (murne) ecotropic retroviral } \\
\text { transforming sequence b }\end{array}$ & 30 \\
\hline receotors cell surface & TM7SF1 & transmembrane 7 superfarnily member 1 & 3.0 \\
\hline
\end{tabular}




\begin{tabular}{|c|c|c|c|}
\hline Category & Gene Symbol & Title & $\begin{array}{l}\text { AVG Fold } \\
\text { Change }\end{array}$ \\
\hline \multicolumn{4}{|l|}{ molecules } \\
\hline ECM/cell adhesion & ENG & endoglin & 2.9 \\
\hline ECM/cell adhesion & GALNACT-2 & chondroitin sulfate GalNACT-2 & 2.9 \\
\hline miscellaneous & - & Homo sapiens cDNA clone IMAGE 4152985 & 2.9 \\
\hline metabolism & KIAA0934 & KIAA0934 protein & 2.9 \\
\hline signal transduction & RIN2 & Ras and Rab interactor 2 & 2.8 \\
\hline $\begin{array}{l}\text { matrix mẹtalloproteinașes, } \\
\text { ECM remodeling }\end{array}$ & MMP27 & matrix metalloproteinase 27 & 2.8 \\
\hline $\begin{array}{l}\text { matrix metalloproteinases, } \\
\text { ECM remodeling }\end{array}$ & MMP2 & matrix metalloproteinase 2 & 2.8 \\
\hline $\begin{array}{l}\text { cell cycle, proliferation, } \\
\text { apoptosis. }\end{array}$ & RARRES1 & retinoic acid receptor responder & 2.8 \\
\hline ECM/cell adhesion & CLDN10 & claudin 10 & 2.7 \\
\hline $\begin{array}{l}\text { receptors, cell surface } \\
\text { molecules }\end{array}$ & KIR2DL3 & killer cell immunoglobulin-like receptor & 2.7 \\
\hline transporter, carrier proteins & SLC38A2 & solute carrier family 38 , member 2 & 2.7 \\
\hline $\begin{array}{l}\text { receptors, cell surface } \\
\text { molecules }\end{array}$ & GPR116 & G protein-coupled receptor 116 & 2.7 \\
\hline metabolism & ABP1 & amiloride binding protein 1 & 2.7 \\
\hline $\begin{array}{l}\text { DNA/RNA proteins, } \\
\text { transcription factors }\end{array}$ & ZNF216 & zinc finger protein 216 & 27 \\
\hline miscellaneous & GAB2 & GRB2-associated binding protein 2 & 27 \\
\hline $\begin{array}{l}\text { DNA/RNA proteins, } \\
\text { transcription factors }\end{array}$ & TIA1 & $\begin{array}{l}\text { TIA1 cytotoxic granule-associated RNA binding } \\
\text { protein }\end{array}$ & 2.6 \\
\hline $\begin{array}{l}\text { receptors, cell surface } \\
\text { molecules }\end{array}$ & MMD & $\begin{array}{l}\text { monocyte to macrophage differentiation:- } \\
\text { associated }\end{array}$ & 26 \\
\hline $\begin{array}{l}\text { receptors, cell surface } \\
\text { molecules }\end{array}$ & MUC16 & mucin 16 & 2.6 \\
\hline signal transduction & FGR & $\begin{array}{l}\text { Gardner-Rasheed feline sarcoma viral (v-fgr) } \\
\text { oncogene homolog }\end{array}$ & 2.6 \\
\hline $\begin{array}{l}\text { DNARNA proteins. } \\
\text { transcription factors }\end{array}$ & MRPS6: & mitochondrial ribosomal protein S6 & 26 \\
\hline immunomodulators & C1QR! & $\begin{array}{l}\text { complement component } 1, q \text { subcomponent, } \\
\text { receptor } 1\end{array}$ & 26 \\
\hline $\begin{array}{l}\text { DNARNA proteins, } \\
\text { transcription factors }\end{array}$ & TBX3 & T-box 3 (uinar mammary syndrome) & 26 \\
\hline receotors cell surface & GPNMB & glycoprotein (transmembrane) nmb & 26 \\
\hline
\end{tabular}




\begin{tabular}{|c|c|c|c|}
\hline Category & Gene Symbol & Tite & $\begin{array}{l}\text { AVG Folk } \\
\text { Change }\end{array}$ \\
\hline \multicolumn{4}{|l|}{ molecules } \\
\hline $\begin{array}{l}\text { growth factors, hormones, } \\
\text { cytokines }\end{array}$ & TNFAIP2 & tumour necrosis factor, alpha-induced protein 2 & 2.5 \\
\hline signal transduction & STK38L & serine/threonine kinase 38 like & 2.5 \\
\hline signal transduction & SSB1 & $\begin{array}{l}\text { SPRY domain-containing SOCS box protein SSB. } \\
1\end{array}$ & 2.5 \\
\hline immunomodulators & C1QTNF3 & $\mathrm{Clq}$ and tumour necrosis factor related protein 3 & 2.5 \\
\hline signal transduction & SLA & Src-like-adaptor & 2.5 \\
\hline $\begin{array}{l}\text { cell cycle, proliferation, } \\
\text { apoptosis }\end{array}$ & PAWR & PRKC, apoptosis, WT1, regulator & 25 \\
\hline metabolism & $\mathrm{DIO} 2$ & deiodinase, iodothyronine, type II & 25 \\
\hline immunornodulators & IFRD1 & interferon-related developmental regulator 1 & 2.5 \\
\hline transporter, carner proteins & SLC3A2 & solute carrier family 3 & 2.5 \\
\hline miscellaneous & RTN3 & reticuion 3 & 25 \\
\hline ECMicell adhesion & SPP1 & secreted phosphoprotein ? & 2.4 \\
\hline proteases, peptidases & PRSS11 & protease, serine, 11 (IGF binding) & 2.4 \\
\hline transporter, carrier proteins & SLC2OA1 & solute carrier family 20, member 1 & 24 \\
\hline $\begin{array}{l}\text { DNARNA proteins, } \\
\text { transcription factors }\end{array}$ & ZFP36L1 & zinc finger protein $36, \mathrm{C} 3 \mathrm{H}$ type-like 1 & 2.3 \\
\hline $\begin{array}{l}\text { receptors, cell surface } \\
\text { molecules }\end{array}$ & CMRF-35H & leukocyte membrane antigen & 23 \\
\hline miscellaneous & KIAA0692 & KIAA0692 protein & 2.3 \\
\hline signal transduction & RIS & Ras family member Ris & 2.3 \\
\hline $\begin{array}{l}\text { DNA/RNA proteins, } \\
\text { transcription factors }\end{array}$ & CEBPB & CCAAT/enhancer binding protein (C/EBP), beta & 2.3 \\
\hline $\begin{array}{l}\text { DNA/RNA proteins. } \\
\text { transcription factors }\end{array}$ & $\mathrm{HLX} 1$ & H2 O-like homeo box 1 (Drosophila) & 2.3 \\
\hline $\begin{array}{l}\text { receptors, cell surface } \\
\text { molecules }\end{array}$ & LEPR & leptin receptor & 23 \\
\hline $\begin{array}{l}\text { growth factors, hormones, } \\
\text { cytokines }\end{array}$ & PRL & prolactin & 2.3 \\
\hline signal transduction & PRKAR2B & $\begin{array}{l}\text { protein kinase, cAMP-dependent, regulatory, type } \\
\text { II, beta }\end{array}$ & 2.3 \\
\hline $\begin{array}{l}\text { DNARNA proteins, } \\
\text { transcription factors }\end{array}$ & RUNX: & runt-related transcription factor 1 & 23 \\
\hline ECMcell adhesion & FBLN5 & fibulin 5 & 2.3 \\
\hline
\end{tabular}




\begin{tabular}{|c|c|c|c|}
\hline Category & Gene Symbol & Titte. & $\begin{array}{l}\text { AVG Fold } \\
\text { Change }\end{array}$ \\
\hline transporter, carrier proteins & DNAJB9 & DnaJ (Hsp40) homolog, subfamily B, member 9 & 2.3 \\
\hline metabolism & CHST6 & $\begin{array}{l}\text { carbohydrate ( } \mathrm{N} \text {-acetylglucosamine } 6-0 \text { ) } \\
\text { sulfotransferase } 6\end{array}$ & 2.3 \\
\hline signal transduction & LCP2 & lymphocyte cytosolic protein 2 . & 2.2 \\
\hline metabolism & LOC123803 & $\mathrm{N}$-terminal Asn amidase & 2.2 \\
\hline transporter, carrier proteins & RBP1 & retinol binding protein 1, cellular & 2.2 \\
\hline miscellaneous & KIAA0379 & KIAA0379 protein & 2.2. \\
\hline transporter, carnier proteins & SLCAA7 & $\begin{array}{l}\text { solute carrier family } 4 \text {, sodium bicarbonate } \\
\text { cotransporter, member } 7\end{array}$ & 2.2 \\
\hline signal transduction & PIK3CD & $\begin{array}{l}\text { phosphoinositide-3-kinase, catalytic, delta } \\
\text { polypeptide }\end{array}$ & 2.2 \\
\hline signal transduction & RAB31 & RAB31, member RAS oncogene family & 2.2 \\
\hline miscellaneous & NUPL1 & nucleoporin like 1 & 2.2 \\
\hline $\begin{array}{l}\text { receptors, cell surface } \\
\text { molecules }\end{array}$ & WWF & von Willebrand factor & 2.2 \\
\hline signal transduction & SOCS5 & suppressor of cytokine signaling 5 & 2.2 \\
\hline miscellaneous & SDCCAG8 & serologically defined colon cancer antigen 8 & 2.2 \\
\hline transporter, carner proteins & DDEF2 & $\begin{array}{l}\text { development and differentiation enhancing factor } \\
2\end{array}$ & 2.1 \\
\hline miscellaneous & C14ort116 & chromosome 14 open reading frame 116 & 2.1 \\
\hline signal transduction & SPRY2 & sprouty homolog 2 (Drosophila) & 2.1 \\
\hline Iransporter, carrier proteins & SLC19A2 & solute carnier family 19, member 2 & 2.1 \\
\hline $\begin{array}{l}\text { receptors, cell surface } \\
\text { molecules }\end{array}$ & HOMER1 & homer homolog 1 (Drosophila) & 2.1 \\
\hline $\begin{array}{l}\text { DNA/RNA proteins, } \\
\text { transcription factors }\end{array}$ & CHES1 & checkpoint suppressor 1 & 2.0 \\
\hline cytoskeleton, structural proteins & WASPIP & $\begin{array}{l}\text { Wiskott-Aldrich syndrome protein interacting } \\
\text { protein }\end{array}$ & 2.0 \\
\hline miscellaneous & ELOVL4 & elongation of very long chain fatty acids-like 4 & 2.0 \\
\hline signal transduction & MAP4K4 & mitogen-activated protein kinase 4 & 2.0 \\
\hline $\begin{array}{l}\text { DNARNA proteins, } \\
\text { transcription factors }\end{array}$ & HBP1 & HMG-box transcription factor 1 & 20 \\
\hline $\begin{array}{l}\text { receptors, cell surface } \\
\text { molecules }\end{array}$ & EPBA1L3 & erythrocyle membrane protein band 4.1 -like 3 & 2.0 \\
\hline $\begin{array}{l}\text { DNARNA proteins. } \\
\text { transcription factors }\end{array}$ & CUGBP2 & CUG triplet repeat, RNA binding protein 2 & 20 \\
\hline
\end{tabular}




\begin{tabular}{|c|c|c|c|}
\hline Category & Gene Symbol & Tite & $\begin{array}{l}\text { AVG Fold } \\
\text { Change }\end{array}$ \\
\hline signai transduction & RRAS2 & related RAS viral (r-ras) oncogene homolog 2 & 20 \\
\hline transporter, carner proteins. & ENSA & endosulfine alpha & 0.5 \\
\hline ECMcell adhesion & CLDN3 & claudin 3 & 0.5 \\
\hline metabolism & WBSCR22 & $\begin{array}{l}\text { Williams Beuren syndrome chromosome region } \\
22\end{array}$ & 0.5 \\
\hline transporter, carner proteins & FRDA & Friedreich ataxia & 0.5 \\
\hline immunomodulators & $|F| 35$ & interteron-induced protein 35 & 0.5 \\
\hline proteases, peptidases & MIPEP & mitochondral intermediate peptidase & 0.5 \\
\hline metabolism & KIAA1698 & KIAA1698 protein & 0.5 \\
\hline signal transduction & LIM & LIM protein & 0.5 \\
\hline ECMcell adhesion & EVA1 & epithelial V-like antigen 1 & 0.5 \\
\hline signal transduction & FLJ10986 & hypothetical protein FLJ10986 & 0.5 \\
\hline metabolism & MRPS11 & milochondrial nbosomal protein S11 & 0.5 \\
\hline metabolism & FKBP4 & FK506 binding protein $4,59 \mathrm{kDa}$ & 0.5 \\
\hline signal transduction & SYNJ2BP & synaptojanin 2 binding protein & 0.5 \\
\hline metabolism & $\mathrm{PECl}$ & peroxisomal $\mathrm{D} 3, \mathrm{D} 2$-enoyl-CoA isomerase & 0.5 \\
\hline miscellaneous & ANKS1 & ankyrin repeat and SAM domain containing 1 & 0.5 \\
\hline $\begin{array}{l}\text { receptors, cell surface } \\
\text { molecules }\end{array}$ & LGALS3BP & $\begin{array}{l}\text { lectin, galactoside-binding, soluble, } 3 \text { binding } \\
\text { protein }\end{array}$ & 0.5 \\
\hline proteases, peptidases & UQCRC2 & ubiquinol-cytochrome c reductase core protein II & 0.5 \\
\hline metabolism & MTHFD1 & methylenetefrahydrofolate dehydrogenase & 0.5 \\
\hline miscellaneous & NET1 & neuroepithelial cell transforming gene 1 & 0.5 \\
\hline metabolism & C11ort8 & chromosome 11 open reading frame 8 & 0.5 \\
\hline metabolism & ALAD & aminolevulinate, delta-, dehydratase & 0.5 \\
\hline $\begin{array}{l}\text { DNA/RNA proteins; } \\
\text { transcription factors }\end{array}$ & HOXA11 & homeo box A11 & 0.5 \\
\hline $\begin{array}{l}\text { DNA/RNA proteins, } \\
\text { transcription factors }\end{array}$ & POP5 & RNase MRP/RNase P protein-like & 0.5 \\
\hline $\begin{array}{l}\text { DNA/RNA proteins, } \\
\text { transcription factors }\end{array}$ & NBS1 & Nipmegen breakage syndrome 1 & 0.5 \\
\hline $\begin{array}{l}\text { DNARNA proteins, } \\
\text { transcription factors }\end{array}$ & DKFZP564M182 & DKFZP564M182 protein & 0.5 \\
\hline $\begin{array}{l}\text { DNARNA proteins, } \\
\text { transcription factors }\end{array}$ & MSX1 & msh homeo box homolog 1 (Drosophila) & 0.5 \\
\hline
\end{tabular}




\begin{tabular}{|c|c|c|c|}
\hline Category & Gene Symbol: & Title & $\begin{array}{l}\text { AVG Fold } \\
\text { Change }\end{array}$ \\
\hline $\begin{array}{l}\text { DNA/RNA proteins, } \\
\text { transcription factors }\end{array}$ & NFIB & nuclear factor $\mathrm{V} / \mathrm{B}$ & 0.5 \\
\hline metabolism & GNS & glucosamine ( $\mathrm{N}$-acetyl)-6-sulfatase & 0.5 \\
\hline miscellaneous & ISG20 & interferon stimulated gene $20 \mathrm{kDa}$ & 0.5 \\
\hline metabolism & GSR & glutathione reductase & 0.5 \\
\hline $\begin{array}{l}\text { receptors, cell surface } \\
\text { molecules }\end{array}$ & EDNRA & endothelin receptor type A & 0.5 \\
\hline miscellaneous & RUVBL2 & RuvB-like 2 (E. coli) & 0.5 \\
\hline miscellaneous & SMT3H1 & SMT3 suppressor of mif two 3 homolog 1 (yeast) & 0.5 \\
\hline miscellaneous & - & $\begin{array}{l}\text { Homo șapiens çDNA FLJ31439 fis, clone } \\
\text { NT2NE2000707. }\end{array}$ & 0.5 \\
\hline $\begin{array}{l}\text { DNARNA proteins, } \\
\text { transcription factors }\end{array}$ & SNRPD 1 & $\begin{array}{l}\text { small nuclear ribonucleoprolein D1 polypeptide } \\
16 \mathrm{kDa}\end{array}$ & 0.5 \\
\hline $\begin{array}{l}\text { DNA/RNA proteins, } \\
\text { transcription factors }\end{array}$ & HNRPC & $\begin{array}{l}\text { heterogeneous nuclear ribonucleoprotein C } \\
\text { (C1/C2) }\end{array}$ & 0.5 \\
\hline signal transduction & RABL2B & RAB, member of RAS oncogene family-like $2 \mathrm{~B}$ & 0.5 \\
\hline $\begin{array}{l}\text { receptors, cell surface } \\
\text { molecules }\end{array}$ & CGI-51 & CGI-51 protein & 0.5 \\
\hline metabolism & NDUFA7 & $\begin{array}{l}\text { NADH dehydrogenase (ubiquinone) } 1 \text { alpha } \\
\text { subcomplex }\end{array}$ & 0.5 \\
\hline miscellaneous & TOR3A & torsin family 3 , member A & 0.5 \\
\hline $\begin{array}{l}\text { ion-binding proteins, metal-ion } \\
\text { regulators }\end{array}$ & TRIM14 & tripartite motif-containing 14 & 0.5 \\
\hline transporter, carrier proteins & PALRBP1 & PAl-1 mRNA-binding protein & 0.5 \\
\hline $\begin{array}{l}\text { DNA/RNA proteins, } \\
\text { transcription factors }\end{array}$ & SMARCA2 & $\begin{array}{l}\text { SWI/SNF related, matrix ass, actin dependent } \\
\text { regulator chromatin }\end{array}$ & 0.5 \\
\hline transporter, carrier proteins & KPNA2 & $\begin{array}{l}\text { karyopherin alpha } 2 \text { (RAG cohort 1, importin } \\
\text { alpha 1) }\end{array}$ & 0.5 \\
\hline signal transduction & NME1 & $\begin{array}{l}\text { non-metastatic cells 1, protein (NM23A) } \\
\text { expressed in }\end{array}$ & 0.5 \\
\hline $\begin{array}{l}\text { ONA/RNA proteins, } \\
\text { transcription factors }\end{array}$ & HNRPH1 & heterogeneous nuclear ribonucleoprotein $\mathrm{H} 1(\mathrm{H})$ & 0.5 \\
\hline metabolism & HMGCR & $\begin{array}{l}\text { 3-hydroxy-3-methylglutaryl-Coenzyme A } \\
\text { reductase }\end{array}$ & 0.5 \\
\hline $\begin{array}{l}\text { growth factors, hormones, } \\
\text { cytokines }\end{array}$ & PTN & pleiotrophin & 0.5 \\
\hline $\begin{array}{l}\text { DNA/RNA proteins, } \\
\text { Iranscription factors }\end{array}$ & DZIP1 & zinc finger DAZ interacting protein 1 & 0.5 \\
\hline
\end{tabular}




\begin{tabular}{|c|c|c|c|}
\hline Category & Gene Symbol & Tise & $\begin{array}{l}\text { AVG Fold } \\
\text { Change }\end{array}$ \\
\hline miscellaneous & DKFZP547E 1010 & DKFZPS47E 1010 protein & 0.5 \\
\hline $\begin{array}{l}\text { DNARNA proteins, } \\
\text { transcription factors }\end{array}$ & SAP18 & sin3-associated polypeptide, $18 \mathrm{kDa}$ & 0.5 \\
\hline metabolism & PMVK & phosphomevalonate kinase & 0.5 \\
\hline metabolism & MRPL17 & mitochondrial ribosomal protein L17 & 0.5 \\
\hline vasoactive substances & SPARCL1 & SPARC-like 1 (mast9, hevin) & 0.5 \\
\hline miscellaneous & - & Homo sapiens LOC347499 mRNA & 0.5 \\
\hline metabolism & FLJ 22222 & hypothetical protein FLJ 222222 & 0.5 \\
\hline $\begin{array}{l}\text { receptors, cell surface } \\
\text { molecules }\end{array}$ & $\mathrm{CD} 24$ & CD24 antigen & 0.5 \\
\hline $\begin{array}{l}\text { cell cycle, proliferation, } \\
\text { apoptosis }\end{array}$ & PHB & prohibitin & 0.5 \\
\hline cytoskeleton, structural proteins & TPM! & tropomyosin 1 (alpha) & 0.5 \\
\hline metabolism & QDPR & quinoid dithydropteridine reductase & 0.5 \\
\hline $\begin{array}{l}\text { DNARNA proteins, } \\
\text { transcription factors }\end{array}$ & POLE3 & polymerase (DNA directed), epsilon 3 & 0.5 \\
\hline metabolism & $\mathrm{ACLY}$ & ATP citrate lyase & 0.5 \\
\hline $\begin{array}{l}\text { receptors, cell surface } \\
\text { molecules }\end{array}$ & THY1 & Thy- 1 cell surface antigen & 0.5 \\
\hline metabolism & $\mathrm{DCl}$ & dodecenoyl-Coenzyme A delta isomerase & 0.5 \\
\hline signal transduction & CKB & creatine kinase, brain & 0.5 \\
\hline metabolism & SORD & sorbitol dehydrogenase & 0.5 \\
\hline signal transduction & GNAL & guanine nucleotide binding protein ( $G$ protein) & 0.5 \\
\hline miscellaneous & MGC4825 & hypothetical protein MGC4825 & 0.5 \\
\hline proteases, peptidases & PSMB9 & proteasome subunit, beta type & 0.5 \\
\hline $\begin{array}{l}\text { DNARNA proteins, } \\
\text { transcription factors }\end{array}$ & MED6 & $\begin{array}{l}\text { mediator of RNA polymerase II transcription, } \\
\text { subunit } 6 \text { homolog }\end{array}$ & 0.4 \\
\hline transporter, carner proteins & SLC15A2 & $\begin{array}{l}\text { solute carner family } 15 \text { ( } \mathrm{H}+\text { /peptide transporter). } \\
\text { member } 2\end{array}$ & 0.4 \\
\hline proteases, peptidases & PSSME2 & proteasome activator subunit 2 (PA28 beta) & 0.4 \\
\hline miscellaneous & ZFYVE21 & zinc finger. FYVE domain containing 21 & 0.4 \\
\hline metabolism & CYB5 & cylochrome b-5 & 0.4 \\
\hline metabolism & FDPS & farnesyl diphosphate synthase & 0.4 \\
\hline metabolism & PPIC & peptidylprolyl isomerase C. & 0.4 \\
\hline
\end{tabular}




\begin{tabular}{|c|c|c|c|}
\hline Category & Gene Symbol & Tite & $\begin{array}{l}\text { AVG Fold } \\
\text { Change }\end{array}$ \\
\hline $\begin{array}{l}\text { cell cycle, proliferation, } \\
\text { apoptosis }\end{array}$ & CETN2 & centrin, EF-hand protein, 2 & 0.4 \\
\hline transporter, carrier proteins & FKBP11 & FK506 binding protein $11,19 \mathrm{kDa}$ & 0.4 \\
\hline $\begin{array}{l}\text { receptors, cell surface } \\
\text { molecules }\end{array}$ & GPR49 & G protein-coupled receptor 49 & 0.4 \\
\hline ECMcell adhesion & ITGA6 & integrin, alpha 6 & 0.4 \\
\hline transporter, carrier proteins & ETFB & electron-transfer-flavoprotein, beta polypeptide & 0.4 \\
\hline cytoskeleton, structural proteins & ACTA2 & actin, alpha 2 & 0.4 \\
\hline $\begin{array}{l}\text { DNA/RNA proteins, } \\
\text { transcription factors }\end{array}$ & HOXA10 & homeo box $A 10$ & 0.4 \\
\hline metabolism & GLA & galactosidase, alpha & 0.4 \\
\hline miscellaneous & BITE & p10-binding protein & 0.4 \\
\hline miscellaneous & FAIM & Fas apoptotic inhibitory molecule & 0.4 \\
\hline $\begin{array}{l}\text { receptors, cell surface } \\
\text { molecules }\end{array}$ & FOLR1 & folate receptor 1 & 0.4 \\
\hline ECM/cell adhesion & COL16A1 & collagen, type XVI, alpha 1 & 0.4 \\
\hline transporter, carrier proteins & HSPB1 & heat shock $27 \mathrm{kDa}$ protein 1 & 0.4 \\
\hline miscellaneous & KIAA0819 & KIAA0819 protein & 0.4 \\
\hline metabolism & PCCA & $\begin{array}{l}\text { propionyl Coenzyme A carboxylase, alpha } \\
\text { polypeptide }\end{array}$ & 0.4 \\
\hline miscellaneous & TUWD12 & TUWD12 & 0.4 \\
\hline transporter, carrier proteins & STX18 & syntaxin 18 & 0.4 \\
\hline $\begin{array}{l}\text { DNA/RNA proteins, } \\
\text { transcription factors }\end{array}$ & LSM5: & LSM5 homolog. U6 small nuclear RNA associated & 0.4 \\
\hline metabolism & MOXD1 & monooxygenase, DBH-like 1 & 0.4 \\
\hline transporter, carrier proteins & ATP5G1 & $\begin{array}{l}\text { ATP synthase, } \mathrm{H} * \text { transporting, mitochondrial F0 } \\
\text { complex }\end{array}$ & 0.4 \\
\hline proteases, peptidases & EYA2 & eyes absent homolog 2 (Drosophila) & 0.4 \\
\hline signal transduction & C14ort159 & chromosome 14 open reading frame 159 & 0.4 \\
\hline $\begin{array}{l}\text { cell cycle, proliferation, } \\
\text { apoptosis }\end{array}$ & PDCD8 & $\begin{array}{l}\text { programmed cell death } 8 \text { (apoptosis-inducing } \\
\text { factor) }\end{array}$ & 0.4 \\
\hline $\begin{array}{l}\text { receptors, cell surface } \\
\text { molecules }\end{array}$ & PGRMC1 & progesterone receptor membrane component 1 & 0.4 \\
\hline miscellaneous & HHLA3 & HERV-H LTR-associating 3 & 0.4 \\
\hline miscellaneous & - & H. saoiens transcr seo with strona similaritv to & 0.4 \\
\hline
\end{tabular}




\begin{tabular}{|c|c|c|c|}
\hline Category & Gene Symbol & Tise & $\begin{array}{l}\text { AVG Fold } \\
\text { Change }\end{array}$ \\
\hline & & protein pir A32800 & \\
\hline signal transduction & PLCE1 & phospholipase C, epsilon 1 & 0.4 \\
\hline miscellaneous & - & $\begin{array}{l}\text { H. sapiens transcr sequence, moderate simil. to } \\
\text { prot. ref NP } 071431.1\end{array}$ & 0.4 \\
\hline metabolism & C12ort8 & chromosome 12 open reading frame 8 & 04 \\
\hline $\begin{array}{l}\text { DNARNA proteins, } \\
\text { transcription factors }\end{array}$ & RUVBL1 & Ruvb-like 1 & 0.4 \\
\hline metabolism & PPID & peptidylprolyl isomerase D & 0.4 \\
\hline $\begin{array}{l}\text { cell cycle, proliferation, } \\
\text { apoptosis }\end{array}$ & $\mathrm{RCL}$ & putative c-Myc-responsive & 04 \\
\hline $\begin{array}{l}\text { ion-binding proteins, metal-ion } \\
\text { regulators }\end{array}$ & SELENBP1 & selenium binding protein 1 & 0.4 \\
\hline miscellaneous & FL」20366 & hypothetical protein FLJ20366 & 04 \\
\hline signal transduction & GRP58 & glucose regulated protein, $58 \mathrm{kDa}$ & 0.4 \\
\hline metabolism & SULT1C1 & sulfotransterase family, cytosolic. 1C. member 1 & 04 \\
\hline metabolism & QRSL1 & $\begin{array}{l}\text { glutaminyl-tRNA synthase (glutamine- } \\
\text { hydrolyzing)-like } 1\end{array}$ & 0.4 \\
\hline miscellaneous & HNOEL-iso & HNOEL-iso protein & 0.3 \\
\hline transporter, carrier proteins & ATP6V1A & $\begin{array}{l}\text { ATPase, } \mathrm{H}+\text { transporting, lysosomal } 70 \mathrm{kDa}, \mathrm{V} 1 \\
\text { subunit A. }\end{array}$ & 03 \\
\hline signal transduction & MAP2K6 & mitogen-activated protein kinase kinase 6 & 03 \\
\hline cytoskeleton, structural proteins & NEFH & neurofilament, heavy polypeptide $200 \mathrm{kDa}$ & 0.3 \\
\hline $\begin{array}{l}\text { DNA/RNA proteins, } \\
\text { transcription factors }\end{array}$ & MID1 & midline T & 0.3 \\
\hline $\begin{array}{l}\text { cell cycle, proliferation, } \\
\text { apoptosis }\end{array}$ & MNS1 & meiosis-specific nuclear structural protein 1 & 0.3 \\
\hline metabolism & NQO1 & $\mathrm{NAD}(\mathrm{P}) \mathrm{H}$ dehydrogenase, quinone 1 & 0.3 \\
\hline immunomodulators & $|\mathrm{F}| 27$ & interferon, alpha-inducible protein 27 & 03 \\
\hline proteases, peptidases & ARTS-1 & $\begin{array}{l}\text { type } 1 \text { TNF receptor shedding aminopeptidase } \\
\text { regulator }\end{array}$ & 03 \\
\hline proteases, peptidases & PLA2G4A & phospholipase A2. group IVA & 0.3 \\
\hline miscellaneous & STXBP6 & syntaxin binding protein 6 & 0.3 \\
\hline metabolism & ASRGL1 & asparaginase like 1 & 0.3 \\
\hline $\begin{array}{l}\text { ion-binding proteins. metal-ion } \\
\text { regulators }\end{array}$ & CLGN & calmegin: & 0.3 \\
\hline
\end{tabular}




\begin{tabular}{|c|c|c|c|}
\hline Category & Gene Symbol & Title & $\begin{array}{l}\text { AVG Fold } \\
\text { Change }\end{array}$ \\
\hline miscellaneous & BTN3A3 & butyrophilin, subfamily 3 , member $A 3$ & 0.3 \\
\hline metabolism & $\mathrm{FAH}$ & fumarylacetoacetate hydrolase & 0.3 \\
\hline signal transduction & DUSP2 & dual specificity phosphatase 2' & 0.3 \\
\hline miscellaneous & - & $\begin{array}{l}\text { H. sapiens transcr sequence, moderate simil. to } \\
\text { prot. ref:NP_054848.1 }\end{array}$ & 0.3 \\
\hline cytoskeleton, structural proteins & COBL & KIAA0633 protein & 0.3 \\
\hline signal transduction & NDP & Norrie disease (pseudoglioma) & 0.3 \\
\hline $\begin{array}{l}\text { DNA/RNA proteins, } \\
\text { transcription factors, }\end{array}$ & EIF2S3: & $\begin{array}{l}\text { eukaryotic translation initiation factor } 2 \text {, subunit } 3 \\
\text { gamma, } 52 \mathrm{kDa}\end{array}$ & 0.2 \\
\hline $\begin{array}{l}\text { growth factors, hormones. } \\
\text { cytokines }\end{array}$ & IGF1 & insulin-like growth factor 1 & 0.2 \\
\hline transporter, carrier proteins & SNAP23 & synaptosomal-associated protein, $23 \mathrm{kDa}$ & 0.2 \\
\hline immunomodulators & $\mathrm{B} 7 \cdot \mathrm{H} 4$ & immune costimulatory protein B7-H4 & 0.2 \\
\hline immunomodulators & GW112. & differentially expressed in hematopoietic lineages & 0.2 \\
\hline ECM/cell adhesion & CTNNA2 & catenin alpha 2 & 0.2 \\
\hline miscellanecus & CG!-38 & brain specific protein & 0.2 \\
\hline signal transđuction & FKBP5 & FK506 binding protein 5 & 0.1 \\
\hline metabolism & GSTT1 & glutathione S-transferase theta 1 & 0.1 \\
\hline immunomodulators & SCGB1D2. & secretoglobin, family $1 \mathrm{D}$, member 2 & 0.1 \\
\hline matrix metalloproteinases & MMP26 & matrix metalloproteinase 26 & 0.1 \\
\hline proteases, peptidases & SERPINA3 & $\begin{array}{l}\text { serine (or cysteine) proteinase inhibitor. } \\
\text { clade A. member } 3\end{array}$ & 0.1 \\
\hline $\begin{array}{l}\text { cytoskeleton, struetural } \\
\text { proteins }\end{array}$ & TNNC1 & troponin C, slow & 0.0 \\
\hline
\end{tabular}




\section{Dankwoord}

Dit proefschrift is het resultaat van de inzet van velen. Tientallen uren zijn besteed aan het bedenken en verfijnen van de onderzoeksvragen, honderden endometriumbiopten en menstruumsamples zijn verzameld en verwerkt, duizenden CAMs zijn getransplanteerd, tienduizenden coupes zijn gesneden en gekleurd, en ontelbare uren zijn gespendeerd om alle vergaarde informatie te verwerken. Heel veel dank aan iedereen die zich voor dit boekje heeft ingezet!

Professor Hans Evers, promotor en opleider, u liet me in 2000 naar Maastricht komen. Het is uiteindelijk toch gelukt om in 2004 te promoveren en gelukkig ook binnen de door u geplande onderzoeksgroep... Bedankt voor uw vertrouwen!

Dr. Gerard Dunselman, "Dr. D", copromotor en mentor, dank voor alle tijd die u vanaf het begin in mij heeft geïnvesteerd. Voor iedere situatie heeft u een passende gevleugelde uitspraak. Bijvoorbeeld: "Niets is zo veranderlijk als de mens" toen ik eerst niet, en later toch maar wel, als onderzoeker deel wilde uitmaken van de endometriumgroep, en "Kwaliteit wint altijd" bij de selectie van mijn abstract voor een oral tijdens de SGI. U bent voor mij het voorbeeld van hoe kliniek en wetenschap op een geweldige manier te combineren zijn.

Dr. Patrick Groothuis, copromotor, jouw deur staat altijd open voor advies, een luisterend oor of gewoon een praatje. De rust die je uitstraalt op stressvolle momenten, en die je dan (een beetje) op mij, stresskip, weet over te brengen is in sommige situaties van cruciaal belang. Ik ben ei trots op dat je bij mijn promotie voor het eerst als copromotor optreedt!

Dr. Ton de Goeij, officieuze copromotor, dank voor je kritische houding ten opzichte van de onderzoeksvragen en voor je zorgvuldige begeleiding bij het schrijven van de artikelen.

Dr. Arjan Griffioen, nestor van het angiogeneseonderzoek in Maastricht, dank voor jouw enthousiaste begeleiding en het in mij gestelde vertrouwen bij de vitvoering van de angiogenesestudies. Misschien halen we later alsnog de $\mathrm{JCl}$ ?

Leden van de beoordelingscommissie, professor Daemen, professor D'Hooghe, professor Marbaix, professor Struijker Boudier en zeer geleerde heer Voncken. dank voor het lezen van het manuscript en voor jullie kritische commentaar. Professor Daemen en professor Struijker Boudier, hartelijk dank voor het feit dat ik in jullie labs mocht werken en voor de persoonlijke belangstelling voor mijn onderzoek. 
Menstruumvrouwen Caroline, Cecilia, Chantal, Ellen, Marij, Marion, Monique en Saskia, door het trouw verzamelen van jullie menstruum hebben jullie een wezenlijke bijdrage geleverd aan hoofdstuk twee van dit proefschrift.

Alle helpende handen bij het praktische werk ben ik zeer erkentelijk. Lilian, dankzij jouw geduldige en gedetailleerde uitleg van het CAM model ben ik in staat geweest de experimenten uit te voeren waarvan dit proefschrift het resultaat is. Hartelijk dank voor je begeleiding. Jacqueline, jij hebt met een enorme nauwkeurigheid een geweldige hoeveelheid werk verzet. Ontzettend bedankt voor alles wat je voor me hebt gledaan. Michelle en Quirine, hartelijk dank voor jullie inzet en voor alle gezelligheid. Ik heb geluk gehad met zulke gemotiveerde student-assistenten! Jessica, bedankt voor de introductie in het muizenwerk. In jouw handen zijn muizen als makke lammetjes. Victor, dank voor het uitvoeren van het RT-PCR werk. Jacques Cleutjens, bedankt voor je hulp bij het werk met de Quantimet. Chamindie en Rick, dank voor het uitvoeren van de array studies. Jullie werken in een ongeëvenaard tempol René van Oerle, ook al had je helemaal geen belang bij mijn onderzoek, je hebt me toch altijd willen helpen met de statistiek. Hartelijk dank.

(Ex-)leden van de Maastricht Endometrium Research Groep: Ayse, Chamindie, Cihrista, dr. Fischer, Hanny, Helen D, Helen M, Kim, Natasja en Rick, jullie hebben meegedacht, meegewerkt en meegeleefd. Natasja en Christa, tijdens de eerste fase van het onderzoek hebben jullie me bijgebracht hoe de instrumenten in een lab werken en wat de reglels zijn als je: labtafels met elkaar deelt... Ik, die een lab hel liefst niet van binnen wilde leren kennen, werd door jullie met de neus op de feiten 134 gedrukt, en met resultaat. Lieve Helen, dank voor het verzamelen van vele endometriumbiopten, en vooral voor je begeleiding op een voor ons zeer belangrijk moment! Lieve Ayse, het motiveren van de menstruumvrouwen stond aan de basis van onze samenwerking. Gezamenlijke congresbezoeken en publicaties waren het resultaat, en belangrijker nog, je werd een dierbare vriendin. Ik ben blij met jou als paranimf!

Collega's van het pathologielab, het angiogeneselab en het farmacologielab, Manon. Marjolein. Guido, Peter, Daisy, Lilian, Helma, Fazzi en alle anderen: het was goed toeven bij, jullie. Dank aan de pathologen en analisten van het pathologielab voor het op de meest (on)gelegen momenten ter beschikking stellen van hun microscoop.

Collega's arts-assistenten en gynaecologen in het cluster Maastricht, dank voor het conscientieus verzamelen van het endometrium, en voor jullie geduld en hulpvaardigheid bij mijn eerste stappen terug in de kliniek. 
Collega's van de IVF-afdeling en het IVF-laboratorium, de kwaliteit van de patiëntenzorg die door jullie wordt geleverd is van een ongeëvenaard hoog niveau. Germaine, Laurence, Cécile, Carla en Marie-José, jullie inze! is omgekeerd evenredig aan de ruimte die jullie ter beschikking staat. Laurence, dank voor de eieren van jouw kippen tijdens de vogelpestcrisis. Dankzij het fanatisme van jouw haan is het MMP-hoofdstuk op tijd af gekomen! Janneke, ik bewonder je precisie en het vermogen om bijna alle patienten bij naam (en IVF-indicatie, FSH-waarde en BMI) te kennen. Kim, het endometriose-onderzoek heeft potentie. Maak er iets moois van!

Wil van Erk, en Tiny Wouters, julie hebben enorm veel tijd gestoken in het perfect verzorgen van de lay-out van dit boekje. Bedanki, ik ben trots op het resuitaat.

Dierbare familieleden en vrienden, dank voor jullie niet aflatende interesse.

Anne-Marie, na je creatieve betrokkenheid bij andere recente life events sprak het vanzelf dat je ook dit ontwerp op je zou nemen. De endometrioseweetjes hebben een prachtige kaft gekregen.

Martijn, paranimf, ik ben er trots op dat jij naast me staat, en niet alleen op deze dag. Jij en Inge zijn erg belangrijk voor ons drieën. Erik, geweldig dat je er ook vandaag weer bij bent. Je legt heel wat kilometers voor ons af!

Lieve papa en mama, jullie onvoonwaardelijke steun en jullie vertrouwen in mij als dochter, moeder, arts en onderzoeker zijn hartverwarmend.

Lieve Peter, ik dank je voor je oneindige geloof in mijn kunnen. Ik vaar al jaren op jouw wijsheid. Lieve Jasper, mooiste "baby" van Limbricht, je bent het middelpunt van onze wereld. 


\section{Curriculum Vitae}

De auteur van dit proefschrift werd op 18 maart 1973 geboren in Zetten. Na het dooriopen van de lagere school in Zetten en het Stedelijk Gymnasium in Nijmegen werkte zij als au pair in Basel, Zwitserland. In 1992. werd de studie geneeskunde begonnen aan de Katholieke Universiteit Nijmegen. Tijdens haar studie liep ze een onderzoeksstage in Asin Foso, Ghana (onderzoek: "Home management of diarthoea in under-fives in rural Ghana") en een tropencoschap in Sumve, Tanzania. Het artsexamen werd op 15 juni 1999 behaald (cum laude). Van juni tot en met december 1999 werkte zij als AGNIO Gynaecologie en Verloskunde in ziekenhuis Rijnstate in Arnhem. Van januari 2000 tot en met december 2003 was ze werkzaam als IVF-arts en onderzoeker op de IVF-afdeling van het academisch ziekenhuis Maastricht. In 2000 hield ze zich bezig met onderzoek naar afwijkingen in de bloedstalling bij vrouwen mel pre-eclampsie in de voorgeschiedenis en bij vrouwen die IVF ondergingen. Vanaf 2001 maakte ze deel uit van de endometrium-onderzoeksgroep ender leiding van dr. GA.L. Dunselman, dr. P. G. Groothuis, dr. A.F P . M. de Gcey en prof dr. J.L.H. Evers en werd begonnen met de studies beschreven in dit proefschrift. Het onderzoek werd uitgevoerd binnen de afdeling ontwikkelingsbiologie van het onderzoeksinstituut Groei en Ontwikkeling (GROW) van de Universiteit Maastricht. In 2003 ontving ze de Pélérinprijs voor artsassistenten werkzaam in het azM voor de voordracht: "Remming van angiogenese' voorkomt vorming van endometriose-achtige laesies in het chorio-allantoïs: membraan (CAM) model". In 2004 wor zij voor haar presentatie: "Angiostatic: therapy for endometriosis: a mouse study" de Promising Young Scientisit award tijdens de $20^{\text {th }}$ Annual Meeting of ESHRE in Berlijn. Vanaf 1 januari 2004 is ze gynaecoloog in opleiding in het academisch ziekenhuis Maastricht (opleider: prof.dr. J.L.H. Evers). Annemiek is getrouwd met Peter Krijns en moeder van Jasper. 


\section{Publications}

\section{Papers}

Nap AW. Van Golde RJT, Tuertings JHAM, De Sutter P, Pieters MHEC, Giltay JC, Kastrop PMM. Braat DDM and Kremer JAM (1999) Reproductive decisions of men with microdeletions of the $Y$ chromosome the role of genetic counselling Hum Reprod 14, 2166-2169

Curvers J. Nienhuis S.J. Nap AW. Hamulyak K. Evers. JLH and Rosing J (2000) Activated protein C resistance during in vitro fertilization treatment Eur J Obstet Gynaecol and Reprod Biol 3840, 1-3

Curvers J. Nap AW, Thomassen CMLGD, Nienhuis SJ. Hamulyak K. Evers JHL. Tans G and Rosing J (2001) Effect of in vitro fertilization treatment and subsequent pregnancy on the protein $\mathrm{C}$ pathway $\mathrm{Br}$ J Haematol $115,400-407$

Van der Schaft DWJ, Dings RPM, de Lussanet QR, van Eijk. LI. Nap AW. Beets-Tan RGH. Bouma-Ter Steege JC, Wagstaft J, Mayo KH and Griffioen. AW (2002). The designed anti-angiogenic peptide anginex targets tumour endothelial cells and inhibits tumour growth in animai models FASEB J 16. $1991-1993$

Nap AW, Groothuis PG. Demit AY, Maas JWM. Dunselman GAJ, De Goeij AFPM and Evers JLH (2003) Tissue integrity is essential for ectopic implantation of human endometrium in the chonoallantoic membrane assay Hum Reprod 18, 30-34

Nap AW, Groothuis, PG, Demir AY, Evers JLH and Dunselman GA.J (2004) Pathogenesis of Endometriosis Best Pract Res Clin Obstet Gynaecol 18, 233-244

Nap AW, Dunselman GAJ, de Goeij AFPM. Evers JLH and Groothus PG (2004) Inhibiting MMP function prevents the development of endometriosis in the chicken chorioallantoic membrane model Hum Reprod 19.2180-2187

Nap AW. Griffioen AW. Dunselman GAJ, Bouma-ter Steege JCA. Thissen VL.JL. Evers JLH and Groothuis PG (2004) Anti-angiogenesis therapy for endometriosis J Clin Endocrin Metab 89, 1089-1095

Nap AW, Hamulyak K, Van Oerle R. Van Pampus LCM, Spaanderman ME Damoiseaux J, Rosing J and Peeters LL (2004) Performance of a novel test to quantify activated protein C resistance in women with a history of pre-eclampsia Eur J Obstet Gynaec Reprod Biol 113. 26-30

Demir AY, Groothuis PG. Nap AW, Punyadeera CA, De Goeil AFPM. Evers JLH and Dunselman GA. (2004) Menștrual effluent induces epithelial-mesenchymal transitions in mesothelial cells Hum Reprod. 19. $21-29$

Groothuis PG. Nap AW. Winterhager E and Grümmer R Vascular development in endometriosis Angiogenesis, in press

Punyadeera CA, Dunselman GA.J, Marbaix E. Kamps R. Galant C. Nap AW. De Goeij AFPM. Ederveen A and Groothuis PG. Triphasic pattern in the ex vivo response of human endometrium to estrogen $J$ Steroid Biochem Mol Biol, in press

Nap AW. Groothuis, PG. Griffioen AW. Evers. JLH. Dunseiman GAJ Anti-angiogenic agents prevent the development of endometrosis in the chorioallantoic membrane Submitted

Nap AW. Groothuis PG. Punyadeera-Mylonas C. Klein Hitpass L. Evers JLH and Dunselman GAJ Use of ora! contraceptives prevents, ectopic implantation of endometrium in the chicken chorioaliantoic. membrane Submitted 


\section{Abstracts}

Nạp AW, Cụrverș J. Thomașșen CMLGD, Niẹnhuis Ș. Hamulyak K, Tans G, Rosing J. Evers JLH. The effect of endogenous sex steroids on blood coagulation. $17^{\text {th }}$ Annual meeting of the ESHRE. Lausanne. Switzerland, Jụly 1-4. 2001. Hum Reprod 2001:16 (abstract book 1):26.

Demir-Weusten AY, Groothuis PG. Nap AW. Herrler A, Dunseiman GAJ, de Goeij AFPM, Evers JLH. A proteomics; approach the induction of protein phosphorylation in mesothelial cells by anterogradely shed menstrual effluent Proteomic Forum. International meeting on proteome analysis, Muenchen, Germany, September 16-19, 2001. Abstract Book Proteomic Forum 2001:135

Nap AW, Groothuis PG, Demir-Weusten AY, De Goeị AFPM, Dunselman GAJ, Evers JLH Development and characterization of endometriotic lesions in the chick chorio-allantoic membrane model. $8^{\text {th }}$. Worid Congress on Endometriosis, San Diego, California, February 24-27, 2002. Fertil Steril 2002;77(2):S4.

Nap AW, Groothuis PG, Demir-Weusten AY, De Goeij AFPM, Dunselman GAJ, Evers. JLH Vascularization of peritoneal, ovarian and rectovaginal endometriotic lesions. $8^{\text {th }}$ World Congress on Endometriosis, San Diego, California, February 24-27, 2002. Fertil Steril 2002,77(2):S29

Demir-Weusten AY. Groothuis PG. Nap AW. Herrler A, de Goeil AFPM. Dunselman GAJ Anterogradely shed menstrual effluent affects protein phosphorylation and expression in cultured human mesothelial cells $8^{\text {th }}$ World Congress on Endometriosis. San Diego, California. February 24-27, 2002. Fertil Steril $2002,77(2)$ S10-11

Demir-Weusten AY, Groothuis PG. Nap AW. Herrler A, de Goeij AFPM, Dunselman GA.! Mesothelial injury factors from anterogradely shed menstrual endometrial cells. $8^{\text {th }}$ World Congress on Endometriosis, San Diego, California, February 24-27, 2002 Fertil Steril 2002,77(2) S11

Nap AW, Groothuis PG, Demir Weusten AY, Dunselman GAJ. Evers JHL. Ontwikkeling en karakteristieken van endometrioselaesies, in het chorio-allantois membraan model. Tijdschrift voor Fertiliteitsonderzoek 2002, 1644

Demir AY, Groothuis PG. Dunselman GAJ, Nap AW. Schurgers L. Herrler A, de Goeij AFPM, Evers JLH Soluble factors from shed menstrual endometrium induce epithelial-mesenchymal tranșitions in mesothelial cells. J Soc Gynecoll Investig 2003:10 (suppl) 10A

138 Demir AY, Groothuis PG, Dunselman GAJ. Herrler A, de Goeij AFPM, Nap AW, Vandekerckhove J, Evers JLH Epithelial-mesenchymal transitions in mesothelial cells induced by shed menstrual endometrium are mediated by tyrosine kinases. J Soc Gynecol Investig 2003:10 (suppl) 10A.

Nap AW. Groothuis PG. Dunselman GAJ, Griffioen AW, Evers JLH. Anti-angiogenic compounds inhibit angiogenesis and endometriosis-like lesion formation in the chicken chorioallantoic membrane. J Soc Gynecol Investig 2003,10 (suppl) 27A

Den Hartog JE, Nap AW, Van der Kuy PHM, Land JA Kunnen Decapeptyl en Puregon in een injectie gecombineerd worden? Tijdschrift voor Fertiliteitsonderzoek 2002, 16: 94

Nap AW. Griffioen AW. Dunseiman GAJ, Bouma-ter Steege JCA. Evers. JLH, Groothuis PG Antiangiogenesis therapy for endometriosis a mouse study $20^{\text {th }}$ Annual meeting of the ESHRE. Berlin. Germany, June27-30, 2004 Hum Reprod 200.4, 19 suppl 1,110 



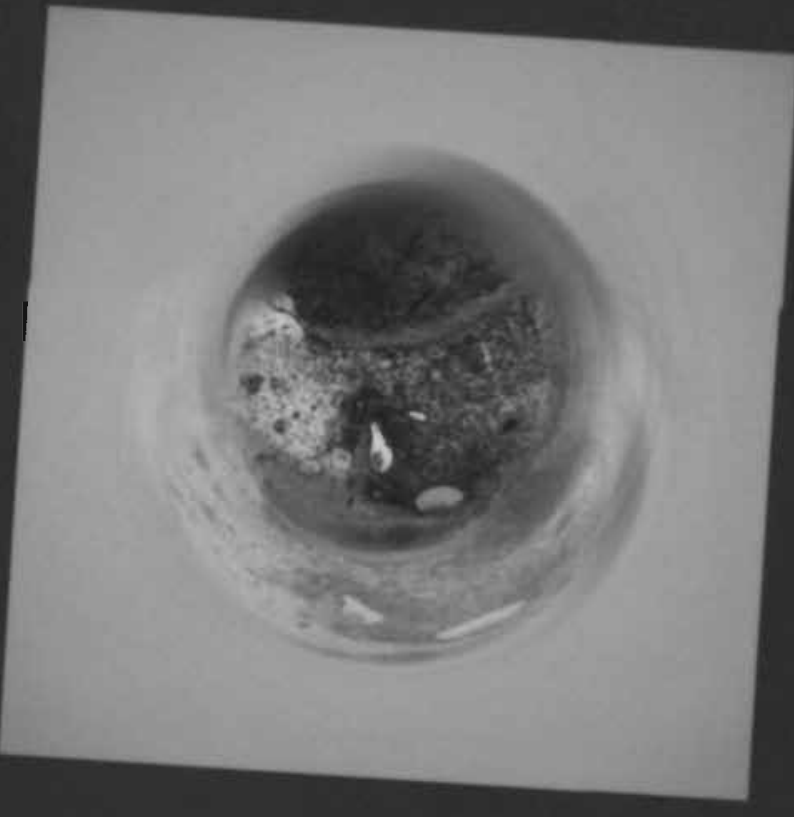

- 